\title{
Percepção dos usuários sobre a qualidade de serviço em rodovias
}

Dissertação apresentada à Escola de Engenharia de São Carlos da Universidade de São Paulo como parte dos requisitos para obtenção do título de mestre em Ciências, Programa de Pós-Graduação em Engenharia de Transportes - Área: Planejamento e Operação de Sistemas de Transporte.

Orientador: Prof. Titular José Reynaldo Anselmo Setti

Versão corrigida

São Carlos, SP

2015 
AUTORIZO A REPRODUÇÃO TOTAL OU PARCIAL DESTE TRABALHO, POR QUALQUER MEIO CONVENCIONAL OU ELETRÔNICO, PARA FINS DE ESTUDO E PESQUISA, DESDE QUE CITADA A FONTE.

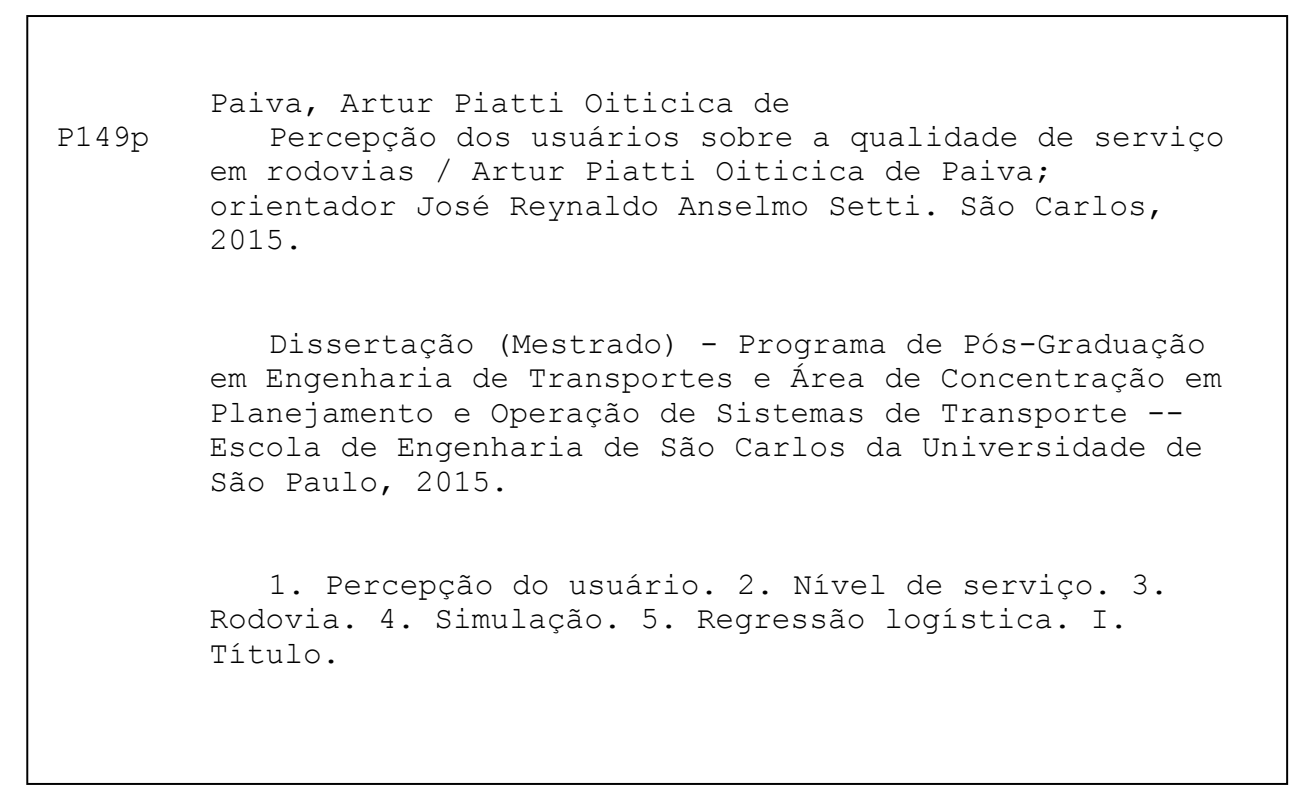


FOLHA DE JULGAMENTO

Candidato: Engenheiro ARTUR PIATTI OITICICA DE PAIVA.

Título da dissertação: "Percepção dos usuários sobre a qualidade de serviço em rodovias".

Data da defesa: 11/08/2015

Comissão Julgadora:

Prof. Titular José Reynaldo Anselmo Setti

(Orientador)

(Escola de Engenharia de São Carlos/EESC)

Profa. Dra. Cira Souza Pitombo

(Escola de Engenharia de São Carlos/EESC)

Profa. Dra. Helena Beatriz Bettella Cybis

(Universidade Federal do Rio Grande do SUI/UFRGS)
Resultado:

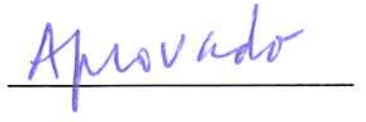

Coordenador do Programa de Pós-Graduação em Engenharia de Transportes: Prof. Associado Paulo Cesar Lima Segantine

Presidente da Comissão de Pós-Graduação:

Prof. Associado Paulo Cesar Lima Segantine 

Dedico aos meus pais, Carlos e Sylvia,

à minha namorada Andressa e à minha família, representada pelos meus irmãos Vitor e Rafael, minha cunhada Mariana e o pequeno Gui.

Sem vocês, não consigo imaginar como alcançaria esta conquista. 



\section{AGRADECIMENTO}

Se você quer ir rápido, vá sozinho. Se quiser ir longe, vá acompanhado.

- Provérbio africano

A companhia de amigos, colegas e familiares, seja perto ou mesmo distante, durante todo o meu mestrado foi fundamental para a conquista desta etapa: vocês proporcionaram, sem dúvidas, um caminho mais tranquilo; encurtaram a distância da minha casa; e permitiram uma adaptação mais rápida e prazerosa a uma nova realidade. Por isso, agradeço aqueles que estiveram comigo, os que me apoiaram e os que torceram por mim. Meu sincero reconhecimento!

A Deus: pelo suporte que me foi dado por toda minha vida; por me colocar ao redor de boas pessoas; por minha família e meus amigos que sempre torceram por mim e me deram força para alcançar meus objetivos.

Aos meus pais, Carlos Paiva e Sylvia Maria Piatti, que sempre acreditaram em mim, deram-me a liberdade de escolher meu caminho e minhas metas, sempre confiando em minhas escolhas. Obrigado pelo amor, apoio e incentivo, devo esta conquista a vocês e saibam que tenho muito orgulho dos pais que são.

À minha namorada Andressa NG, pelo amor, alegria, companhia e estímulo (...), fundamentais ao meu amadurecimento pessoal e profissional, assim como, para trilhar este caminho.

Aos meus irmãos, Vitor e Rafael, pela torcida, palavras de incentivo e por serem referências de um sucesso que eu almejo conquistar.

Ao meu orientador, Professor José Reynaldo Setti que desempenhou o papel de orientador com competência, dedicando-se ao trabalho e enriquecendo-o com sua experiência. Sou grato por ter sido seu aluno, queria dizer que é motivador ver sua dedicação à profissão e seu empenho por um trabalho de qualidade.

Aproveito para agradecer as contribuições dadas ao meu trabalho na banca examinadora pela Professora Helena Cybis, na banca de qualificação pela Professor Ana Paula Larocca e nas duas bancas pela Professora Cira Pitombo.

Agradeço à agência de fomento CAPES pela bolsa de mestrado concedida e ao meu pai pelo 'paitrocínio' nestes anos, essenciais para uma dedicação exclusiva.

Aos meus colegas de sala, Fernando Piva, Felipe Bethônico, Elievam Bessa Jr. e André Cunha, agradeço por nossa união, por terem sido sempre solícitos, pelas contribuições dadas à minha dissertação, as dicas por caminhos melhores, o apoio nas horas difíceis, aos ensinamentos e, claro, pelos momentos de descontração, afinal, ninguém é de ferro. Uma equipe!

A todos aqueles que contribuíram para o enriquecimento do meu trabalho, especialmente ao Professor André Cunha que sempre atendeu aos meus pedidos, ajudou com dicas de macros e na programação do velocímetro, entre outras. Agradeço, especialmente também, ao amigo Fernando Piva, quem formou comigo uma verdadeira dupla do início ao fim: na mesma turma, 
mesma orientação, compartilhando das mesmas aflições com prazos e desfrutando de muitas mesas de bar; à Professora Cira Pitombo por ter dedicado tempo (muito concorrido) para contribuir com o meu trabalho e fornecer dicas estatísticas; e ao Cassiano Isler que se mostrou prestativo, sempre clareando o meu caminho com seus ensinamentos quando eu pedia uma dica. Não posso deixar de fora o amigo Heymar Arancíbia que demonstrou valor por nossa amizade nos momentos complicados e incentivou bastante o foco para finalização da dissertação.

Agradeço também a todos que dedicaram tempo para colaborar com a minha pesquisa respondendo ao questionário durante o experimento piloto, sua contribuição foi muito valiosa para a conclusão desta pesquisa. Obrigado!

Aos novos (relativamente) membros da família Piatti de Paiva, Mariana e o pequeno Gui, extensivo a todos meus familiares e amigos, dos quais senti falta durante estes anos! Foi difícil viver longe dos almoços e pizzas em família, do badalado crescimento da nova geração e dos aniversários, casamentos, praias e jantares para reunião dos amigos. Não é fácil acompanhar tudo apenas pelo Whatsapp.

Aos meus primos Letícia e Cadu que foram verdadeiros irmãos e sempre me acolheram em SP quando fui para distrair e visitar amigos, primos e tios. Vocês sem dúvidas encurtaram a distância de Maceió. Vou guardar todos os momentos e passeios e torço para que tenhamos muito mais!

Aos meus amigos que proporcionaram, como irmãos, uma convivência diária prazerosa: valeu pela companhia Diego Vasconcelos (e Rafaela Facciola), Diôgo Oliveira, Anthony Gomes e o agregado Alisson Medeiros. A RePiatti não teria sido a mesma sem a presença de vocês e dos ilustres hóspedes que vieram me visitar ou precisaram de um teto temporário. Bom demais!

Agradeço ao acolhimento da amiga Irene Pimentel e a todos os momentos que junto a ela e à turma da UFAL que se bandeou para São Carlos, nos divertíamos, 'tapeando' um pouco a saudade de Alagoas. Comer sururu aqui não teve preço! Em especial ao João Manoel, à Thaíse Morais, à Daysy Lyra e à 'Pariconha'.

À minha turma de mestrado, companheiros de estudo, das noites em claro, de diversão e de muitas risadas, valeu por tudo e por terem aceitado o convite para visitar Alagoas (pena que não foram todos). Obrigado Andrea Nicola, Antônio Guga, Conrado Plaza, Diego Néris, Edgard Misael, Fernando Piva, Fernando Velázquez, Gláucia Maia, Heymar Arancíbia, Javier Mahecha e Mateus Gama.

Aos meus amigos do STT que compartilharam de momentos ao longo do mestrado. Obrigado pelas mesas de Dalmir e Toco, aos churrascos do AMA, aos momentos do cafezinho e todas as boas lembranças nestes anos. Muito bom ter conhecido vocês: Andressa NG, Tiago Torquato, Thalita Nascimento, Suzana Valverde, Renaude Carneiro, Nil Zamúner, Murilo Santos, Monique Martins, Miguel Castillo, Matheus Inocente, Mateus Gama, Marcela Navarro, Joicy Poloni, Heymar Arancíbia, Gláucia Maia, Gabi Morais, Fernando Velázquez, Fernando Piva, Felipe Bethônico, Elievam Bessa Jr., Diego Camargo, Cecília Lima, Cassiano Isler, Antônio Guga, Angélica Meireles, Andrea Nicola e André Cunha.

Meu sincero agradecimento, Artur. 
"Tudo aquilo que se compartilha, se multiplica."

- Papa Francisco 

RESUMO

Paiva, A. P. O. de (2015). Percepção dos usuários sobre a qualidade de serviço em rodovias. Dissertação de Mestrado, Escola de Engenharia de São Carlos, Universidade de São Paulo, São Carlos, SP.

Com o intuito de fornecer subsídios para adaptar o HCM ao cenário brasileiro, propõe-se um método que se baseia na percepção dos usuários sobre a qualidade de serviço em rodovias, para estimar os limites de densidade que delimitam os níveis de serviço. A justificativa é que o conceito de nível de serviço considera a qualidade de serviço com base na percepção dos usuários, mas os limites entre os níveis de serviço em rodovias definidos no HCM não considera a opinião dos usuários. Esse método baseia-se num questionário online para coletar as informações necessárias para estimar os limites entre os níveis de serviço por uma análise de regressão logística. No método proposto, a percepção dos usuários sobre a qualidade de serviço é medida através de uma escala contínua e as condições operacionais são mostradas através de vídeos obtidos com um simulador microscópico de tráfego. Um experimento piloto foi realizado para testar o questionário e o método de análise propostos. As variáveis operacionais utilizadas no experimento piloto foram percentual de veículos pesados, velocidade média e concentração veicular. Os resultados desse experimento piloto foram usados para refinar o questionário e mostraram que, dentre as consideradas, a densidade foi a medida operacional que mais influiu na qualidade de serviço percebida pelos respondentes. Por meio do experimento piloto, foi possível estimar o tamanho do questionário e a duração dos vídeos. $\mathrm{O}$ método proposto pode ser aplicado para obter os limites entre os níveis de serviço com base na percepção do usuário, no Brasil ou em qualquer outro país, uma vez que um simulador microscópico devidamente calibrado para refletir as condições operacionais locais esteja disponível.

Palavras-chave: Percepção do usuário; Nível de serviço; Rodovia; Simulação; Regressão logística. 



\begin{abstract}
Paiva, A. P. O. de (2015). Users’ perception of quality of service at highways. Master Thesis, Escola de Engenharia de São Carlos, Universidade de São Paulo, São Carlos, SP.

This thesis proposes a method to estimate thresholds for levels of service based on the users' perception of the quality of service on highways. Whereas the level of service concept includes the users' perception of the quality of service among the aspects that should be taken into consideration, the level of service criteria used in the highway chapters of the HCM were defined without taking into account the users' opinion. The proposed approach uses an online questionnaire to obtain the data needed to estimate the thresholds between levels of service, which are then calculated using logistic regression. In the proposed method, the users' perception of the quality of service is measured using a continuous scale and the operating conditions are shown by means of short videos created using microscopic traffic simulation of predetermined scenarios on a virtual highway. By using simulation to create scenarios, it is possible to control all operational variables, covering all conditions from very low flow to capacity, and, at the same time, to generate a video from the driver's point of view. A pilot experiment was used to validate the questionnaire and the method adopted to estimate level of service thresholds. The operational variables used in this pilot experiment included truck percent, average travel speed and density. The results of the pilot experiment were used to refine the questionnaire and have shown that density is the operational variable that has the greatest influence on the users' perception of the quality of service. The pilot experiment results also defined the number and the length of the videos to be shown to respondents. Despite its creation to support the adaptation of the HCM to Brazil, the proposed method could be applied to any other location, if a microscopic traffic simulator calibrated to represent traffic flow on local highways is available.
\end{abstract}

Keywords: Traveler's perception; Level of service (LOS); Highways; Simulation; Logistic regression. 



\section{LISTA DE FIGURAS}

FiguRA 1. VisuALIZAÇÃO DA SIMULAÇÃO: CAMPO DE VISÃO DO CONDUTOR (CÂMERA DENTRO DO VEÍCULO) .....43

FIGURA 2. INTERFACE DE UM CENÁRIO 45

FIGURA 3. REPRESENTAÇÃO EM 2D DO TRAÇADO DA SIMULAÇÃO: OS CÍRCULOS EM AZUL SÃO LOCALIZAÇÕES DE ÁRVORES

FIGURA 4. VISTA AÉREA DA RODOVIA SIMULADA 48

FIGURA 5. MÉDIA DE VELOCIDADE VERSUS MÉDIA DE DENSIDADE VEICULAR NO LAÇO INDUTIVO; \%VP= $0 \% \ldots . . .51$

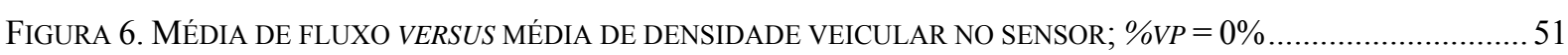

FIGURA 7. MÉDIA DE VELOCIDADE VERSUS MÉDIA DE DENSIDADE VEICULAR NO LAÇO INDUTIVO; \%VP=20\% .....51

FIGURA 8. MÉDIA DE FLUXO VERSUS MÉDIA DE DENSIDADE VEICULAR NO SENSOR; \%VP=20\% ..........................5 52

FIGURA 9. MÉDIA DE VELOCIDADE VERSUS MÉDIA DE DENSIDADE VEICULAR NO LAÇO INDUTIVO; \%VP = 40\% .....52

FIGURA 10. MÉDIA DE FLUXO VERSUS MÉDIA DE DENSIDADE VEICULAR NO SENSOR; \%VP=40\% ........................52

FIGURA 11. DISTRIBUIÇÃO DE DENSIDADE VEICULAR MÉDIA POR INTERVALO DE TEMPO (ENTRE CARROS E CAMINHÕES) EM UM DETECTOR, NA ITERAÇÃO 92, PARA 20\% DE VEÍCULOS PESADOS NA CORRENTE DE TRÁFEGO

FiguRA 12. (A) VÍdEO GERADO PELO SIMULADOR A PARTIR DO PONTO DE VISÃO DO MOTORISTA; (B) VÍDEO PREPARADO PARA APLICAÇÃO DO QUESTIONÁRIO, COM SUPERPOSIÇÃO DO PAINEL, PARABRISA, DIREÇÃO E VELOCÍMETRO DIGITAL

FIGURA 13. QUESTÃo INSERIDA NO QUESTIONÁRIO PARA AUXILIAR NA DETERMINAÇÃO DE QUANTOS CENÁRIOS OS AVALIADORES TOLERARIAM ANALISAR

FIGURA 14. ESCALA MÉTRICA CONTÍNUA COMO APRESENTADA NO QUESTIONÁRIO: PARA FORNECER A AVALIAÇÃO, O RESPONDENTE MOVE O CURSOR DA ESCALA, POSICIONANDO-O EM UM PONTO ENTRE OS DOIS EXTREMOS CORRESPONDENTE À SUA PERCEPÇÃO SOBRE A QUALIDADE DE SERVIÇO DO CENÁRIO

FIGURA 15. DIAGRAMA EM CAIXA (BOX-PLOT) PARA AS CATEGORIAS DE TEMPO: (A) TEMPO TOTAL PARA RESPONDER O QUESTIONÁRIO; (B) TEMPO GASTO NAS PÁGINAS INICIAIS, PERFIL DO RESPONDENTE E INSTRUÇÕES; E (C) TEMPO GASTO NA SESSÃO FINAL, FEEDBACK DO QUESTIONÁRIO

FIGURA 16. PORCENTAGEM ACUMULADA DO NÚMERO DE VÍDEOS ASSISTIDOS POR CADA PARTICIPANTE DURANTE O EXPERIMENTO PILOTO.

FIGURA 17. DiSTRIBUIÇÃO DE PORCENTAGEM ACUMULADA DO TEMPO DE VISUALIZAÇÃO DOS VÍDEOS, EM MINUTO, GASTO PELOS PARTICIPANTES DA PESQUISA PARA FORNECER SUA AVALIAÇÃO 64

FIGURA 18. DiSTRIBUIÇÕES DE RESPOSTAS PARA AVALIAÇÃO DA DURAÇÃO DO QUESTIONÁRIO E DOS FILMES OBTIDAS NA SESSÃO FINAL

FiguRA 19. DisTRIBUIÇÕES DE RESPOSTAS ÀS SENTENÇAS CUJO PROPÓSITO ERA (I) AVALIAR A CAPACIDADE DO RESPONDENTE DISCERNIR OS CENÁRIOS APRESENTADOS; (II) AVALIAR A QUALIDADE DE SERVIÇO POR MEIO DE CENÁRIOS MICROSSIMULADOS; E (III) VERIFICAR A QUALIDADE DOS VÍDEOS.....

FiguRA 20. RELAÇÃO ENTRE A MEDIANA DA PERCEPÇÃO DE QUALIDADE DE SERVIÇO (P) E A DENSIDADE MÉDIA DO DETECTOR $\left(K_{M D}\right)$, PARA $0 \%$ DE VEÍCULOS PESADOS NA CORRENTE DE TRÁFEGO

FIGURA 21. RELAÇÃO ENTRE A MEDIANA DA PERCEPÇÃO DE QUALIDADE DE SERVIÇO (P) E A DENSIDADE MÉDIA DO DETECTOR $\left(K_{M D}\right)$, PARA $20 \%$ DE VEÍCULOS PESADOS NA CORRENTE DE TRÁFEGO 
FIGURA 22. RELAÇÃO ENTRE A MEDIANA DA PERCEPÇÃO DE QUALIDADE DE SERVIÇO (P) E A DENSIDADE MÉDIA DO DETECTOR $\left(K_{M D}\right)$, PARA $40 \%$ DE VEÍCULOS PESADOS NA CORRENTE DE TRÁFEGO

Figura 23. DisTRIBUIÇÕES DE RESPOSTAS PARA PERGUNTAS SOBRE A ESCALA ADOTADA PARA AVALIAR A QUALIDADE DE SERVIÇO

FIGURA 24. DisTRIBUIÇÕES DE RESPOSTAS PARA PERGUNTAS SOBRE AS CARACTERÍSTICAS COMPORTAMENTAIS DOS MOTORISTAS DAS SIMULAÇÕES

FIGURA 25. DiAGRAMA EM CAIXA APRESENTANDO A VARIAÇÃO DAS NOTAS PARA CADA CATEGORIA DE PERCENTUAL DE VEÍCULOS PESADOS

FIGURA 26. DiAGRAMA EM CAIXA APRESENTANDO A VARIAÇÃO DAS NOTAS PARA CADA CLASSE DE VELOCIDADE MÉDIA NO TEMPO

FIgURA 27. DiAGRAMA EM CAIXA APRESENTANDO A VARIAÇÃO DAS NOTAS PARA CADA DENSIDADE [VEIC/(KM.FAIXA)]; ESTRELAS SÃO OBSERVAÇÕES ATÍPICAS EXTREMAS E CÍRCULOS SÃO OBSERVAÇÕES ATÍPICAS MODERADAS

FIGURA 28. EXEMPLO DE CURVA LOGIT (HAIR JR. ET AL., 2005)

FiguRA 29. RESULTADO ENCONTRADO PARA O AGRUPAMENTO K-MEANS EM 5 NÍVEIS, BASEADO NA MEDIDA PERCEPÇÃO DA QUALIDADE DE SERVIÇO.....

FIGURA 30. HisTOGRAMA DA DENSIDADE PARA CADA CLUSTER BASEADO NA VARIÁVEL PERCEPÇÃO DA QUALIDADE DE SERVIÇO

FIGURA 31. FUNÇÕES LOGÍSTICAS E SUAS COMPLEMENTARES QUE ESTIMAM A PROBABILIDADE DE ELEMENTOS COM UMA DENSIDADE VEICULAR ESPECÍFICA PERTENCER OU NÃO A UM DADO NÍVEL DE SERVIÇO .

FIGURA 32. FUNÇÕES LOGÍSTICAS E SUAS COMPLEMENTARES QUE ESTIMAM A PROBABILIDADE DE ELEMENTOS, COM UMA DENSIDADE ESPECÍFICA, PERTENCER OU NÃO A UM DADO NÍVEL DE SERVIÇO 86 


\section{LISTA DE TABELA}

TABELA 1. AS MEDIDAS DE SERVIÇO DO HCM 2010 PARA CADA MODO DE TRANSPORTE (ADAPTADA DE TRB, 2010, PP. 2-6). 29

TABELA 2. LIMITES DO NÍVEL DE SERVIÇO EM AUTOESTRADAS EM FUNÇÃO DA MEDIDA DE SERVIÇO DENSIDADE.

QUANDO A RAZÃO ENTRE VOLUME E CAPACIDADE É MAIOR QUE 1, CLASSIFICA-SE O NÍVEL DE SERVIÇO EM F (TRB, 2010, PP. 10-9). 30

TABELA 3. OS QUATRO PRINCIPAIS TIPOS DE ESCALAS DE MEDIDA, COM USO DE VARIÁVEL NUMÉRICA (STEVENS, 1975)

TABELA 4. RESUMO DA CONFIGURAÇÃO DA RODOVIA VIRTUAL CRIADA PARA O EXPERIMENTO PILOTO 49

TABela 5. CoEFiCIENTE de CORRELAÇão de PEARSON $(R)$ E RESPECTIVA SIGNIFICÂNCIA (SIG), PARA DUAS EXTREMIDADES, ENTRE A VARIÁVEL DEPENDENTE PERCEPÇÃO (P) E AS VARIÁVEIS INDEPENDENTES DENSIDADE MÉDIA DO DETECTOR $\left(K_{M D}\right)$, VELOCIDADE MÉDIA NO TEMPO (VM) E PERCENTUAL DE VEÍCULO PESADO (\%VP), POR AVALIADOR E DE FORMA CONJUNTA (GERAL) .70

TABELA 6. ESTATÍSTICA DESCRITIVA DOS GRUPOS FORMADOS PELA ANÁLISE DE CLUSTER K-MEANS .83

TABELA 7. APRESENTAÇÃO DOS CASOS ROTULADOS COMO OUTLIERS PELO MÉTODO DOS ESCORES PADRÃO, DE BOX-PLOT E RESÍDUO ESTUDENTIZADO. 

1.1 Contextualização 21

1.2 Justificativa

1.3 Objetivo e estrutura metodológica

2 REVISÃO DA LITERATURA

2.1 Nível de serviço

2.1.1 Highway Capacity Manual (HCM) _ـ 25

2.1.2 Qualidade e nível de serviço

$\begin{array}{lll}\text { 2.1.2.1 Nível de serviço em autoestrada __ } 29 & 29\end{array}$

2.2 Percepção como medida 31

2.2.1 Escalas de medida para percepção da qualidade de serviço __ 34

2.2.1.1 Escalas de medidas na Psicofísica $\quad 36$

2.2.1.2 Escalas de medidas na Psicometria $\quad 37$

2.2.2 Estudos relativos à percepção da qualidade de serviço __ 38

3 O MÉTODO PROPOSTO

3.1 Estrutura geral do método proposto ___ 43

3.2 Experimento piloto_ 4

$\begin{array}{lll}3.2 .1 & \text { Criação da rodovia virtual } & 47\end{array}$

3.2.2 Definição dos cenários para simulação __ 49

$\begin{array}{ll}3.2 .3 \text { Geração dos filmes } & 50\end{array}$

3.2.3.1 Determinação dos dados de entrada da simulação _ـ 50

3.2.3.2 Gravação do cenário __ 53

3.2.3.3 Painel veicular —

$\begin{array}{lll}3.2 .4 & \text { Criação do questionário } & 54\end{array}$

3.2.4.1 Estrutura do questionário _ـ 56

3.2.4.2 Escala métrica contínua $\quad 57$

$\begin{array}{lll}3.2 .5 & \text { Formulário online _ـ } & 58\end{array}$

3.2.6 Aplicação do experimento piloto __ 58

4 QUESTIONÁRIO___ 61

4.1 Forma de análise dos dados _ـ 61

4.2 Análise da extensão do questionário e da duração do vídeo__ 62

4.3 Impacto das características operacionais dos vídeos na avaliação da qualidade de serviço _ _ 66

4.3.1 Avaliação baseada na opinião do respondente ___ 66

4.3.2 Relação entre a percepção e as características da corrente de tráfego ___ 67 
5 ANÁLISE DE DADOS PROPOSTA

5.1 Eliminação de observações atípicas 77

$\mathbf{5 . 2}$ Identificação dos limites dos níveis de serviço __ 80

5.2.1 Discretização da variável

6 CONSIDERAÇÕES FINAIS 87

7 REFERÊNCIAS 91

APÊNDICE A 95

APÊNDICE B 99 APÊNDICE C 


\section{INTRODUÇÃO}

\subsection{Contextualização}

A situação atual da infraestrutura do sistema de transporte brasileiro apresenta gargalos que dificultam o desenvolvimento econômico brasileiro ao patamar de seu potencial, principalmente, por não favorecer uma logística eficiente no transporte de pessoas e cargas.

Com o intuito de tornar o sistema eficiente, é ideal que ações estruturais sejam executadas baseadas, e em paralelo, ao desenvolvimento científico e tecnológico. Como exemplo, pode-se citar o caso dos Estados Unidos que, em razão da acentuada expansão de seu sistema rodoviário após a Segunda Guerra Mundial, investiu em pesquisas sobre capacidade viária, desenvolvendo, inclusive, um manual sobre esse tema (Highway Capacity Manual - HCM) (TRB, 2010). Hoje, tanto o manual de capacidade viária produzido, como o sistema de transporte são referências mundiais.

No caso brasileiro, parece ter havido esforços que objetivaram a produção científica e técnica para nortear as ações práticas. Entretanto, foram trabalhos pontuais que não foram continuados a fim de lograr êxito no sentido de produzir referências bibliográficas pertinentes para os dias atuais.

Uma prova disso é que, em todas as áreas de transportes, normas e manuais baseiam-se na literatura desenvolvida por outros países. Por exemplo, na área de infraestrutura, é comum a adoção de métodos propostos pela AASHTO (American Association of State Highway and Transportation Officials), como é o caso da norma IPR - 719 (DNIT, 2006a) que dispõe sobre dimensionamento de pavimentos flexíveis.

$\mathrm{Na}$ área de planejamento de transportes, em 1965, o Instituto de Pesquisa Rodoviárias (IPR) publicou um documento intitulado "A capacidade das vias e o congestionamento do tráfego", escrito pelo Eng ${ }^{\mathrm{o}}$ Luiz Ribeiro Soares, no qual, percebe-se uma tentativa de iniciar a discussão sobre congestionamento brasileiro para nortear as ações que visam o conforto das viagens (Soares, 1965).

Apesar dessa contribuição, não houve continuidade dos estudos e, hoje, o DNIT (Departamento Nacional de Infraestrutura de Transportes), por meio de suas instruções normativas (DNIT, 2006b), recomenda a utilização dos métodos propostos na edição mais recente (com essas palavras) do manual de capacidade viária americano (HCM) em estudos de tráfego que 
necessitam determinar: (a) a capacidade das vias; (b) a provável velocidade de operação em elementos viários; (c) as condições operacionais (ex.: nível de serviço); entre outras.

O HCM, de fato, é uma publicação conceituada internacionalmente no ramo rodoviário por estar em constante evolução e já ter sido consagrado pela experiência internacional durante as últimas sete décadas, destacando-se como principal referência na avaliação operacional (Setti, 2009).

Porém, basear normas brasileiras em normas de outros países sem sua devida adequação paramétrica e contextual (tipo de pavimentos, legislação vigente, comportamento do condutor etc.) pode gerar resultados que não representam adequadamente as condições operacionais avaliadas.

Isso é reconhecido por instituições de pesquisa e órgãos brasileiros, como o TCU e o próprio DNIT. Inclusive, esses órgãos já recomendaram a adaptação dos métodos do HCM à condição brasileira (DNIT, 2006b; TCU, 2008; Andrade, Silva \& Puty Filho, 2011).

O próprio HCM alerta sobre o risco da não adaptação de seus métodos para a condição local, recomendando expressamente, em todas as edições publicadas, uma prévia análise da necessidade de calibração de seus parâmetros. O motivo é que as pesquisas elaboradas para a produção do manual foram baseadas no contexto americano, resultando em parâmetros que não necessariamente refletem a realidade de outros países (características da frota, tecnologia utilizada em pavimentos e no setor automotivo, comportamento do condutor, entre outras).

Diante desse cenário, as instituições brasileiras de pesquisa que estudam essa temática seguem a recomendação dos órgãos brasileiros mencionados, desenvolvendo estudos que realizam adaptações paramétricas do manual americano, uma vez que estão cientes da importância da calibração e da parametrização para a condição nacional; e estão convencidas de que não há necessidade de criação de um manual com métodos alternativos, uma vez que os métodos do HCM já estão validados pela experiência internacional.

Com a finalidade de fornecer subsídios para adaptar o HCM ao cenário brasileiro, o presente trabalho inicia um projeto de pesquisa para a adaptação de uma medida do HCM, o nível de serviço, que tem como meta final a identificação da quantidade de níveis de serviço percebidos pela população brasileira e os limiares operacionais entre os níveis de serviço. 


\subsection{Justificativa}

Como dito no item anterior, a razão do estudo desse tema de pesquisa é que o próprio HCM recomenda expressamente a adaptação do método à condição local, a fím de validar sua aplicação.

Em estudos de tráfego, essa adaptação é relevante devido ao uso frequente do nível de serviço, calculado pelo método do HCM, na avaliação da condição operacional da rodovia e por ser uma medida que está presente nas diversas etapas de engenharia:

- Nos estudos preliminares à realização de obras;

- Na previsão de qualidade de serviço oferecida por alternativas de projeto (etapa de planejamento);

- No monitoramento do padrão da qualidade de serviço oferecido por concessionárias e por órgãos gestores (etapa operacional); e

- Na etapa de projeto, quando as características de projeto são definidas a partir do nível de serviço desejado.

Além do exposto, Washburn e Kirschner (2006) relatam que os estudos com relação ao nível de serviço são importantes em razão de ser comum que decisões de investimentos em infraestrutura de transportes sejam influenciadas pelos resultados de estimativas do nível de serviço.

\subsection{Objetivo e estrutura metodológica}

Este trabalho delimita como objetivo de pesquisa a proposição de um método capaz de estimar os valores operacionais limites que definem os níveis de serviço, baseando-se na percepção dos usuários de rodovias brasileiras.

Para isso, aplica-se um experimento piloto com a finalidade de testar a viabilidade do método proposto e de coletar informações para definir aspectos do método que geraram dúvida ao longo de sua concepção.

Destaca-se que o presente trabalho se baseia no ponto de vista do usuário de rodovia por considerar que a opinião do usuário deve ser considerada na análise da qualidade de qualquer serviço. Afinal, por mais que a percepção seja um critério subjetivo, ela indica se o sistema está cumprindo com sua função e satisfazendo quem o utiliza. 
A proposta do método é delimitar os níveis de serviço em situação não-congestionada, pois o limite entre o fluxo não-congestionado e o congestionado é definido pela capacidade da via e não depende da percepção dos usuários do sistema.

Para atingir o objetivo de pesquisa, foi necessário criar um mecanismo pelo qual um usuário avaliasse o nível de serviço oferecido por um sistema viário. O método proposto utiliza um simulador de tráfego microscópico para gravar os cenários, coleta a impressão do usuário por meio de uma escala métrica contínua e estima os resultados por meio de regressão logística.

A estrutura da dissertação é composta por seis capítulos. Este capítulo apresenta uma breve introdução sobre o assunto abordado. O Capítulo 2 apresenta a revisão da literatura sobre o tema. O Capítulo 3 descreve o método proposto e o experimento piloto. Nos Capítulos 4 e 5, os resultados encontrados na pesquisa são discutidos e no Capítulo 6 são apresentadas as conclusões do estudo e as recomendações para trabalhos futuros. 


\section{REVISÃO DA LITERATURA}

Este capítulo apresenta uma revisão da literatura com relação aos seguintes aspectos: o HCM e o conceito de nível de serviço; pesquisas que estudaram a forma como usuários percebem a qualidade de serviço; e as formas como a percepção pode ser medida em Psicofísica e Psicometria.

\subsection{Nível de serviço}

O conceito de nível de serviço (NS) foi apresentado pelo Highway Capacity Manual, em sua edição de 1965, como sendo uma medida qualitativa que reflete a qualidade de serviço oferecido por componentes do sistema de transportes (TRB, 2010). O HCM é o manual de capacidade viária americano e, em todo o mundo, é a referência básica e primordial para avaliação da capacidade e da qualidade de serviço (Setti, 2009).

\subsubsection{Highway Capacity Manual (HCM)}

O HCM foi a primeira publicação que focou o tema capacidade viária. Além dos conceitos relativos à capacidade viária, esse manual descreve métodos de quantificação da capacidade de escoamento em vias de transportes (TRB, 2010) e de análise da condição operacional de tráfego.

A motivação para elaboração do HCM surgiu por conta do contexto histórico dos EUA após a Segunda Guerra Mundial, quando houve a necessidade de investimento na produção científica e técnica para acompanhar o acentuado crescimento do sistema rodoviário americano, visando torná-lo mais eficiente (TRB, 2010).

Inicialmente, a autoria do manual foi responsabilidade de dois órgãos americanos: Bureau of Public Roads, atual Federal Highway Administration (FHWA), e o Highway Research Board, que hoje é conhecido por Transportation Research Board (TRB), uma instituição de pesquisa americana vinculada ao National Research Council. Atualmente, o manual está em sua quinta edição, que foi publicada no ano de 2010.

A primeira edição, publicada em 1950, foi produzida a partir de uma parceria (joint venture) entre o órgão Bureau of Public Roads e o comitê de capacidade viária do Highway Research Board. Essa parceria não se manteve na produção da segunda edição (1965), assinada apenas pelo Highway Research Board. A partir da terceira versão do HCM (1985), a produção e publicação foram responsabilidades do TRB, que publicou duas atualizações da terceira versão, disponibilizadas em 1994 e 1997, a quarta edição em 2000 e a quinta em 2010. 
A elaboração do manual apresenta um estilo colaborativo, através do qual, durante mais de 60 anos, diversos grupos de trabalho e pesquisas acadêmicas foram desenvolvidas paralelamente às suas edições, visando o seu aprimoramento constante. Os recursos necessários para a condução dos estudos são providos pelo comitê HCQS (Highway Capacity and Quality of Service), instância do TRB que gerencia os trabalhos. A cada edição são publicados novos métodos, conceitos, além de revisões e atualizações do conteúdo existente. Percebe-se que a ideia é fornecer o conhecimento técnico mais apropriado concebido até o momento.

O HCM define procedimentos que estimam medidas operacionais de tráfego (velocidade, densidade, atraso etc.), sistematizando e uniformizando técnicas de avaliação úteis para as diferentes etapas da engenharia: planejamento; estudos preliminares a obras, execução de projetos e operação. Os conceitos e técnicas de análise apresentados no manual foram desenvolvidos para diversos modos de transporte, como o modo rodoviário, de pedestres, cicloviário e de transporte público (TRB, 2010). Entretanto, o modo para o qual o manual apresenta técnicas mais apuradas e desenvolvidas é o modo rodoviário.

Previamente à aplicação das técnicas sugeridas pelo HCM, deve ser realizada uma comparação entre as características americanas e as da região em estudo, para identificar diferenças comportamentais dos motoristas e de características do tráfego (ex. porcentagem de veículos pesados), dos veículos (ex. relação massa/potência) e das vias de transporte, a fim de verificar a necessidade de adaptação paramétrica (Setti, 2009; TRB, 2010). Essa necessidade é ressaltada no manual, que não assegura resultados representativos caso não seja efetuada a adaptação dos parâmetros de seus métodos.

O motivo é que os estudos a partir dos quais os parâmetros dos modelos foram determinados, foram realizados, em sua grande maioria, nos Estados Unidos. Dessa forma, qualquer estudo que venha a ser realizado em uma região com características diferentes da americana, precisa promover, previamente, uma etapa de adaptação paramétrica e de compatibilização do método à região, a fim de validar o método à condição local para obter resultados fiéis à realidade estudada (TRB, 2010).

Em concordância com a necessidade de adaptação da técnica, estão os órgãos gestores e fiscalizadores brasileiros, além dos centros de pesquisa que estudam o assunto. Todos reconhecem a necessidade da adaptação e, por isso, recomendam realizar a calibração de equações e procedimentos para a condição local antes da aplicação do método. Por exemplo, o DNIT por meio de suas instruções normativas apresenta o manual HCM, recomendando que os estudos sejam baseados na edição mais recente do manual e destacando que é necessário realizar 
a adaptação paramétrica à condição local (DNIT, 2006b). O Tribunal de Contas da União (TCU), por meio de um acórdão, sugere à ANTT que sejam efetuados os ajustes necessários a adoção dos métodos do HCM, a fim de torná-lo mais adequado à realidade brasileira (TCU, 2008; Andrade, Silva \& Puty Filho, 2011).

No campo acadêmico, Setti (2009) apresenta as investigações realizadas sobre o tema por um grupo de estudos da Universidade de São Paulo, compara as diferenças do sistema de transporte rodoviário brasileiro e o americano e discute a necessidade de adaptação da versão americana para formar um manual de capacidade rodoviária brasileiro. A conclusão é que a adaptação do HCM aos padrões brasileiros é necessária, já que estudos (Utimura et al., 2007; Cunha \& Setti, 2009) apontam que o uso de parâmetros adaptados ao Estado de São Paulo produziu resultados mais confiáveis do que a utilização de parâmetros da versão americana.

\subsubsection{Qualidade e nível de serviço}

De acordo com o HCM (TRB, 2010), qualidade de serviço representa o nível de satisfação em que um serviço ou sistema de transporte opera, do ponto de vista do usuário. A qualidade de serviço é usualmente expressa por um nível de serviço para facilitar seu uso e entendimento, não apenas pelos operadores de sistemas de transporte, mas também por gestores públicos e pela comunidade de usuários em geral.

O conceito de nível de serviço foi introduzido na edição do HCM de 1965 e gerou uma nova interpretação sobre o conceito de capacidade viária. Assim, na edição de 1985, capacidade viária deixou de ser considerada apenas como a máxima capacidade da via e passou a contemplar a percepção do usuário.

O aprimoramento do conceito leva em consideração que a capacidade de vias envolve indivíduos sensíveis à qualidade do serviço oferecido e que reagem ao que lhe é oferecido. Por isso, o entendimento sobre capacidade deixou de ser o mesmo dado ao suporte de carga em vigas e à capacidade de tubulações acomodar fluidos e passou a ser calculado por meio da relação entre o fluxo e a qualidade do serviço oferecido (TRB, 1985, p. iii).

O novo entendimento sobre capacidade viária resultou, também na edição 1985, no refinamento do conceito de nível de serviço. Nessa edição, foi incorporado ao conceito a percepção do motorista sobre a qualidade de serviço, pondo fim à avaliação do elemento viário através de uma consideração puramente operacional. 
Apesar da evolução conceitual, na edição de 2000, os métodos de determinação do nível de serviço continuaram resultando em uma única medida que, simultaneamente, representavam o nível de serviço em campo (condições operacionais); o percebido pelos viajantes; e o considerado pelos gestores viários e operadores do sistema.

Assim, a partir de 2000, estudos foram desenvolvidos com a finalidade de averiguar se fatores não operacionais deveriam ser usados, bem como a capacidade de um único fator operacional representar o nível de serviço de modo a satisfazer às exigências conceituais (TRB, 2010, pp. 1-10), especificamente:

(i) a incorporação de múltiplos indicadores de satisfação do usuário; e

(ii) novas configurações de limites de níveis de serviço, baseados na percepção dos viajantes sobre a qualidade de serviço.

Considerando o cálculo de nível de serviço no modo rodoviário, a expectativa de melhoria metodológica ainda não foi satisfeita, embora tenha sido mencionado na edição de 2010 que o comitê HCQS pretende monitorar e avaliar as pesquisas futuras e em curso, para uma provável inclusão do assunto nas próximas edições.

Em outros modos de transportes, verificou-se um avanço quando foram propostos métodos que se baseiam na percepção do usuário para estimar o nível de serviço no modo cicloviário, de pedestre e de transporte público (TRB, 2010, pp. 1-10). Para mais detalhes sobre a consideração da percepção, o tópico 2.2.2 aborda os estudos que investigam a percepção da qualidade de serviço, sob o ponto de vista do usuário em diversos componentes e sistemas de transporte.

Para avaliar a qualidade de serviço, o HCM usa medidas de serviço, que simplesmente são as medidas de desempenho utilizadas em seus métodos para avaliar a qualidade em termos de atraso e/ou mobilidade do serviço oferecido (TRB, 2010).

As medidas de serviço usadas atualmente no HCM para o modo rodoviário são: (i) densidade veicular; (ii) atraso; (iii) velocidade média; (iv) percentual da velocidade de fluxo livre; e (v) percentual de tempo viajando em pelotão (TRB, 2010).

A análise do nível de serviço pode ser feita tanto em elementos do sistema de transporte de forma individualizada, como em caráter combinado de elementos (sistemas). Na Tabela 1, estão apresentados todos os elementos dos sistemas de transporte rodoviário, assim como, as combinações desses elementos que possuem método de análise de nível de serviço presentes 
no HCM 2010. Estão mostradas também as correspondentes medidas de serviço utilizadas na análise (TRB, 2010).

Tabela 1. As medidas de serviço do HCM 2010 para cada modo de transporte (Adaptada de TRB, 2010, pp. 2-6)

\begin{tabular}{ll}
\hline Elemento do sistema rodoviário & Medida de serviço \\
\hline Autoestrada & Densidade \\
Segmento simples em autoestradas & Densidade \\
$\begin{array}{l}\text { Segmento de entrelaçamento em } \\
\text { autoestradas }\end{array}$ & Densidade \\
Segmento de divergência ou & Densidade \\
convergência em autoestradas & Densidade \\
Rodovia de pista dupla & $\begin{array}{l}\text { Porcentagem de tempo viajando em pelotão; } \\
\text { velocidade média; e percentual da velocidade de } \\
\text { fluxo livre }\end{array}$ \\
Rodovia de pista simples & Velocidade média; e percentual da velocidade de \\
fluxo livre
\end{tabular}

Para cada componente da infraestrutura de transporte, assim como para suas combinações, o HCM propõe uma estratificação da medida de serviço (ou do valor de saída de um modelo matemático baseados em múltiplas medidas de serviço) para determinação do nível de serviço.

\subsubsection{Nível de serviço em autoestrada}

Para o caso de autoestradas, a medida de desempenho que o HCM definiu para representar o nível de serviço é a densidade veicular em veículo equivalente. Entretanto, a qualidade de serviço pode ser determinada por outras duas medidas de serviço: velocidade média espacial e 
razão entre a demanda e a capacidade da via (TRB, 2010). Isso ocorre porque todas essas medidas estão correlacionadas entre si por meio da equação fundamental do tráfego: o uso de uma, indiretamente utiliza a outra (Papadimitriou, Mylona \& Golias, 2010).

A escolha do HCM se justifica, uma vez que a densidade veicular é a medida de serviço que melhor representa a percepção do usuário sobre a qualidade de serviço e pela baixa capacidade das demais em fornecer informações que auxiliem na avaliação da percepção (Washburn, Ramlackhan \& McLeod, 2004; TRB, 2010).

Por exemplo, a variável "razão entre a demanda e a capacidade da via" só se torna discernível ao viajante quando o fluxo se aproxima da capacidade; já a "velocidade média espacial" fica praticamente constante até o nível de serviço $\mathrm{C}$, quando a velocidade de operação dos veículos começa a sofrer impacto com o aumento da densidade veicular (TRB, 2010).

No total, o HCM 2010 define seis categorias operacionais para representar os níveis de serviço, indicadas de A (melhor) até F (pior). Cada categoria é delimitada por uma estratificação quantitativa (step function, função definida por partes) da medida de serviço densidade veicular (Tabela 2).

O nível de serviço A é caracterizado majoritariamente pela condição de fluxo livre, já o limiar entre a categoria $\mathrm{E}$ e $\mathrm{F}$ é definido pela capacidade máxima da via, obtida por métodos empíricos. Dessa forma, a categoria $\mathrm{F}$ é representada pelo fluxo congestionado, quando a demanda excede a capacidade viária e quando a maioria dos usuários passa a qualificar o cenário como insatisfatório (TRB, 2010). Os demais níveis (A ao E) representam fluxos não-congestionado.

Tabela 2. Limites do nível de serviço em autoestradas em função da medida de serviço densidade. Quando a razão entre volume e capacidade é maior que 1, classifica-se o nível de serviço em F (TRB, 2010, pp. 10-9)

\begin{tabular}{cc}
\hline Nível de serviço & Limite [(veic/(km.faixa)] \\
\hline A & $0-6,9$ \\
B & $>6,9-11,2$ \\
C & $>11,2-16,2$ \\
D & $>16,2-21,9$ \\
E & $>21,9-28,1$ \\
F & $>28,1$ \\
\hline
\end{tabular}

Para que essa classificação de nível de serviço contemple a percepção do usuário, a mudança de uma categoria para outra deveria refletir a mudança de percepção do usuário sobre a qualidade de serviço oferecido. Dessa forma, a percepção sobre o sistema rodoviário estaria de 
acordo com a categoria operacional definida pelos estratos da densidade veicular. Entretanto, os limiares de mudança de uma categoria a outra foram definidos arbitrariamente pelo comitê HCQS, por meio do conhecimento técnico dos membros, sem qualquer investigação sobre a percepção do usuário a respeito das condições operacionais (TRB, 2010).

Como dito, essa classificação provavelmente não é válida para o cenário brasileiro, pois o comportamento do usuário americano e a sua exigência por qualidade de serviço (entre outras características) podem ser distintas do contexto brasileiro (Setti, 2009).

Assim, como há necessidade de incorporar a percepção dos usuários na determinação dos limites dos níveis de serviço, além de adequá-los à realidade brasileira, a pesquisa proposta se justifica.

Antes de discutir os trabalhos que investigam a percepção dos usuários sobre a qualidade de serviço, serão discutidos os fatores que influenciam essa atitude, assim como, as escalas de medida sugeridas em análises subjetivas.

\subsection{Percepção como medida}

A percepção da qualidade de serviço de sistemas de transporte é formada em função de fatores como a experiência de situações vivenciadas e a forma de processamento da informação absorvida pelo corpo. Como exemplo dessa informação absorvida, pode-se citar as características do sistema de transporte - cenário.

O HCM 2010 apresenta os fatores considerados como impactantes à qualidade de serviço, que são: (a) tempo de viagem; (b) confiabilidade no tempo de viagem; (c) velocidade de tráfego; (d) tempo de atraso; (e) número de paradas; (f) conforto; (g) conveniência de navegação; (h) segurança; (i) custo da viagem; (j) disponibilidade de elementos viários e serviços complementares; (k) estética dos elementos viários; (l) disponibilidade de informação; e (m) impediência a manobras.

Como visto, são vários os fatores que influenciam a percepção de uma viagem. Entretanto, pouco se sabe sobre quais fatores são os mais adequados para representar a qualidade de serviço percebida pelos usuários em um dado componente do sistema viário, pois poucos estudos analisaram esse tema (Washburn, Ramlackhan \& McLeod, 2004).

Suprindo essa carência ao modo rodoviário, mais precisamente para autoestradas, foram realizadas pesquisas que, além de avaliar a influência de variáveis na percepção, identificava as mais significantes para diferentes grupos de usuários. 
Em uma rodovia rural, Nakamura, Suzuki e Ryu (2000) identificaram que, dentre as variáveis consideradas no método, a taxa de fluxo de tráfego (traffic flow rate) era a mais correlacionada ao nível de satisfação dos motoristas. Outras variáveis, tais como o número de mudança de faixa, o tempo gasto seguindo um veículo mais lento, a experiência de direção e a frequência no uso da rodovia, também foram analisadas e também demonstraram uma relação significativa com a satisfação dos motoristas.

Washburn, Ramlackhan e McLeod (2004) realizaram uma análise exploratória para identificar os fatores adequados para avaliar a qualidade da viagem. A coleta foi realizada em uma autoestrada rural e os seis fatores identificados como os mais impactantes à qualidade da viagem foram: (i) manutenção da velocidade desejada; (ii) viajar em velocidade maior que a máxima permitida; (iii) liberdade para manobrar; (iv) condição do pavimento; (v) etiqueta e cortesia dos outros motoristas; e (vi) área na via em construção ou manutenção. Cabe destacar que os respondentes avaliaram os fatores a partir de uma lista de fatores predeterminada.

Washburn e Kirschner (2006) constataram que a densidade foi a variável do modelo concebido na pesquisa que apresentou a maior capacidade de prever a percepção da qualidade da viagem em autoestradas rurais. Nessa pesquisa, também foram testadas outras variáveis e notou-se que todas contribuíram para a previsão do modelo (características da rodovia e do tráfego; e características do usuário e de viagens em rodovias rurais). Entretanto, os autores sugeriram não usar as características dos indivíduos e da viagem, pelo irrelevante ganho de previsão do modelo e por serem variáveis de difícil obtenção.

Os trabalhos de Choocharukul, Sinha e Mannering (2004) e Papadimitriou, Mylona e Golias (2010) foram realizados em autoestradas urbanas. No trabalho de Choocharukul, Sinha e Mannering (2004), além da densidade, foi encontrado que o número de faixas, a velocidade média, a variação da velocidade, a variação de headway, o percentual de veículos pesados e algumas variáveis demográficas também exercem forte influência sobre a percepção de qualidade de serviço. No caso de Papadimitriou, Mylona e Golias (2010), as variáveis consideradas foram idade, gênero, experiência em conduzir veículos, familiaridade com a rodovia, motor do veículo e fluxo de tráfego. Como resultado, a única que contribuiu significativamente para a percepção da qualidade de serviço foi o fluxo de tráfego.

Hall, Wakefield e Al-Kaisy (2001) identificaram que para viajantes frequentes (commuters), o tempo total da viagem é o mais importante, embora a segurança, a informação ao viajante e a liberdade a manobras (que está relacionada com a densidade) também influenciem. Hostovsky e Hall (2003) escolheram uma amostra de motoristas profissionais de caminhão (tractor-trailer 
driver) e concluíram que esse grupo considera, como principais fatores, o tempo de viagem (velocidade), a densidade do tráfego (liberdade a manobras) e, principalmente, o fluxo. Para esses motoristas profissionais, a densidade não é o fator determinante, mas a fluência no tráfego, pois a viagem torna-se desconfortável quando é necessário alternar constantemente entre o freio e o acelerador (mudança de marcha).

Outro trabalho conduzido por Hostovsky, Wakefield e Hall (2004) analisou três grupos de usuários: viajantes frequentes em rodovias de zona rural, viajantes frequentes em rodovias de zona urbana e motoristas profissionais. $\mathrm{O}$ estudo concluiu que as viagens em zona urbana são qualificadas em função principalmente do tempo de viagem, enquanto que as viagens em zona rural majoritariamente pela liberdade de manobra. Para o caso dos motoristas de caminhões, estes preocupam-se com a fluência do tráfego (steady traffic flow) e com pavimento em bom estado de conservação.

Além de apresentar os fatores que impactam na qualidade de serviço, o HCM também sugere as formas de coleta de informação relacionada à qualidade do serviço oferecido, listando (TRB, 2010, pp. 5-2): (a) observação de fatores direta ou indiretamente percebíveis e importantes ao usuário; (b) pesquisas com os usuários; (c) identificação de reclamações/elogios; (d) previsão da satisfação por meio de modelos concebidos a partir de pesquisas previamente realizadas; e (e) observação de fatos não percebidos diretamente pelos usuários, mas que afetam medidas percebidas.

Com relação aos métodos (instrumentos de coleta) usados para obter a percepção, o HCM menciona os grupos focais, pesquisas por questionários, experimentos em campo (ex. condução de um veículo) e gravações de experimentos em campo (ex. filmes) (TRB, 2010, pp. 5-7).

Outro método adequado para o propósito e desconsiderado pelo HCM é a simulação. A simulação, seja por meio de simuladores de direção ou por simuladores microscópicos de tráfego, possui potencial em superar as dificuldades apontadas pelo HCM 2010 para a avaliação da condição operacional sob o ponto de vista do usuário: (i) conceber um método que capture todos os fatores que afetam a percepção do usuário e, ao mesmo tempo, que exclua fatores irrelevantes e que podem desviar o foco do estudo; e (ii) conseguir replicar as condições desejadas para obter mais respostas. Cabe destacar que essas dificuldades são problemas inerentes à experimentos em campo, pois não há controle sobre as condições locais que serão vivenciadas no momento do experimento. 
A utilização de simuladores microscópicos de tráfego permite a gravação de uma viagem vista a partir do campo de visão do condutor (drive-through). A partir de um simulador que disponha de um bom processamento gráfico para visualização do ambiente simulado, é possível gerar um filme que retrate os fatores desejados para análise do serviço oferecido por um sistema de transporte.

Os simuladores de tráfego representam a realidade de forma mais simplificada do que os simuladores de direção, pois sua finalidade possibilita uma maior simplificação da realidade. Entretanto, uma vantagem dos simuladores de tráfego é que por meio deles, é possível realizar uma comparação pareada entre cenários, já que os simuladores de direção têm como princípio a experiência de condução em situação hipotética.

\subsubsection{Escalas de medida para percepção da qualidade de serviço}

A mensuração da percepção da qualidade de serviço pode ser feita de forma qualitativa (alocação em uma categoria) ou quantitativa (de posição em uma escala numérica). As variáveis quantitativas podem ser classificadas em discretas e contínuas e as qualitativas em categóricas nominais ou ordinais (Pereira, 2004).

Quanto ao tipo de escala de medida, a classificação possui quatro categorias (Stevens, 1975), são elas:

a) Nominal: a variável rotula (ou nomeia) simplesmente para identificação;

b) Ordinal: a variável, além das propriedades da escala nominal, aponta o ordenamento entre as categorias;

c) Intervalar: a variável possui unidade de medida e valor zero arbitrário;

d) Proporcional (ou de razão): a variável possui unidade de medida e valor zero absoluto.

Diante dessas classificações, nota-se que as escalas de medida do tipo nominal e ordinal só possuem variáveis qualitativas, ou seja, categóricas; pois mesmo que sejam números que rotulem as categorias, estes não satisfazem as propriedades aritméticas. Com relação às escalas intervalar e proporcional, ambas possuem unidade de medida associada e, portanto, sua representação é feita por variáveis quantitativas.

Stevens (1975) apresenta a Tabela 3 que mostra as operações e transformações permitidas, além de estatísticas e exemplos associados a cada tipo de escala de medida. Essa tabela foi construída para uma situação em que todos os tipos de escala utilizavam números (seja de natureza 
qualitativa ou quantitativa), dessa forma, cada tipo de escala usa diferentes propriedades do sistema numérico, pois números podem expressar identidade, ordem, diferença ou proporção.

Tabela 3. Os quatro principais tipos de escalas de medida, com uso de variável numérica (Stevens, 1975)

\begin{tabular}{|c|c|c|c|c|}
\hline $\begin{array}{l}\text { Tipo de } \\
\text { Escala } \\
\end{array}$ & $\begin{array}{l}\text { Operações } \\
\text { possíveis }\end{array}$ & $\begin{array}{l}\text { Transformações } \\
\text { permitidas }\end{array}$ & Estatística apropriada & Exemplo \\
\hline Nominal & $\begin{array}{l}\text { Identificar e } \\
\text { classificar }\end{array}$ & $\begin{array}{l}\text { Substituição por } \\
\text { outro número }\end{array}$ & $\begin{array}{l}\text { Número de casos; } \\
\text { Moda; } \\
\text { Correlação de } \\
\text { contingência }\end{array}$ & Numeração de jogador \\
\hline Ordinal & Ordenar & $\begin{array}{l}\text { Qualquer } \\
\text { mudança que } \\
\text { preserve a ordem }\end{array}$ & $\begin{array}{l}\text { Mediana; } \\
\text { Percentis; } \\
\text { Correlação da ordem } \\
\text { de classificação } \\
\text { (rank-order } \\
\text { correlation) }\end{array}$ & $\begin{array}{l}\text { Lista de preferência; } \\
\text { Dureza dos minerais; } \\
\text { Lista em ranking }\end{array}$ \\
\hline Intervalar & $\begin{array}{l}\text { Calcular } \\
\text { distâncias e } \\
\text { diferenças }\end{array}$ & $\begin{array}{l}\text { Multiplicação por } \\
\text { uma constante; } \\
\text { Adição de uma } \\
\text { constante }\end{array}$ & $\begin{array}{l}\text { Média; } \\
\text { Desvio-padrão; } \\
\text { Product-moment } \\
\text { correlation }\end{array}$ & $\begin{array}{l}\text { Temperatura } \\
\text { (Fahrenheit e Celsius); } \\
\text { Tempo do calendário; } \\
\text { Resultados } \\
\text { padronizados }\end{array}$ \\
\hline $\begin{array}{l}\text { Proporcional } \\
\text { (ou de } \\
\text { razão) }\end{array}$ & $\begin{array}{l}\text { Calcular } \\
\text { proporção, } \\
\text { fração e } \\
\text { múltiplos }\end{array}$ & $\begin{array}{l}\text { Multiplicação por } \\
\text { uma constante }\end{array}$ & $\begin{array}{l}\text { Média geométrica; } \\
\text { Variabilidade } \\
\text { percentual }\end{array}$ & $\begin{array}{l}\text { Comprimento; Peso; } \\
\text { Numeração; Duração; } \\
\text { Temperatura (em } \\
\text { Kelvin) }\end{array}$ \\
\hline
\end{tabular}

A mensuração torna-se uma ação complexa quando são avaliados elementos subjetivos como a percepção, mas, mesmo complexa, é possível segundo a Psicofísica e Psicometria.

Stevens (1975) aponta em sua bibliografia a divisão de opinião entre os cientistas da psicofísica sobre a forma de mensuração: uns acreditam que para mensurar sensação é preciso de uma escala categórica (qualitativa); outros, como ele, defendem a possibilidade de mensurar a subjetividade através de mecanismos quantitativos, desde que a escala de medida seja do tipo proporcional.

O motivo de Stevens (1975) restringir a mensuração por uma escala proporcional é uma controvérsia na área; ele acredita que o ser humano compara duas sensações de forma proporcional. Complementando, a escala proporcional é a única que permite calcular proporções entre unidades da escala, enquanto que a intervalar só determina proporção entre intervalos da escala. Por exemplo, não é possível afirmar que $20^{\circ} \mathrm{C}$ é equivalente a duas vezes a temperatura de $10^{\circ} \mathrm{C}$, pois a escala de temperatura em Celsius é uma escala intervalar. Porém, 
é possível afirmar que $300 \mathrm{~K}$ é equivalente a duas vezes $150 \mathrm{~K}$, pois a escala foi criada com base no zero absoluto $(0 \mathrm{~K})$, temperatura onde a agitação térmica das moléculas cessa.

\subsubsection{Escalas de medidas na Psicofísica}

A psicofísica é a ciência que estuda a relação entre o mundo interior da sensação com o mundo exterior do estímulo (Stevens, 1975). Essa ciência, além de buscar formas de quantificar magnitudes sensoriais, permitiu o desenvolvimento do estudo sobre consenso social (psicofísica social), ou seja, o julgamento humano sobre elementos sociais, como por exemplo o prestígio de uma profissão e a gravidade de um crime.

A vertente da psicofísica defendida por Stevens (1975) aponta que a investigação de uma escala de medida que relacione sensação e estímulo seja realizada por métodos que analisem a proporção/razão entre sensações. A outra vertente acredita que o ser humano não é capaz de julgar proporções/razão entre sensações, apenas diferenças.

Cada abordagem resulta em procedimentos experimentais diferentes: o defendido por Stevens (1975) solicita que o observador produza ou estime a magnitude de uma sensação (julgamento em proporção/razão), enquanto que o outro utiliza escalas de partição para que o julgamento se baseie na análise de diferenças entre sensações.

Segundo Stevens (1975), os procedimentos experimentais que se basearam em mensurar diferenças ou intervalos entre sensações geraram resultados confusos, diferentemente na análise por magnitude, o que sugere que o corpo humano processe as informações (estímulo) para mensurar sensações por meio de uma relação similar à estimativa por proporções/razões.

O uso da escala de partição na mensuração de sensação não é criticado totalmente por Stevens (1975), que recomenda a utilização de um desse tipo de escala para estimar limiares: a escala categórica, que é um tipo de escala ordinal e discreta.

Ambos procedimentos de estimativa (por magnitude e categórico) baseiam-se no mesmo mecanismo: assinalar um valor (referente à sensação) para um dado estímulo. A diferença entre os tipos de estimativas é que a estimativa por magnitude permite a marcação livre sem imposição de limites, ou seja, a resposta pode ser qualquer valor que reflete melhor a impressão subjetiva do observador.

Uma imposição de categorias (ou limites) impede que o observador aponte a magnitude relativa da sensação, pois limita o continuum na escala de resposta, sendo, portanto, deturpada a relação de proporção/razão que seria gerada a partir de uma marcação livre. A imposição de limites 
induz o respondente a subdividir a escala em intervalos, ou seja, realizando uma operação de partição.

Dentre as formas de escala de partição, pode-se listar com base em dois critérios (Stevens, 1975):

1. Ajuste de estímulos que produzem as sensações apresentadas:

a. Bisecção: define-se o estímulo médio entre dois extremos (as sensações apresentadas);

b. Equidistância: define-se os estímulos que repartem o continuum em $n$ intervalos iguais definidos por $n+1$ sensações apresentadas;

c. Distâncias desiguais: define-se os estímulos que repartem o continuum em $n$ intervalos desiguais definidos por $n+1$ sensações apresentadas;

2. Apontamento das percepções de sensações produzidas por estímulos.

a. Marcação em linha: define-se a percepção marcando sua posição relativa entre as demais sensações produzidas por outros estímulos. Uma variação dessa modalidade é solicitar a marcação da percepção entre dois extremos de sensações.

\subsubsection{Escalas de medidas na Psicometria}

Segundo Pasquali (2009), a psicometria tem suas origens na psicofísica dos psicólogos alemães Ernst Heinrich Weber e Gustav Fechner (defensores do uso de escala categórica na geração de uma escala sensação-estímulo). Com o passar do tempo, foi diferenciada da psicofísica e considerada o estudo da mensuração do comportamento do organismo por meio de processos mentais (lei do julgamento comparativo), enquanto que a psicofísica manteve seu foco na mensuração de processos diretamente observáveis, ou seja, o estímulo e a resposta do organismo.

Dentre as técnicas de medida desenvolvidas pela psicometria, uma delas é a escala de atitude. Uma escala de atitude é um instrumento de autoavaliação que fornece como resposta o posicionamento do indivíduo em um continuum que varia desde a atitude extremamente desfavorável à atitude extremamente favorável em relação ao objeto avaliado (Faria, 1991).

Uma escala de atitude solicita que o indivíduo se posicione com relação a assuntos por meio de sentenças, de modo que a partir das respostas dadas a cada item, seja possível estimar o 
posicionamento do indivíduo, sem que seja perguntado diretamente a opinião dele; é, portanto, um método indireto de medida.

A escala de atitude do tipo Likert é um tipo de escala de atitude e compõe-se de uma série de proposições (itens de Likert) sobre uma realidade psicossocial referente a uma atitude. A escala é ordinal, dividida em categorias que variam do posicionamento de concordância total ao de discordância total envolvendo todos os componentes de atitude: cognitivo, afetivo e comportamental (Faria, 1991). Normalmente, são cinco níveis de categorias, denominados por: concordo totalmente; concordo parcialmente; indiferente; discordo parcialmente; discordo totalmente.

Como exemplo de escala de atitude, pode-se citar o Questionário do Comportamento do Motorista - QCM (adaptado da versão em inglês Driver Behavior Questionnarie - DBQ), uma ferramenta útil para analisar o tipo de comportamento de condutores (Pinatti, 2007).

\subsubsection{Estudos relativos à percepção da qualidade de serviço}

Os estudos que abordam quantitativamente a relação entre a condição de tráfego, o comportamento do motorista e a percepção do usuário sobre a qualidade de serviço são poucos e diferentes quanto à escala de medida usada, ao método escolhido de apresentação dos cenários, à forma de análise dos dados, ao modo de transporte analisado etc.

Inicialmente, serão apresentados trabalhos no modo de transporte público e em praça de pedágio, desenvolvidos no Brasil, para em seguida apresentar as pesquisas relativas a autoestrada.

Faria (1991) desenvolveu um método que avalia a qualidade de serviço oferecida por sistemas de transporte coletivo urbano sob o ponto de vista do usuário, pois até o momento os métodos que estimavam o nível de serviço em transporte coletivo desconsideravam a percepção que o usuário tinha sobre o sistema.

O objetivo da pesquisa foi desenvolver um método que retornasse um indicador global a partir da opinião do usuário sobre atributos do sistema (características associadas ao tempo de viagem; ao conforto; e ao desempenho do sistema).

O estudo de caso foi em uma linha de ônibus da cidade de São Paulo e os dados foram obtidos por meio de um processo de entrevista ao usuário. Nessa entrevista foi utilizado um formulário que obteve dados da viagem e socioeconômicos do entrevistado, além da opinião dos usuários. A opinião dos usuários foi investigada por meio de uma escala de atitude do tipo Likert. 
Para tratar os dados e estimar o indicador global que reflita a qualidade de serviço do sistema, foram utilizados três métodos multivariados: a análise fatorial, a análise de cluster e a análise discriminante.

Também sob o enfoque da percepção dos usuários sobre a qualidade de serviço, Oliveira (2009) propôs um método para criar uma escala que permitisse mensurar o nível de serviço em praças de pedágios. O intuito era suprir a falta de um procedimento de avaliação operacional desse tipo de componente rodoviário, que é cada vez mais comum em função do aumento de concessões rodoviárias pelos governos federal e estaduais.

Esse método posteriormente foi aperfeiçoado e ajustado por Obelheiro (2010) com a finalidade de torná-lo adequado para aplicação em todo o cenário rodoviário brasileiro. O método proposto sugere mostrar cenários microssimulados de praças de pedágio através de um website e utiliza como escala de resposta uma variável categórica ordinal de 7 níveis (péssimo; muito ruim; ruim; regular; bom; muito bom; excelente). Cada variável dessa escala está associada a um numeral de 1 a 7 para fins analíticos. Os cenários microssimulados foram gravados em perspectiva aérea.

Outro trabalho, desta vez conduzido nos EUA, também usou vídeos gravados sob uma perspectiva aérea, entretanto, apresentando um cenário real para avaliar a percepção da qualidade de serviço em autoestradas. $O$ objetivo era verificar quão adequado era $\mathrm{o}$ procedimento de estimativa de nível de serviço do HCM para autoestradas. Os arquivos foram gravados em diversos trechos de autoestrada urbana no Estado de Indiana, nos EUA. Aos participantes do experimento foram fornecidas as descrições de cada um dos 6 níveis de serviço, apresentando 12 vídeos, 2 representativos para cada nível de serviço. Após assisti-los o respondente qualificava o cenário por meio da classificação de nível de serviço do HCM. O método de análise de dados foi através de um modelo Probit ordenado (ordered Probit model) e para conduzir uma análise exploratória foram colhidas informações demográfica e de hábitos de direção dos participantes. Os resultados sugerem que os limites especificados pelo HCM aos níveis de serviço não são próximos aos estimados com base na percepção do usuário (Choocharukul, Sinha \& Mannering, 2004).

Nos trabalhos de Nakamura, Suzuki e Ryu (2000), Washburn e Kirschner (2006) e Papadimitriou, Mylona e Golias (2010) - realizados respectivamente no Japão, nos EUA (Flórida) e na Grécia - o componente rodoviário estudado também foi autoestradas, mas a forma de apresentação dos cenários foi diferente. Nesses estudos, os cenários rodoviários foram 
visualizados pelos participantes dos experimentos da mesma forma como os condutores enxergam o tráfego quando estão dirigindo: do ponto de visão do condutor.

No Japão, Nakamura, Suzuki e Ryu (2000) propôs um experimento em campo, onde os participantes trafegavam em uma seção de uma via expressa enquanto a condição do fluxo era captada por uma câmera acoplada no próprio veículo do participante, por sensores e por câmeras colocadas ao longo do trecho . Após trafegar pela seção era solicitado ao motorista que completasse um questionário onde era obtida a impressão sobre a condição do tráfego, por meio de uma escala categórica ordinal de cinco níveis. Usou-se uma análise de regressão múltipla para investigar a relação entre a condição de tráfego em fluxo não-congestionado, o comportamento de condução e o grau de satisfação dos motoristas.

Washburn e Kirschner (2006) escolheram trechos de rodovias rurais onde havia monitoramento de tráfego por sensores. O objetivo de Washburn e Kirschner (2006), entre outros, era verificar a hipótese dos limites dos níveis de serviço fornecidos pelo método do HCM representarem a percepção dos usuários. Os resultados mostraram que os limites encontrados foram menores do que os sugeridos pelo HCM para todas as categorias de nível de serviço. Entretanto, cabe destacar que há diferença entre a condição de entorno da rodovia, pois, na abordagem de Washburn e Kirschner (2006), os cenários gravados mostravam rodovias situadas em zona rural, enquanto que no HCM não se faz distinção entre procedimentos para rodovia rural e urbana.

A diferença encontrada pode ter duas razões: (i) os limites são inadequados para representar a percepção do usuário sobre a qualidade de serviço; ou (ii) a percepção da qualidade de serviço em rodovias situadas em zona rural é diferente em relação a uma abordagem exclusiva com rodovias em vias urbanas ou mista.

O método proposto por Washburn e Kirschner (2006) baseia-se na apresentação de filmagens de fluxo rodoviários, realizadas com o cuidado de gravar o campo de visão de um condutor (drive-through). Os vídeos apresentavam condições de tráfego nos diversos níveis de serviço, mas as situações presenciadas durante a fase de gravação dos vídeos não apresentaram uma dispersão bem distribuída na gama de possibilidades de fluxo de tráfego possíveis.

Os vídeos foram mostrados para grupos de participantes que, em seguida, respondiam um questionário que, além de suas opiniões acerca dos cenários apresentados pelos filmes e dos fatores que contribuíram para a avaliação realizada, também solicitava informações pessoais e dos hábitos de direção em rodovias rurais. A escala utilizada era categórica ordinal de seis níveis 
(quantidade de níveis de serviço do HCM): muito fraco, fraco, razoável, bom, muito bom e excelente. A análise dos dados foi realizada por meio de modelo Probit ordenado (ordered Probit model).

O objetivo do estudo conduzido por Papadimitriou, Mylona e Golias (2010) era identificar e analisar a relação entre a percepção do nível de serviço, as características do condutor e as condições de tráfego, além de verificar a quantidade de níveis de serviço percebidos pelo usuário. O método adotado foi uma pesquisa de campo por meio de entrevista, para a qual os motoristas, que trafegavam em uma autoestrada urbana próxima à Atenas, eram escolhidos aleatoriamente quando paravam em um sinal vermelho após sair do trecho de autoestrada onde o monitoramento de tráfego estava sendo realizado. Mais uma vez, o método restringiu a gama de condições operacionais às presenciadas durante a fase de coleta de dados.

Nessa pesquisa, o usuário respondia uma rápida entrevista na qual fornecia sua avaliação a partir de sua experiência de condução, além de informações como: idade; experiência em direção; e familiaridade com o trecho analisado. Informações como gênero do motorista; tipo de veículo; categoria de motor; e duração da entrevista também foram anotadas (Papadimitriou, Mylona \& Golias, 2010).

A avaliação do condutor era fornecida em uma escala quantitativa discreta de 1 a 10 . Uma escala repartida em muitos níveis foi usada para permitir a análise da quantidade de níveis de serviço percebidos. Dessa forma, não seria interessante utilizar uma escala com poucas repartições, pois poderia fornecer um viés à determinação de quantos níveis são percebidos (Papadimitriou, Mylona \& Golias, 2010).

A análise dos dados foi realizada por meio de uma regressão linear por partes que utilizou como variável representativa do tráfego a razão entre o fluxo e a capacidade da via $(v / c)$. Foram analisados três cenários, dos quais cada um supôs um perfil de motorista diferente (suposição de condutores com baixa, média e alta tolerância à congestionamento). Em cada cenário, foram determinados quantos níveis de serviço são percebidos, assim como seus limites. Na hipótese de condutores com alta e média tolerância à congestionamentos, foram distinguidos três níveis de serviço, enquanto que para os motoristas de baixa tolerância, apenas dois níveis.

Os três trabalhos que conduziram experimento em autoestradas para analisar a percepção do usuário por meio da visualização de cenário a partir do campo de visão do motorista utilizaram situações reais que foram vivenciadas pelo pesquisador durante a filmagem ou vivenciada pelo próprio participante. Neste trabalho, propõe-se uma abordagem diferente a esses estudos. 
A proposta deste trabalho é utilizar um cenário rodoviário hipotético, concebido por meio de um microssimulador de tráfego. O intuito é testar sua eficácia e usar cenários representativos de toda a gama de valor das variáveis operacionais utilizadas, uma vez que um simulador possui a vantagem de ser possível o controle de todas as variáveis envolvidas. 


\section{O MÉTODO PROPOSTO}

Este capítulo inicialmente apresenta a forma de abordagem para avaliação dos cenários que representam a condição operacional do tráfego; em sequência, descreve as etapas que constituem o método proposto para identificar os limites dos níveis de serviço como percebidos pelos usuários de rodovias brasileiras; e apresenta quais etapas foram implementadas no experimento piloto.

A forma de representação dos cenários é através de um filme que exibe a viagem de um veículo em uma rodovia virtual a partir do ponto de visão do motorista (drive-through), gerado por meio de um simulador microscópico de tráfego (Figura 1).

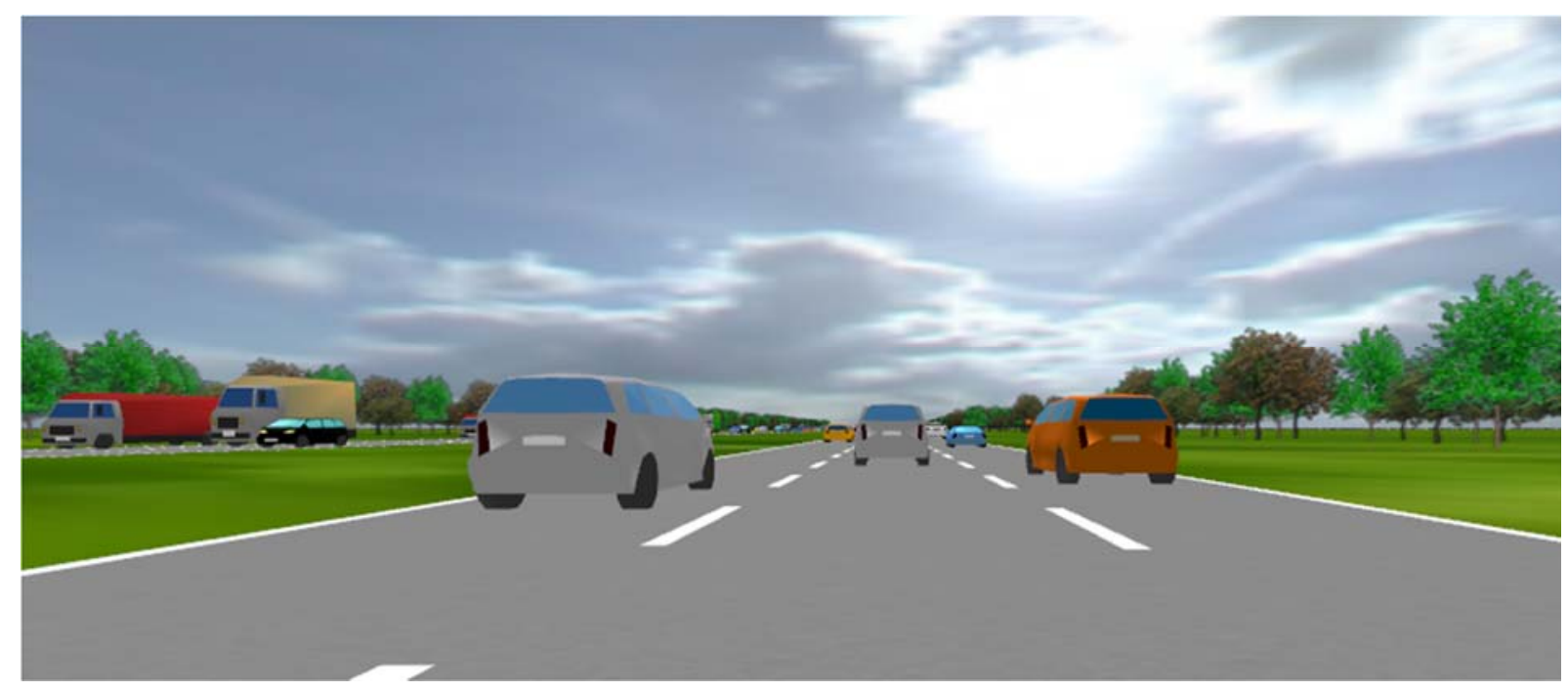

Figura 1. Visualização da simulação: campo de visão do condutor (câmera dentro do veículo)

Essa forma de apresentação de cenário é diferente, porém análoga às apresentadas por Nakamura, Suzuki e Ryu (2000), Washburn e Kirschner (2006) e Papadimitriou, Mylona e Golias (2010), pois todas apresentam um cenário no campo de visão do motorista.

Um simulador foi escolhido como ferramenta por ser capaz de gerar uma representação da realidade em qualquer condição desejada, simplesmente com o ajuste dos dados de entrada do programa, ou seja, com controle das variáveis que formam o fluxo.

\subsection{Estrutura geral do método proposto}

O método proposto foi concebido para aplicação em rodovias de zona rural, mas está apresentado nesta seção de forma geral, a fim de ser útil em avaliações de outros tipos de 
rodovias também. A seguir, estão apresentadas de forma resumida as etapas que constituem o método proposto:

a. Criação de uma rodovia virtual

Inicialmente, é preciso criar uma rodovia virtual por meio de um simulador microscópico de tráfego, definindo o tipo de rodovia, a extensão e forma do traçado vertical e horizontal, o número de faixas, as larguras dos acostamentos laterais e do canteiro central, a velocidade máxima permitida, a existência de intersecções e acessos, e por último, a ambientação dos arredores da rodovia em função de sua localização (zona rural ou urbana). É nessa rodovia que as simulações serão geradas.

b. Calibração do simulador

Nesta etapa, o objetivo é calibrar os parâmetros de entrada do simulador para que este represente uma rodovia típica brasileira. Parâmetros como a capacidade viária e a distribuição dos headways são definidos como os que melhor representam o tráfego brasileiro. O simulador calibrado será usado para criar os vídeos das viagens pela rodovia virtual.

c. Definição dos cenários para simulação

Esta etapa visa definir a quantidade de níveis para cada variável operacional envolvida no método (neste caso: porcentagem de veículos pesados e densidade veicular). Em seguida, são criados os cenários com base na combinação dos níveis de cada variável.

d. Geração dos filmes

Nesta etapa, usa-se o simulador para gerar e gravar duas viagens em situações diferentes, para cada cenário definido na etapa anterior. Geram-se dois filmes, pois o método proposto também pretende estimar a variação da nota dada por um avaliador para condições operacionais similares.

Após a gravação da simulação, um painel veicular e um velocímetro digital, configurado para mostrar a velocidade instantânea do veículo cuja viagem foi gravada, são sobrepostos sobre o vídeo, como se mostra na Figura 2.

e. Validação dos filmes

A validação dos filmes é uma etapa necessária para evitar que o banco de dados possua algum cenário que normalmente é avaliado com base em características que o 
pesquisador não deseja considerar na análise dos dados. Por exemplo, deseja-se que a avaliação seja fornecida com base em características operacionais do tráfego, dessa forma, os vídeos avaliados com base em eventos relativos às características nãooperacionais, como segurança viária ou ao comportamento do condutor do veículo, seriam retirados do banco de dados por meio desta etapa.

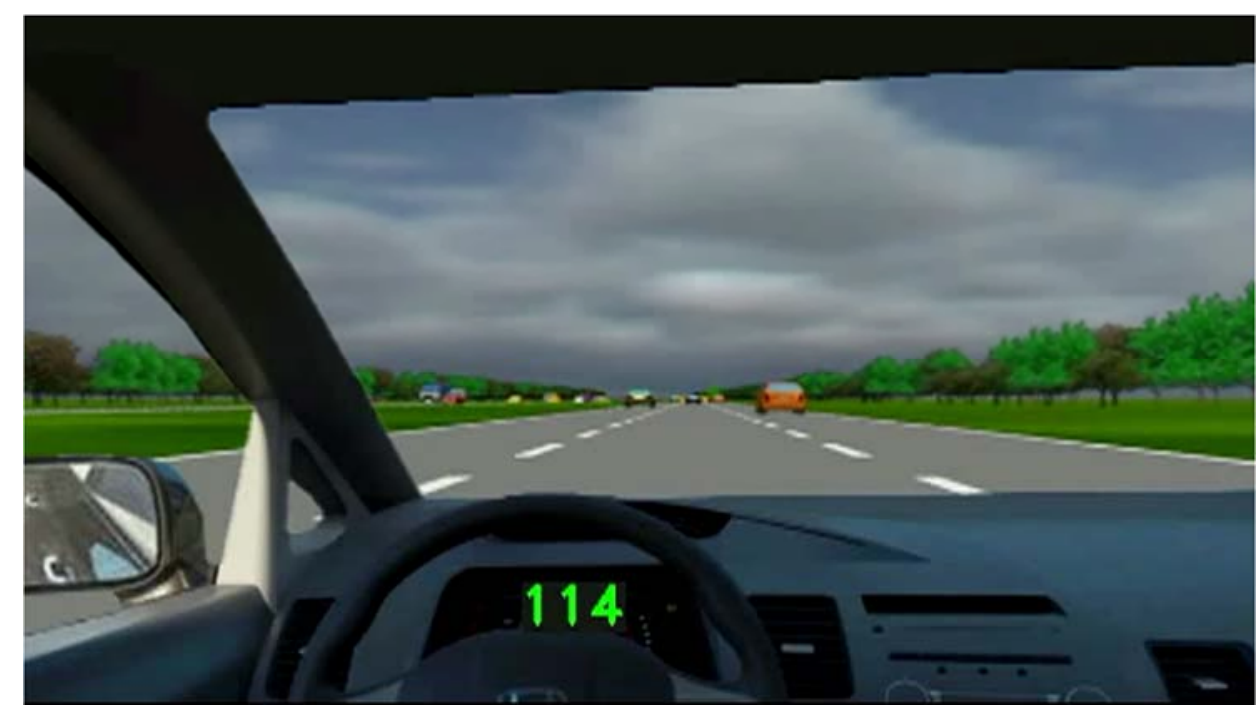

Figura 2. Interface de um cenário

Esta etapa visa sistematizar o processo e deve ser elaborada da seguinte forma: (i) seleciona-se, para esta etapa, uma amostra de respondentes instruídos; em seguida, (ii) solicita-se que cada membro da amostra analise uma quantidade de vídeos, identificando os critérios que foram usados por ele durante a avaliação do cenário; e por último, (iii) identifica-se os filmes que receberam respostas desfavoráveis (características não-operacionais) para descarte do banco de dados. Nesta etapa, a escala de resposta é discreta, o respondente pode selecionar mais de uma resposta e cada opção de resposta é um fator que normalmente influencia a percepção da qualidade de cenários rodoviários (segundo a literatura e a experiência desta pesquisa). Uma sugestão de formato para ser aplicado nesta etapa de validação está apresentada no Apêndice A.

f. Formatação do banco de dados

Esta etapa visa criar categorias no banco de dados para que os cenários sejam classificados em função de suas variáveis. A intenção é permitir a seleção aleatória de um cenário, condicionando o sorteio a uma categoria específica, para assegurar 
que seja apresentado a cada avaliador cenários distribuídos em toda gama de condições operacionais de tráfego.

Como proposta para o número de categorias no banco de dados, sugere-se um número igual a quantidade de níveis de percentual de veículos pesados vezes 10 categorias de densidade veicular. Definiu-se arbitrariamente 10 categorias de densidade veicular para que cada nível de serviço em fluxo não-congestionado (5 níveis) possua 2 categorias no banco de dados.

g. Criação de um questionário

Nesta etapa, o objetivo é montar um questionário para avaliação da percepção da qualidade de serviço. Mais precisamente: selecionar as perguntas e alternativas que caracterizarão o perfil do respondente; escolher a escala psicométrica que será utilizada para coletar a resposta das avaliações dos cenários; e definir o número de vídeos que serão apresentados a cada avaliador e a duração que terão esses vídeos.

h. Criação de um website

Para a aplicação do método proposto, é preciso criar um website configurado no formato do questionário definido na etapa anterior, com o intuito de facilitar sua aplicação. O website deve apresentar um mecanismo que permita selecionar os cenários (vídeos) por meio de um sorteio condicionado e sem reposição. A condição da seleção aleatória é pertencer a uma categoria do banco de dados (etapa formatação do banco de dados), escolhida também por meio de uma seleção aleatória e sem reposição. O motivo de ambos sorteios serem sem reposição é de que cada cenário e categoria sejam escolhidos o mesmo número de vezes.

i. Definição da amostra e coleta de dados

Em seguida, deve-se definir o tipo e o tamanho da amostra (respondentes) do estudo. Com base nessas informações, define-se a forma de coleta dos dados, ou seja, a forma como os membros da amostra selecionada para responder o questionário serão abordados.

j. Análise das respostas

A etapa final do método consiste em analisar os dados coletados para: (i) eliminar respostas incoerentes; (ii) estimar a variação da nota dada por um avaliador a condições operacionais similares; (iii) estimar os limites dos níveis de serviço em 
fluxo não-congestionado; e (iv) analisar o efeito da composição do tráfego nesses limites.

\subsection{Experimento piloto}

Um experimento piloto foi idealizado para investigar questões relevantes à definição do método proposto, além de testar o questionário elaborado e responder a perguntas relacionadas com o(a):

a. Forma de representação dos cenários;

b. Quantidade de cenários apresentada a um respondente;

c. Tempo de análise dos cenários;

d. Perguntas, alternativas e instruções do questionário;

e. Escala de medida das respostas.

No experimento piloto, foi implementada uma versão preliminar do método, quando algumas etapas, tais como a etapa de validação dos filmes e a de formatação do banco de dados, não haviam sido concebidas. Outras etapas, como a de calibração do simulador e de criação de um website, foram suprimidas devido a sua complexidade e às limitações dos recursos e tempo disponíveis.

A seguir detalham-se as etapas executadas no experimento piloto.

\subsubsection{Criação da rodovia virtual}

O software utilizado para produzir os vídeos foi o Aimsun (versão 8.0.2). Nele, foi criado um traçado em terreno plano de 7 quilômetros com características geométricas semelhantes às encontradas em rodovias de pista dupla típicas do estado de São Paulo - como a SP-310 (Rodovia Washington Luís).

O traçado horizontal forma um ' $\mathrm{S}$ ' e suas curvas horizontais são suaves. A configuração representa uma rodovia do tipo freeway com três faixas de rolamento (largura de 3,60 m) por sentido, velocidade máxima é de $120 \mathrm{~km} / \mathrm{h}$, sem intersecção e nem acessos ao longo do trecho. Nos dados de entrada do Aimsun foram criados um acostamento esquerdo de 0,60 $\mathrm{m}$ e direito de 2,50 m (Figura 3). Porém, como visto nas Figura 1 e Figura 4, a visualização gráfica da simulação não apresenta essa informação. As árvores colocadas para representar um ambiente em zona rural distam em torno de 20 metros e o canteiro central tem largura de 20 metros. 


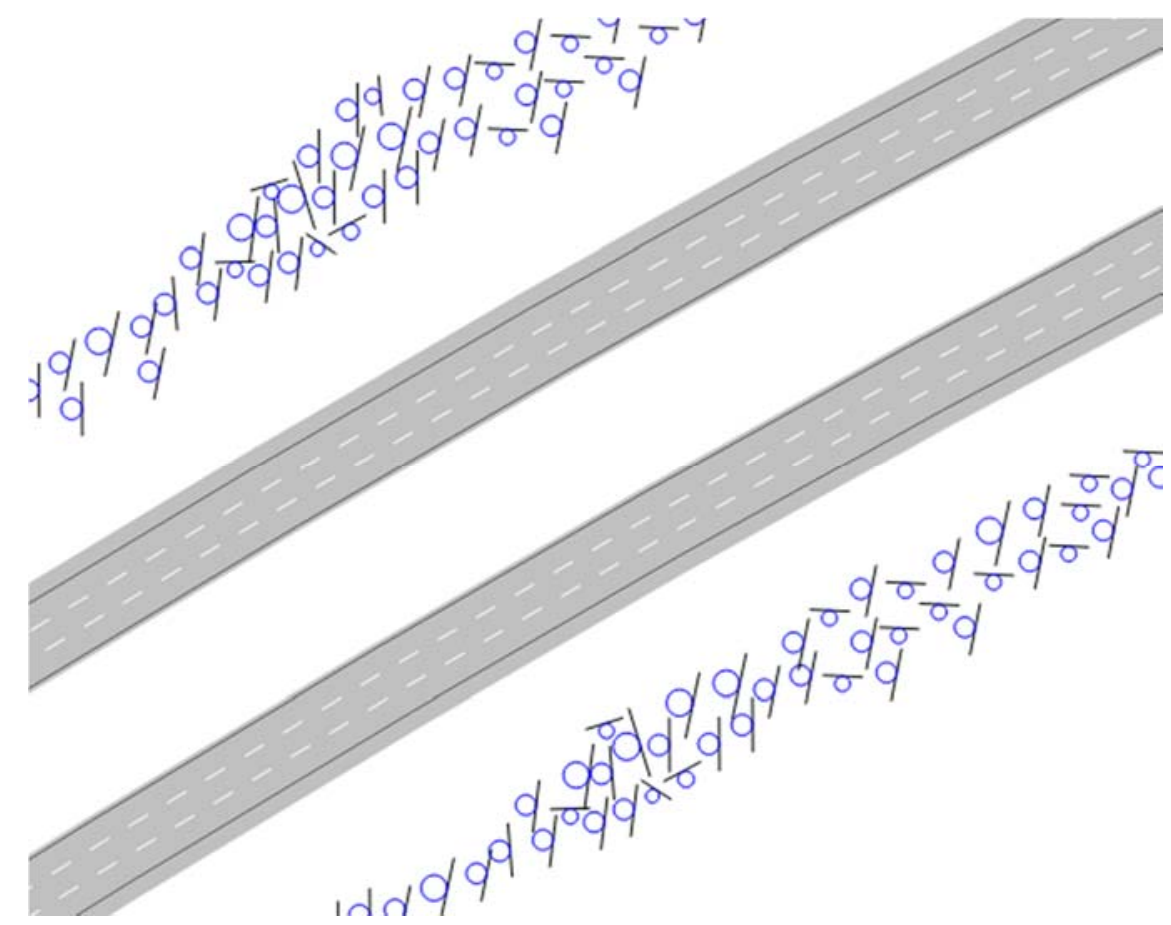

Figura 3. Representação em 2D do traçado da simulação: os círculos em azul são localizações de árvores

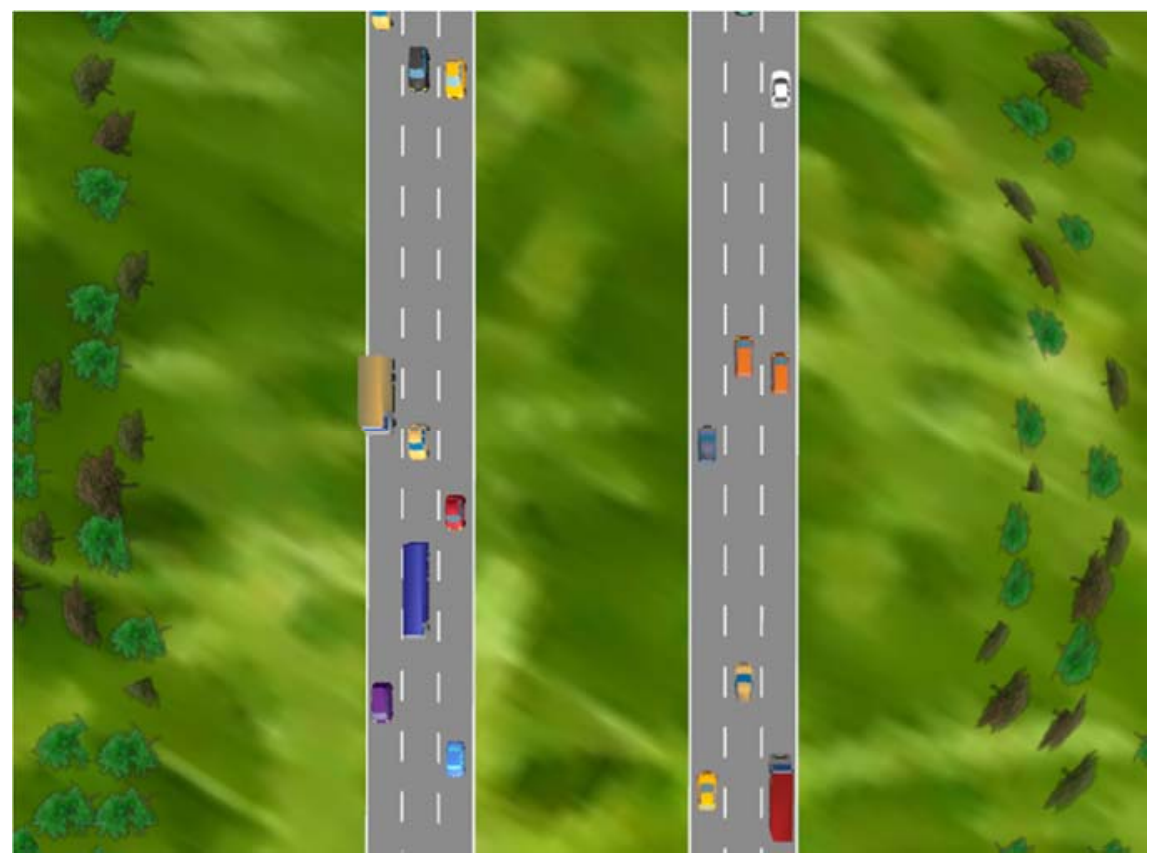

Figura 4. Vista aérea da rodovia simulada

Quanto à capacidade em cada faixa, foi adotado um valor de $2550 \mathrm{cpe} /($ h.faixa), conforme determinação de Andrade (2012) para rodovias rurais do estado de São Paulo. Portanto, a capacidade da via é de $7650 \mathrm{cpe} / \mathrm{h}$ por sentido. Segundo o mesmo trabalho, a densidade na capacidade estimada é de cerca de 27 cpe/(km.faixa). 
Tabela 4. Resumo da configuração da rodovia virtual criada para o experimento piloto

\begin{tabular}{ll}
\hline CARACTERÍSTICA & CONFIGURAÇÃO \\
\hline Traçado & $7 \mathrm{~km}$ em terreno plano \\
Número de faixas & 3 por sentido \\
Largura da faixa & $3,60 \mathrm{~m}$ \\
Velocidade máxima & $120 \mathrm{~km} / \mathrm{h}$ \\
Acostamento lateral & $0,6 \mathrm{~m}$ (esquerdo); $2,5 \mathrm{~m}$ (direito) \\
Canteiro central & $20 \mathrm{~m}$ \\
Capacidade da via (Andrade, 2012) & 2550 [cpe/(h.faixa)] \\
Densidade na capacidade (Andrade, 2012) & 27 [cpe/(km.faixa)] \\
Distribuição das chegadas & exponencial \\
\hline
\end{tabular}

Admitiu-se que os veículos entram na rede obedecendo a uma distribuição exponencial dos headways entre os veículos. A corrente de tráfego é formada unicamente por veículos de passeio e caminhões.

Por último, para que veículos pesados não trafeguem na faixa da esquerda, conforme impõe a legislação do trânsito brasileiro, foi criada uma política de gerenciamento de tráfego que mantinha a faixa da esquerda fechada para veículos pesados.

\subsubsection{Definição dos cenários para simulação}

A variação entre cada cenário se deu no quesito densidade veicular $(k)$ e percentual de veículos pesados (\%vp), pois foram as duas variáveis escolhidas para estudar a influência sobre a percepção da qualidade de serviço.

O método concebido propõe trabalhar com 6 categorias de \%vp $(0 \% ; 10 \% ; 20 \% ; 30 \% ; 40 \%$; e $50 \%$ ) - a mesma abordagem do trabalho de Cunha (2007) - e propõe que o número de níveis de $k$ seja igual a densidade na capacidade da rodovia (resultado de variar em 1 cpe/(km.faixa), de 1 até a densidade na capacidade).

Para rodovias de pista dupla paulista, a densidade na capacidade em zona rural é de 27 cpe/(km.faixa) (Andrade, 2012). Logo, seria preciso criar 162 cenários.

Para a etapa de teste, o número de cenários foi reduzido por duas razões. A primeira razão foi simplificar. Dessa forma, escolheu-se criar cenários apenas com $0 \%, 20 \%$ e $40 \%$ de caminhões e variar $k$ em duas unidades, a partir de 1 até $27 \mathrm{cpe} /(\mathrm{km}$.faixa) (14 níveis para $k$ ).

A segunda razão para reduzir o número de cenários deveu-se ao fato do simulador não ter sido recalibrado para representar uma rodovia brasileira. Com os valores default, as densidades na capacidade fornecidas pelos sensores do Aimsun foram $21 \mathrm{cpe} /(\mathrm{km}$.faixa) para \%vp igual a $0 \%$; e $23 \mathrm{cpe} /(\mathrm{km}$.faixa) para $20 \%$ e $40 \%$ de caminhões. 
Assim sendo, para o experimento piloto foram criados 35 cenários. Essa limitação, entretanto, não foi considerada suficientemente danosa para prejudicar as conclusões do estudo piloto. Cabe destacar que para aplicar o método proposto, a recalibração do simulador é um passo vital, do qual dependerá a qualidade dos resultados que serão obtidos.

\subsubsection{Geração dos filmes}

A produção dos filmes teve três etapas: (i) determinação dos dados de entrada da simulação; (ii) a gravação do cenário; e (iii) a adição do painel veicular e do velocímetro digital.

\subsubsection{Determinação dos dados de entrada da simulação}

A tentativa inicial de calcular os dados de matriz origem-destino (fluxo para uma velocidade de fluxo livre) que resultassem em um cenário com a densidade desejada não obteve êxito, pois o modelo não estava calibrado para as formulações utilizadas.

Como alternativa para encontrar qual volume de tráfego fornecia a densidade desejada, optouse por um método iterativo, onde se definia o fluxo e distribuição de tráfego na corrente para um fator de veículo equivalente entre caminhões e carros de passeio igual a 2 cpe/caminhão (ЕT). A variação para cada iteração de fluxo foi de $30 \mathrm{cpe} /($ h.faixa).

O monitoramento das densidades veiculares ao longo do trecho foi obtido por meio de detectores de laço indutivo. Foi colocado um sensor em cada sentido da rodovia, distantes $5 \mathrm{~km}$ depois do ponto de controle de início da gravação da simulação (um pórtico de sinalização na via). Ambos foram programados para fornecer dados de médias de densidade a cada 2,5 minutos. Esse monitoramento é necessário, pois a distribuição de tráfego segue uma função exponencial: os headways não são constantes e há variação de densidade ao longo do trecho. Dois minutos e meio é o tempo estimado para durar a viagem de um veículo entre os dois pontos de controle da gravação da simulação $(5 \mathrm{~km})$ para uma velocidade em torno de 120 $\mathrm{km} / \mathrm{h}$ (velocidade de fluxo livre). O ideal é que no formato final do método, esse tempo seja o determinado para o vídeo de um cenário durar, para que haja mais segurança que a densidade apontada pelo detector é a vivenciada pelo veículo gravado.

Através dos sensores, obtiveram-se também os dados médios de velocidade e fluxo durante cada intervalo (2,5 minutos) das 5 horas de simulação. Os gráficos das Figura 5 a Figura 10 plotam os dados de saída dos detectores em cada categoria de veículos pesados, desconsiderando a primeira hora de cada simulação. 


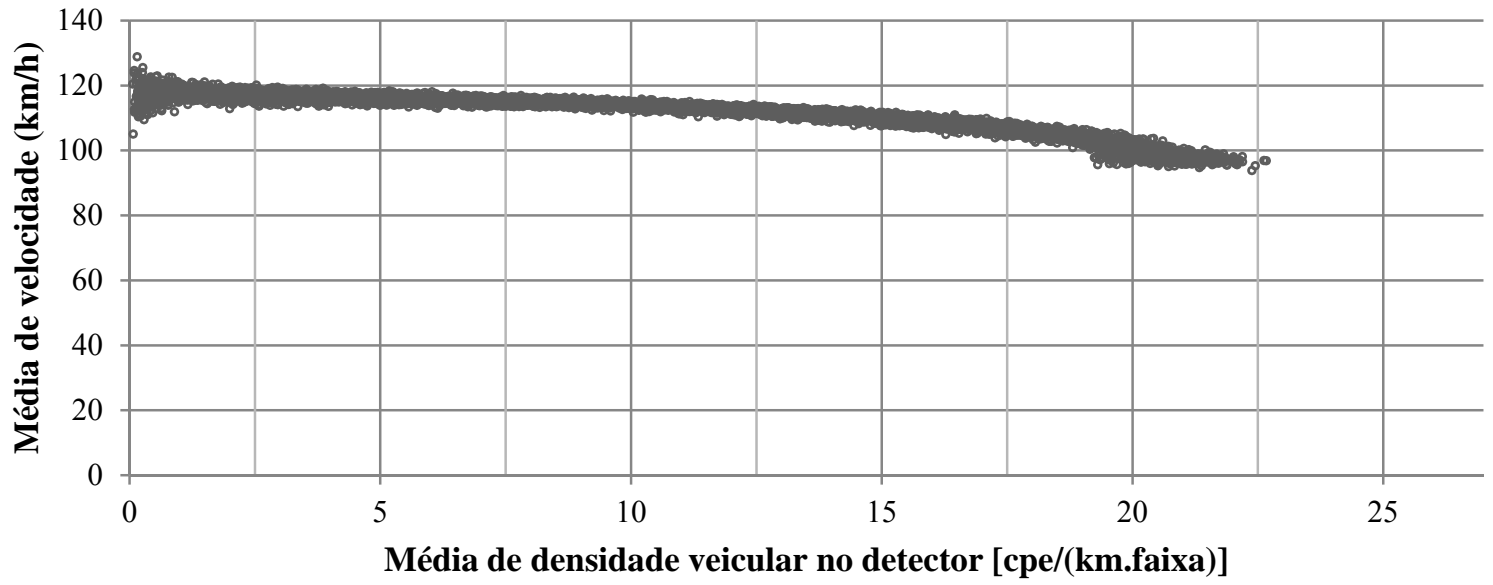

Figura 5. Média de velocidade versus média de densidade veicular no laço indutivo; $\% v p=0 \%$

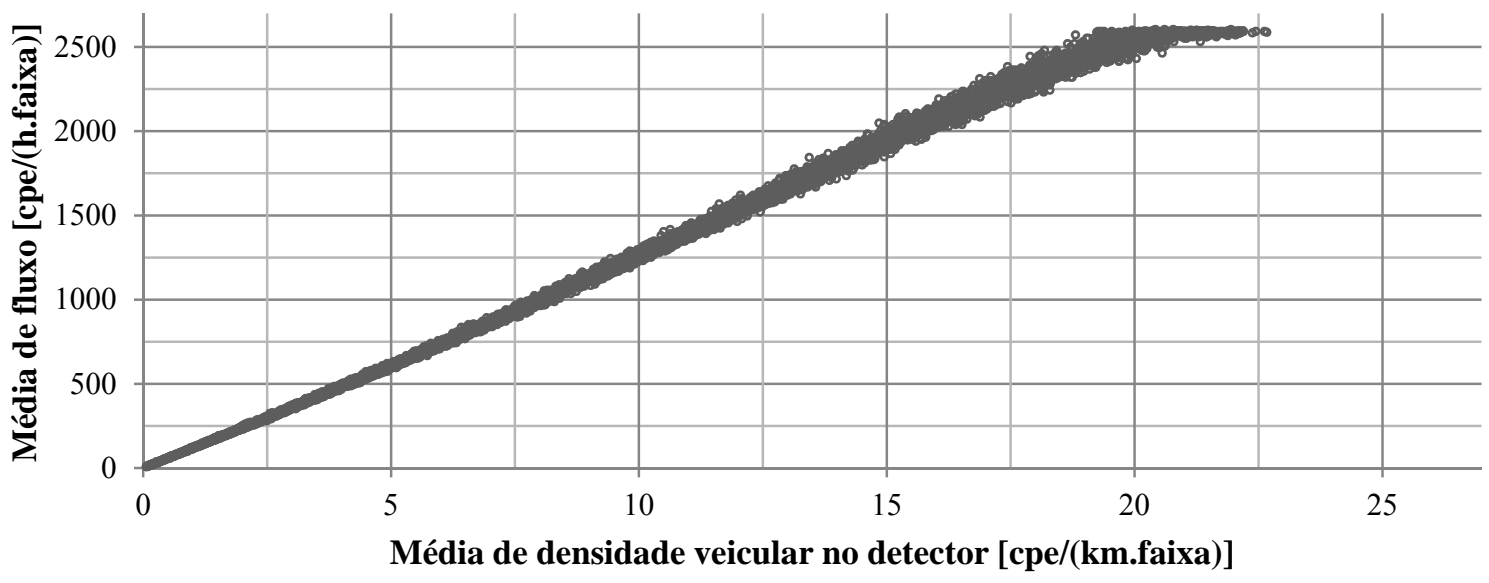

Figura 6. Média de fluxo versus média de densidade veicular no sensor; $\% v p=0 \%$

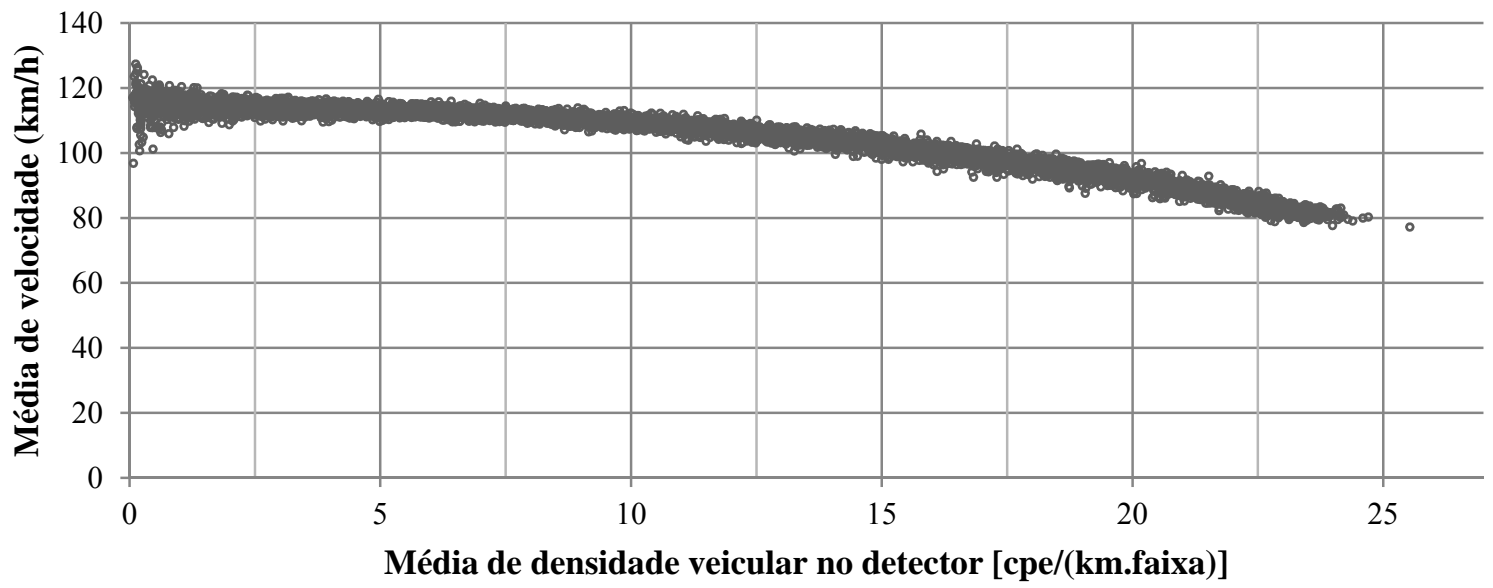

Figura 7. Média de velocidade versus média de densidade veicular no laço indutivo; $\% v p=20 \%$ 


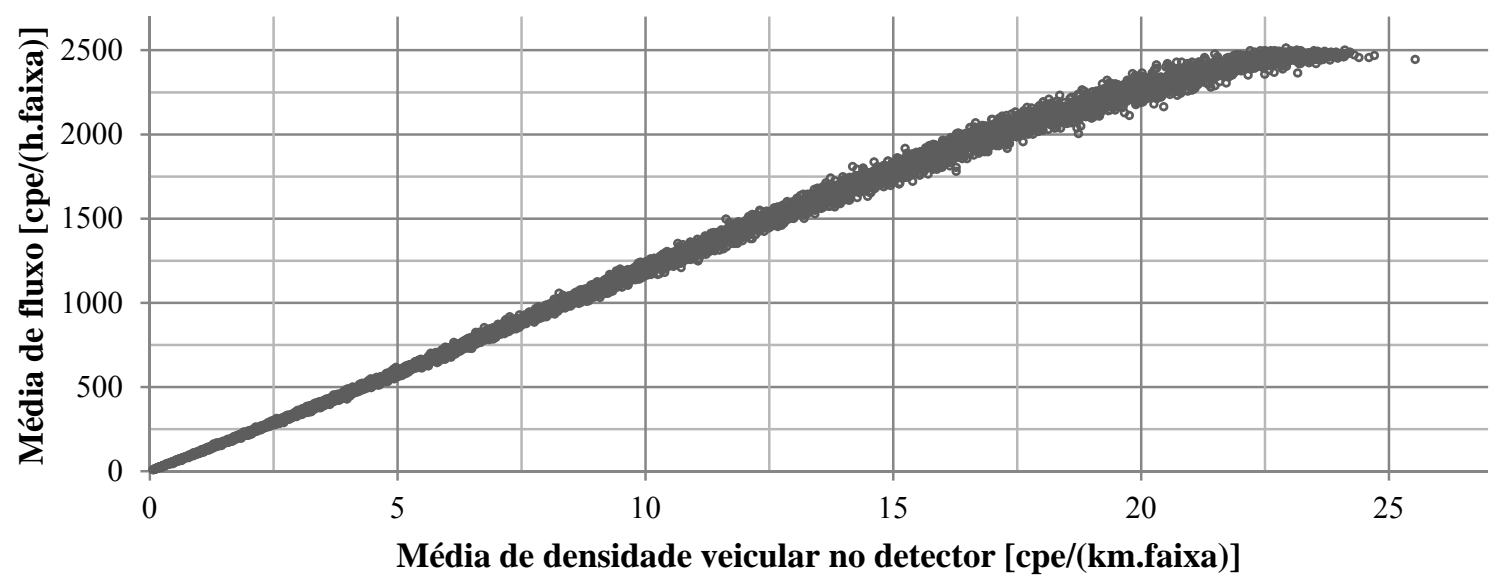

Figura 8. Média de fluxo versus média de densidade veicular no sensor; $\% v p=20 \%$

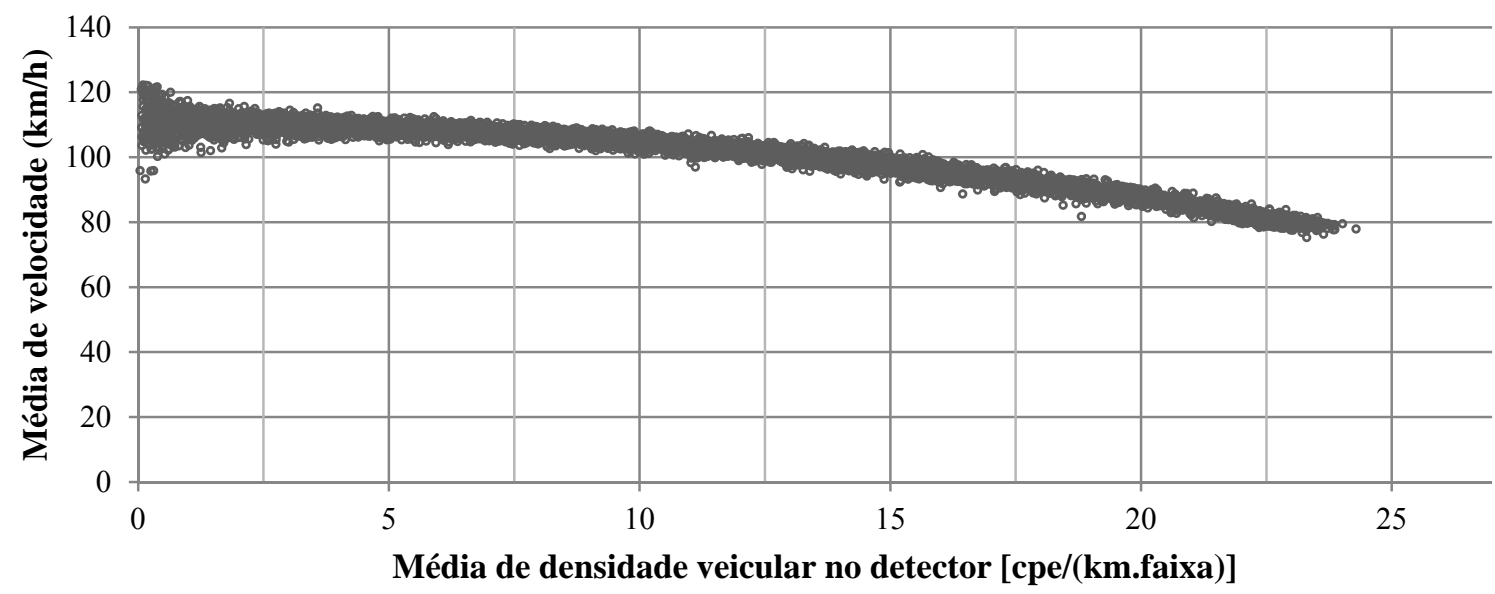

Figura 9. Média de velocidade versus média de densidade veicular no laço indutivo; $\% v p=40 \%$

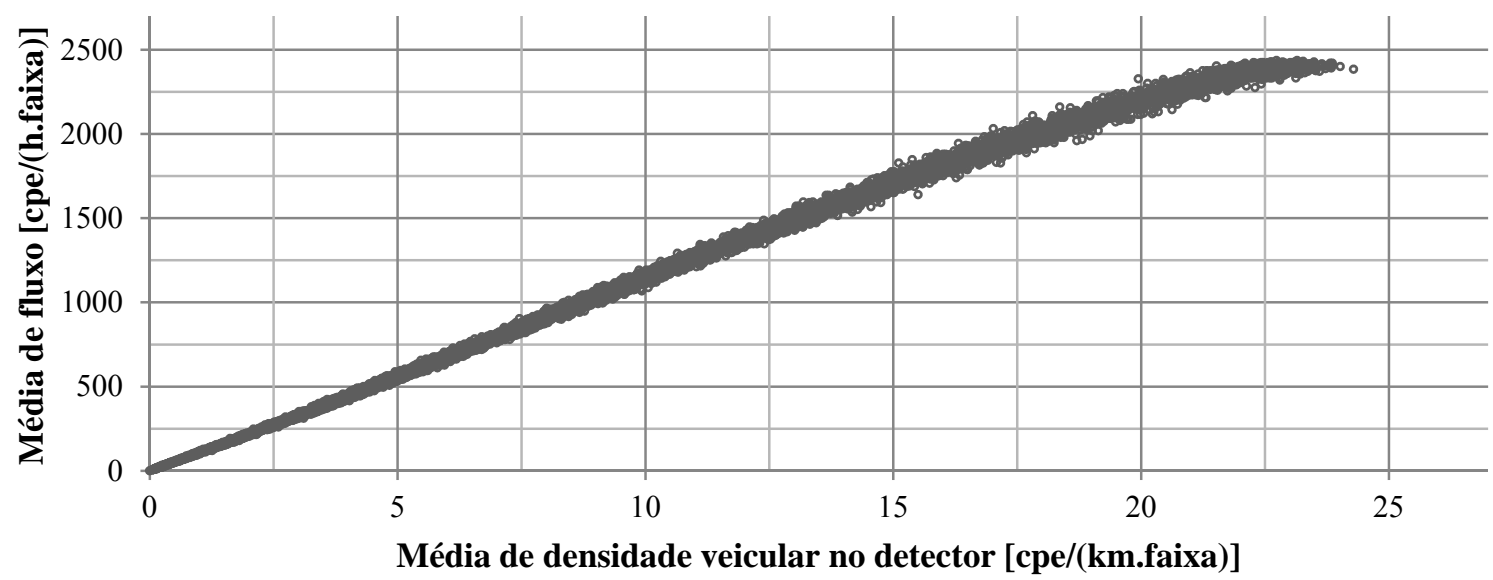

Figura 10. Média de fluxo versus média de densidade veicular no sensor; $\% v p=40 \%$ 
Em virtude da ausência de calibração do simulador, para nenhuma concentração de veículos pesados (\%vp), conseguiu-se atingir a concentração veicular de 27 cpe/(km.faixa). Em uma simulação completa, a máxima média geral (entre todos os intervalos de uma iteração) obtida com $0 \%$ de caminhão foi de $21 \mathrm{cpe} /(\mathrm{km}$.faixa); e com $20 \%$ e $40 \%$ foi de $23 \mathrm{cpe} /(\mathrm{km}$.faixa).

A iteração escolhida para representar o cenário era a que apresentava a média geral de densidade veicular mais próxima ao valor da densidade desejada para representar o cenário. Selecionada a iteração, plotava-se um gráfico como o apresentado na Figura 11 (com descarte da primeira hora de simulação), a fim de selecionar os dois intervalos consecutivos mais próximos ao valor desejado de densidade. Essa prática teve o intuito de aumentar a probabilidade de que o veículo selecionado para a filmagem viajaria em um fluxo com densidade próxima à desejada.

O tempo inicial do primeiro desses intervalos era o tempo da simulação escolhido para iniciar a gravação.

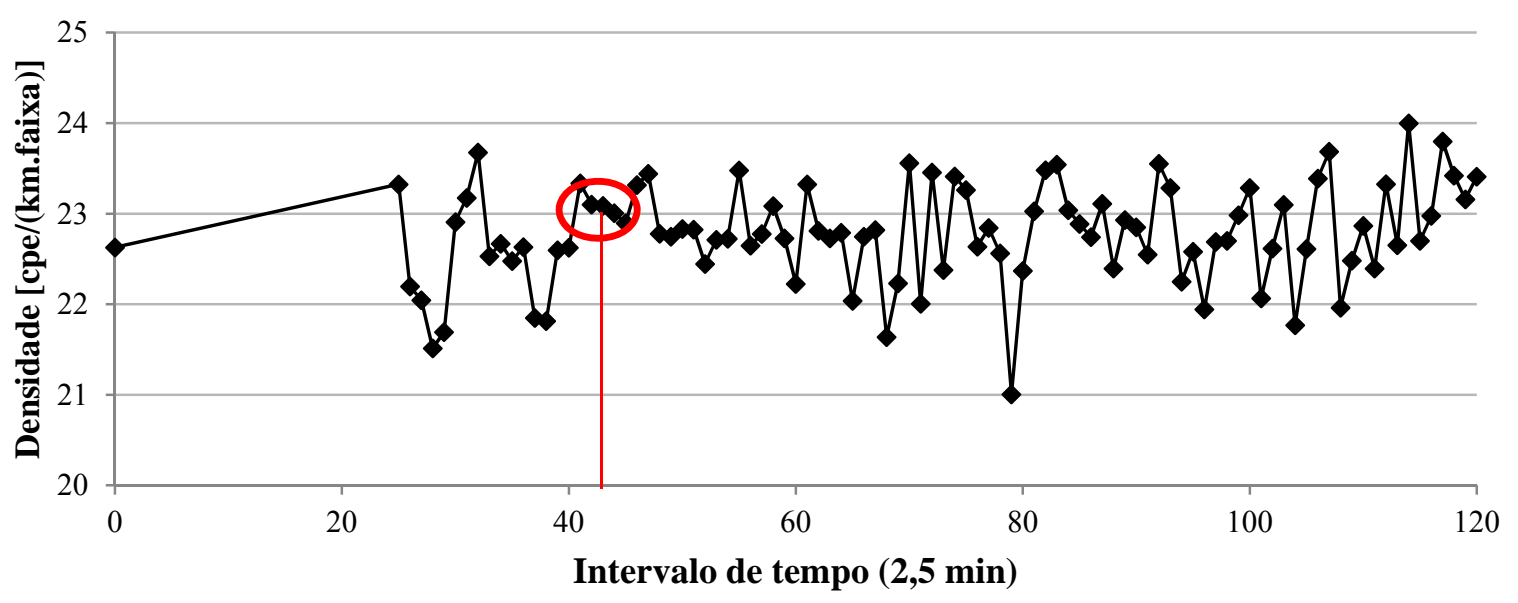

Figura 11. Distribuição de densidade veicular média por intervalo de tempo (entre carros e caminhões) em um detector, na iteração 92 , para $20 \%$ de veículos pesados na corrente de tráfego

\subsubsection{Gravação do cenário}

Para cada densidade veicular desejada, a simulação utilizada para gravar o cenário é a da iteração selecionada no item anterior. Em princípio, rodava-se a simulação até o tempo escolhido para a gravação iniciar. Nesse tempo, escolhia-se o veículo que passava no ponto de controle próximo (um pórtico de sinalização) naquele instante, selecionava-se a câmera do campo de visão do motorista e iniciava-se a gravação do cenário. Para esse veículo, obtinha-se do Aimsun a série temporal de velocidades ao longo da viagem, com a finalidade de gerar o velocímetro digital, como será explicado no tópico a seguir. 
Para gravar o outro vídeo do cenário, adotou-se o mesmo procedimento, porém foram usados os dados do sensor do sentido oposto da rodovia. O mesmo sensor poderia ser usado, sendo selecionado outro intervalo da simulação ou, caso o tempo de viagem de um carro na rodovia virtual fosse longo o suficiente, o primeiro vídeo gravado poderia ser cortado em dois.

No total foram gravados 70 vídeos, 2 para cada um dos 35 cenários, um no sentido norte e outro no sentido sul.

\subsubsection{Painel veicular}

A visualização gráfica gerada pelo simulador não permite a adição direta de um painel veicular para melhor representar o campo de visão do condutor. Assim, foi necessário o uso de um editor de vídeo para sobrepor um painel veicular no filme.

Além do painel, um velocímetro digital foi também adicionado. Esse velocímetro foi gerado por meio de um programa que transformou a série temporal de velocidade do veículo usado em um mostrador digital que indicava a velocidade instantânea do veículo a cada segundo no painel do carro.

Após a adição da máscara, formada pelo painel e o velocímetro, obtiveram-se vídeos com interface no formato do apresentado na Figura 12 para representar os cenários.

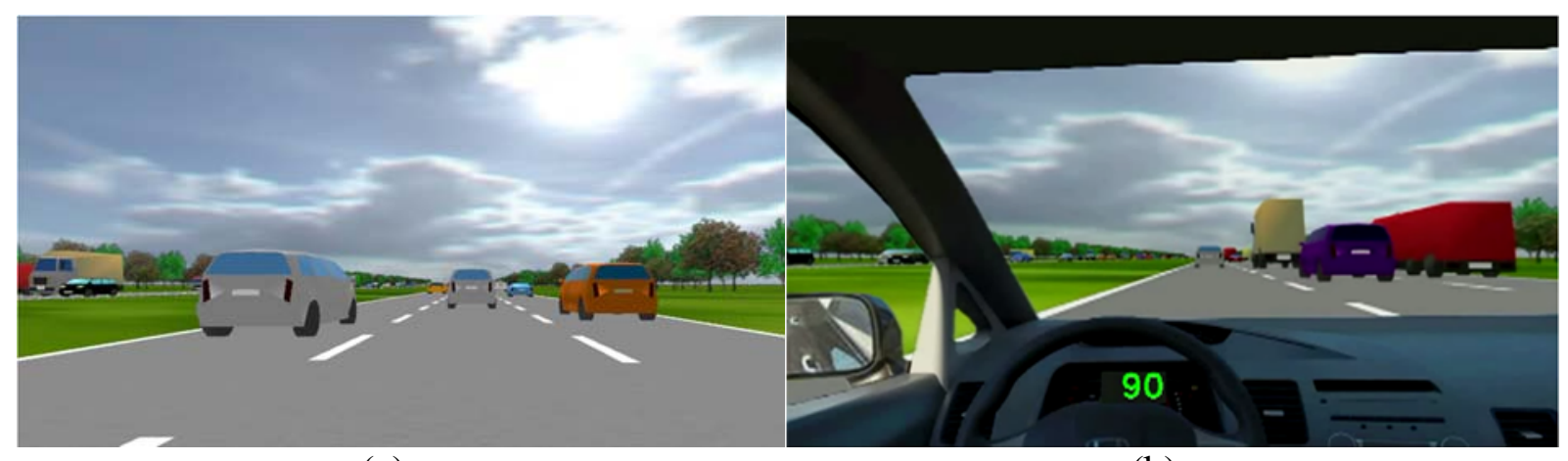

(a)

(b)

Figura 12. (a) Vídeo gerado pelo simulador a partir do ponto de visão do motorista; (b) Vídeo preparado para aplicação do questionário, com superposição do painel, parabrisa, direção e velocímetro digital

\subsubsection{Criação do questionário}

O questionário criado para o experimento piloto continha dois tipos de perguntas, diferentes em sua finalidade. Algumas perguntas foram criadas para analisar a percepção da qualidade de 
serviço, enquanto que outras foram inseridas para avaliar a escala de resposta, o vídeo tutorial, as questões e as instruções propostas para o questionário.

Além disso, a versão preliminar do questionário deveria ter um formato que permitisse responder as duas perguntas seguintes:

a. Quantos cenários um participante toleraria avaliar?

b. Qual o tempo adequado de duração dos vídeos (cenários)?

Para responder à questão sobre o tempo adequado de duração do vídeo, determinou-se um mecanismo tal que os vídeos fossem apresentados em loop até que o avaliador decidisse a sua nota, ou seja, caso o avaliador não tivesse fornecido sua nota até o fim do vídeo, este se reiniciava automaticamente.

Para a questão de quantos cenários o avaliador toleraria analisar, montou-se uma estrutura que apresentava uma sequência de cenários ( 9 cenários - quantidade mínima definida a priori), para em seguida, perguntar se o avaliador estava disposto a continuar colaborando com a pesquisa (Figura 13).

\section{Q8. Para continuar colaborando com nossa pesquisa, você aceita assistir e avaliar mais 5} vídeos?

\section{Aceito continuar colaborando}

Não aceito.

Figura 13. Questão inserida no questionário para auxiliar na determinação de quantos cenários os avaliadores tolerariam analisar

Em caso afirmativo, um bloco com 5 cenários era apresentado, seguindo esse processo até o respondente parar de responder ou responder a todos os vídeos do banco de dados.

Foram definidos 9 vídeos para o bloco inicial, pois 5 colhiam informações para a verificação do método de identificação dos limites de densidade veicular para os níveis de serviço, enquanto que os outros 4 estavam estruturados para analisar a variação de resposta dada por um respondente a vídeos com condições operacionais similares.

A seguir apresenta-se a estrutura do questionário e, em sequência, discute-se a escala de resposta escolhida para obter a percepção dos cenários. 


\subsubsection{Estrutura do questionário}

O questionário montado (Apêndice B) possui quatro partes: (i) caracterização do perfil do respondente; (ii) vídeo treino - qualidade da viagem; (iii) avaliação de cenários rodoviários; e (iv) comentários e sugestões.

A primeira parte do questionário tem o propósito de caracterizar a amostra. As informações obtidas nessa etapa são: idade, gênero, escolaridade, tempo de habilitação, experiência em condução de veículos, frequência de condução em rodovias de pista dupla, tipo de veículo usado, além de uma autoavaliação de comportamento quando se está conduzindo em rodovias (agressivo, normal ou cauteloso).

Esse tipo de informação coletada nessa parte (perfil do respondente) também foi obtido em investigações da relação entre a percepção da qualidade de serviço e variáveis operacionais, como nos trabalhos de Nakamura, Suzuki e Ryu (2000), de Washburn e Kirschner (2006) e de Papadimitriou, Mylona e Golias (2010).

As informações obtidas nessa primeira etapa não foram utilizadas na análise dos dados do experimento piloto, pois a amostra obtida apresentou perfis de respondentes homogêneos (sem diversidade), o que impossibilitou realizar uma análise exploratória válida. Entretanto, a aplicação da etapa no experimento piloto foi útil para testar as perguntas e suas alternativas para a versão final do questionário.

A segunda parte do questionário define os aspectos que devem ser considerados durante a análise dos filmes, por meio de um vídeo tutorial. Um vídeo foi escolhido, uma vez que fornecer as instruções por meio de um filme é mais eficaz do que fornecer por um texto instrucional, além de cansar menos o respondente.

Esse vídeo tem como roteiro os seguintes tópicos:

(a) mostrar quais itens devem ser considerados durante a análise do cenário, com o intuito de evitar que o cenário seja avaliado com base em variáveis que não são consideradas na análise, como, por exemplo, o comportamento do condutor (Stevens, 1975);

(b) apresentar um vídeo treino para que o respondente se familiarize com a forma de apresentação dos cenários; e

(c) mostrar como usar a escala para fornecer a resposta, com o objetivo de minimizar a probabilidade de o questionário ser respondido com erro gerado por falta de compreensão do uso da escala métrica contínua. 
Após visualizar o vídeo tutorial, solicita-se que o respondente avaliasse o vídeo treino por meio de uma escala métrica contínua (Figura 14).

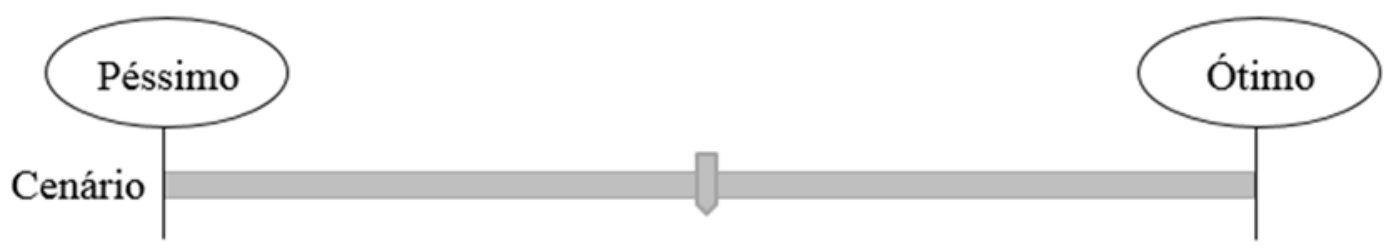

Figura 14. Escala métrica contínua como apresentada no questionário: para fornecer a avaliação, o respondente move o cursor da escala, posicionando-o em um ponto entre os dois extremos correspondente à sua percepção sobre a qualidade de serviço do cenário

A terceira parte do questionário consiste na observação dos cenários e suas correspondentes avaliações. O respondente assiste a um vídeo e atribui-lhe uma nota por meio da escala.

Na quarta parte do questionário, abre-se um espaço para comentários e sugestões. Essa parte auxiliou na melhoria do método, objeto da pesquisa, pois foram investigados assuntos relacionados ao tamanho do questionário, ao uso de simuladores de tráfego para representar os cenários, à duração e qualidade dos vídeos e à escala métrica.

O Capítulo 4 apresenta as questões do questionário que sofreram ajustes e a opinião dos respondentes sobre o questionário e seus elementos.

\subsubsection{Escala métrica contínua}

A escala métrica contínua foi escolhida para medir a percepção do usuário sem suposições $a$ priori acerca da quantidade de níveis de serviço percebidos pelos usuários (Figura 14).

O uso de uma escala discreta foi descartado, pois a quantidade de níveis dessa escala forçaria o respondente a usar a repartição da escala discreta, ao invés de responder com base na repartição que o seu próprio inconsciente normalmente realiza quando percebe a qualidade de serviço.

A escala apresenta simplesmente dois extremos e solicita que o respondente escolha um ponto entre eles como resposta. Ao selecionar um ponto entre os dois extremos, é definido a distância do extremo esquerdo, que tem valor zero, em uma escala de 0 a 100, onde 100 é o ponto extremo da direita. Esse valor foi utilizado para a análise dos dados, mas o seu valor não é mostrado para o respondente. 


\subsubsection{Formulário online}

Em virtude da impossibilidade de criar um website para coletar os dados, escolheu-se uma plataforma de questionário online para auxiliar a coleta de dados do experimento piloto. Essa plataforma se mostrou útil por possuir a escala métrica contínua nos tipos de escala de resposta, por permitir a inserção de vídeos em questões e por possuir um modo de seleção aleatória de questão.

Por permitir a inserção de mídia nas questões e um modo de seleção aleatória de questão foi possível codificar o questionário nessa plataforma conforme era idealizado para o website. Assim, cada cenário foi representado por uma questão.

A plataforma permite selecionar as questões tanto de forma aleatória como também sem reposição no banco de dados até que uma rodada de avaliação seja completada. Essa opção foi ativada e cada cenário só foi avaliado pela enésima vez quando todos foram avaliados $n-1$ vezes.

\subsubsection{Aplicação do experimento piloto}

A realização do experimento piloto foi a etapa em que o questionário preliminar foi testado, por meio da sua aplicação em uma amostra formada por oportunidade, com a finalidade de determinar os ajustes necessários para o seu formato final.

O público que respondeu ao questionário foi formado por 35 alunos de pós-graduação das engenharias da Universidade de São Paulo (USP), campus São Carlos.

A aplicação do questionário, realizada em dezembro de 2014, foi conduzida por um facilitador para auxiliar e observar as dúvidas surgidas durante o processo. Para cada participante foi reservado um horário e, como forma de registro das observações feitas ao longo do questionário, o facilitador gravou os comentários feitos sobre as perguntas, as alternativas, as instruções, a escala de medida, a forma de apresentação dos cenários, o formato do questionário e os assuntos discutidos na Parte IV: Comentários e sugestões.

A partir dos dados obtidos por meio do experimento piloto foi possível responder as perguntas apresentadas anteriormente por este capítulo e testar o método de análise proposto para verificar sua viabilidade e habilidade para atingir o objetivo da pesquisa.

Nos Capítulos 4 e 5 apresenta-se a forma de análise dos dados obtidos, definem-se a extensão do questionário e a duração dos vídeos, discute-se o impacto das características operacionais 
sobre a qualidade de serviço e analisa-se o mecanismo de determinação dos limites entre os níveis de serviço, além de outros pontos relevantes para o ajuste do método em proposição. 



\section{QUESTIONÁRIO}

Neste capítulo e no Capítulo 5, os dados obtidos por meio das respostas ao questionário preliminar aplicado no experimento piloto são analisados para verificar a adequação do próprio questionário aos objetivos do estudo, para determinar o tamanho do questionário e o tempo de visualização dos vídeos e para explicar a análise proposta para determinar os limites dos níveis de serviço em fluxo não-congestionado.

Inicialmente, neste capítulo, são discutidos aspectos ligados ao questionário, tais como: (a) a forma de análise dos dados; (b) o tamanho do questionário e o tempo de visualização dos vídeos; (c) as características operacionais dos vídeos versus sua influência na avaliação dos filmes; (d) a opinião do respondente; e (e) a edição dos enunciados e das alternativas do questionário.

No total, trinta e cinco pessoas aceitaram responder o questionário e, ao todo, foram fornecidas 773 avaliações; a amostra foi por oportunidade. Das 773 avaliações, 140 seriam utilizadas para analisar a variação de resposta dada por um respondente a características operacionais de tráfego similares. Entretanto, essa análise não foi realizada pela ausência da etapa de validação dos vídeos. As 773 avaliações foram utilizadas apenas para estimar o tamanho do questionário e o tempo de duração dos vídeos; para as demais etapas foram utilizadas 633 (773-140) avaliações.

\subsection{Forma de análise dos dados}

Para análise dos dados, as cadeias de respostas vinculadas por avaliador (ou por vídeo) foram fragmentadas de forma que cada resposta passou a constituir um elemento isolado, ou seja, a análise não considerou, de forma conjunta, o grupo de notas fornecidas a cada vídeo ou por cada avaliador, mas considerou que cada uma separadamente seria um indivíduo na amostra.

O vínculo da resposta ao avaliador e ao vídeo não foi perdido, pois foram criadas duas outras variáveis (avaliador e vídeo), permitindo que as análises por vídeo e por avaliador fossem realizadas e nenhuma informação fosse perdida.

Dessa forma, por meio dos 35 respondentes foram gerados 773 elementos. Cada elemento era formado pelas informações das características operacionais do vídeo a que se vinculava, da resposta (percepção, $p$ ) e das características socioeconômicas do avaliador que forneceu a avaliação. 


\subsection{Análise da extensão do questionário e da duração do vídeo}

Por conta do formato do experimento piloto, o tempo levado para responder o questionário não pode ser considerado o tempo estimado para um dado participante respondê-lo. Como apresentado no Capítulo 3, os respondentes eram questionados se desejavam prosseguir colaborando com a pesquisa ou se desejavam finalizá-la, pois pretendia-se estimar quantos vídeos os participantes toleravam avaliar. Assim, a extensão do questionário foi variável para cada avaliador, o que impossibilitou estimar o tempo necessário para responder ao questionário.

O box-plot da Figura 15 mostra a variação no tempo para responder ao questionário considerando três categorias: (a) o total gasto; (b) o usado para responder às questões iniciais (perfil socioeconômico do respondente - Parte I) e ler as instruções do questionário (Parte II); e (c) o gasto na sessão final (Parte IV), onde a opinião dos respondentes foi obtida.

Para a primeira categoria (tempo total), o primeiro quartil é de 29 minutos; a mediana de 36 minutos; e o terceiro quartil de 46 minutos. Para a segunda categoria (Parte I e II), os valores são respectivamente: 9; 10,5; e 13,5 minutos. Na sessão final (Parte IV), respectivamente, 3,5; 4,5; e 7 minutos.

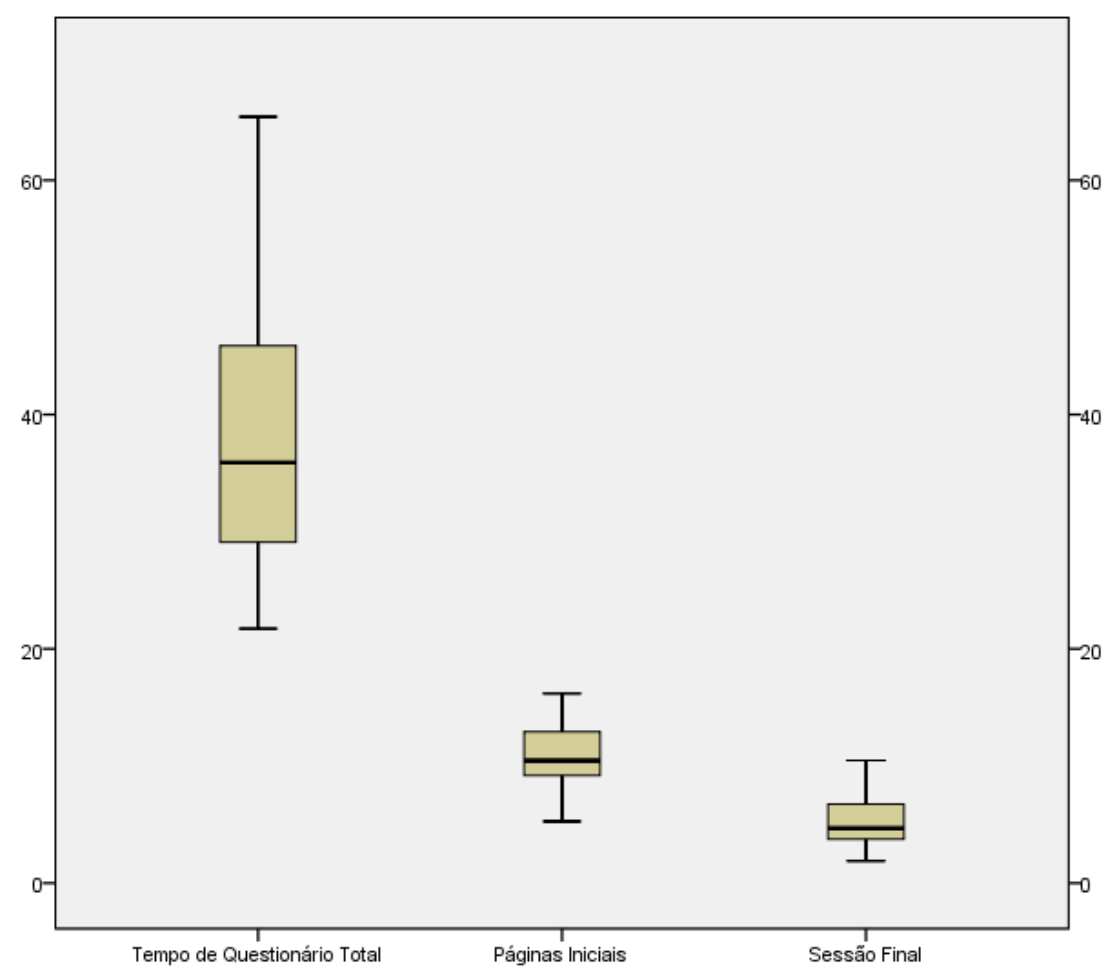

Figura 15. Diagrama em caixa (box-plot) para as categorias de tempo: (a) tempo total para responder o questionário; (b) tempo gasto nas páginas iniciais, perfil do respondente e instruções; e (c) tempo gasto na sessão final, feedback do questionário 
Na Figura 16, apresenta-se a distribuição do número de cenários avaliados por cada participante. Nota-se que o número variou de 9 (mínimo), com dois casos, até 69 vídeos; a mediana foi de 19 vídeos avaliados.

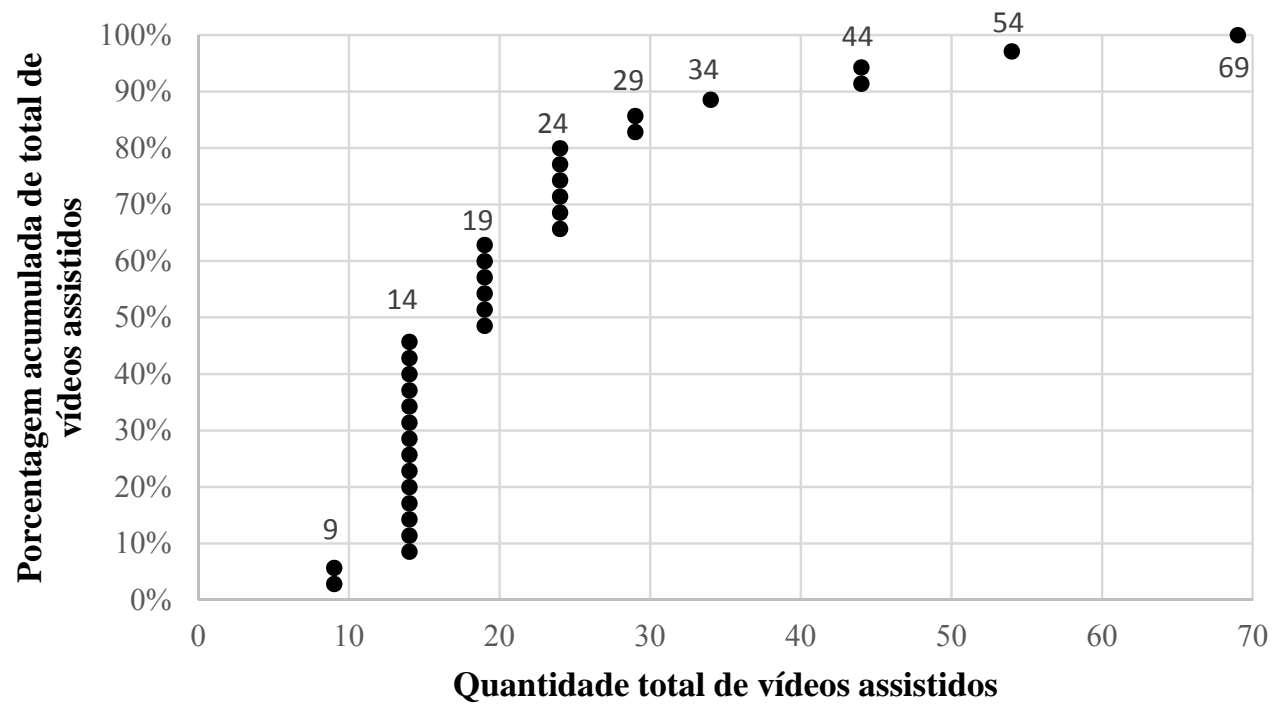

Figura 16. Porcentagem acumulada do número de vídeos assistidos por cada participante durante o experimento piloto

Após a análise desse gráfico, recomenda-se que o formato final do questionário possua 14 vídeos (4 para analisar a variação de resposta dada por um respondente a condições operacionais de tráfego similares e 10 para a determinação dos limites entre os níveis de serviço em fluxo não-congestionado), todos com o mesmo tempo de duração, definido como será mostrado a seguir.

Como dito no Capítulo 3, apesar de os vídeos do experimento piloto possuírem uma extensão definida (aproximadamente com duração de 2,5 minutos), eles eram apresentados em loop aos avaliadores, de forma que se reiniciavam ao chegar no final. O propósito era deixar os participantes livres para avaliar os filmes durante o tempo que achassem necessário.

Dessa forma, a variedade no tempo de visualização foi grande, como pode ser visto na Figura 17. O gráfico apresenta a distribuição das porcentagens acumuladas dos tempos de visualização das simulações, com exceção dos tempos gastos na primeira análise de cada participante. $\mathrm{O}$ descarte dos tempos das primeiras avaliações foi motivado porque alguns participantes não entenderam as instruções apresentadas no texto do questionário (loop) e ficaram aguardando demasiadamente a conclusão do primeiro vídeo. Nesses casos, antes do segundo vídeo, o facilitador intercedeu, esclarecendo como funcionava o experimento. 
As duas distribuições presentes na Figura 17 diferenciam-se porque uma considera apenas os tempos das avaliações posicionadas entre a segunda e a nona (as oito primeiras avaliações de cada avaliador que foram consideradas); enquanto que a outra considera todos os tempos a partir de segunda avaliação.

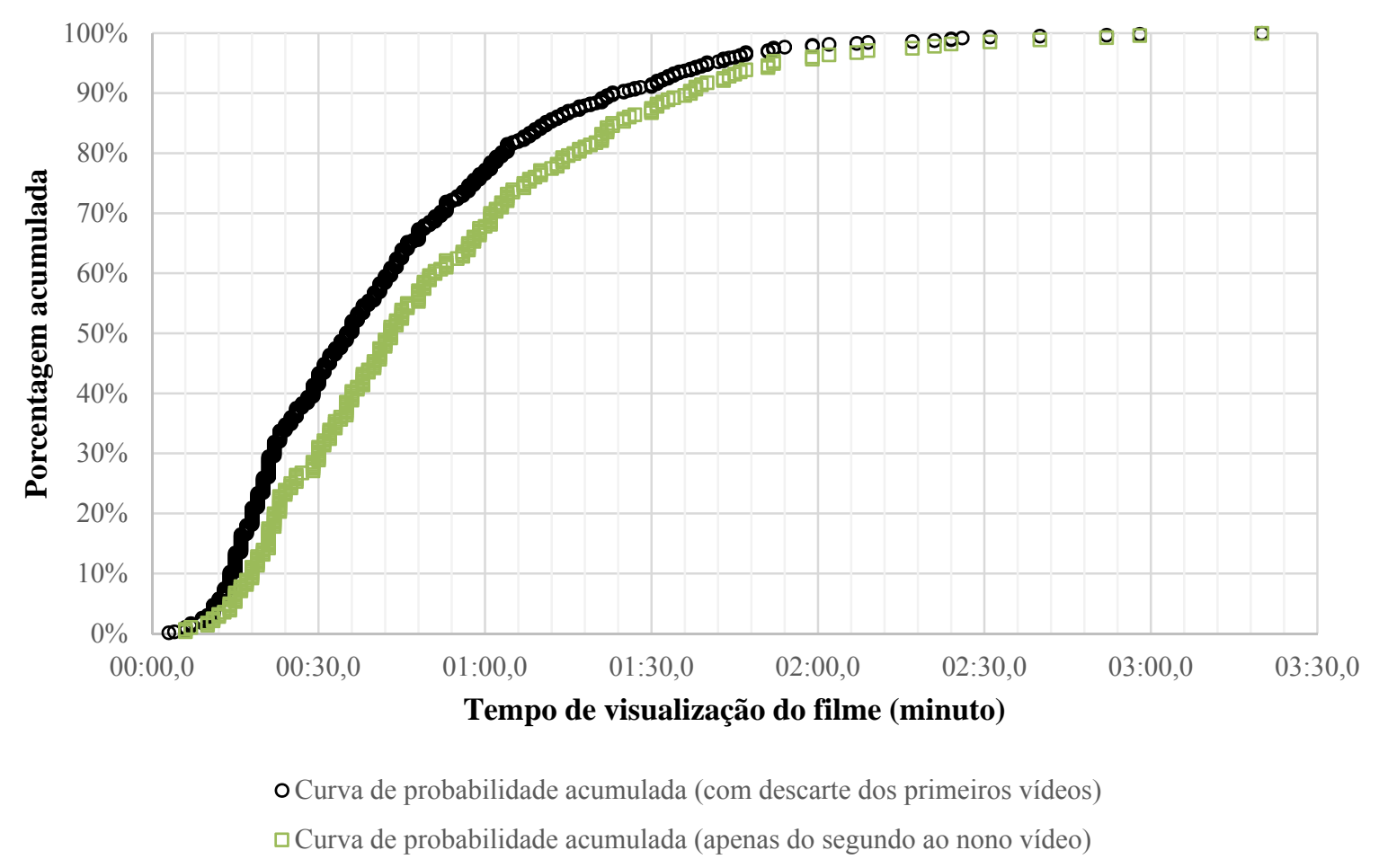

Figura 17. Distribuição de porcentagem acumulada do tempo de visualização dos vídeos, em minuto, gasto pelos participantes da pesquisa para fornecer sua avaliação

$\mathrm{Na}$ curva com descarte apenas dos primeiros vídeos (preta), em 98\% dos casos, o tempo usado para análise do vídeo foi menor que 2 minutos; em $76 \%$ dos casos, foi gasto até um minuto para avaliar; e em $43 \%$, menos que 30 segundos. A mediana foi de 35 segundos.

A razão para plotar a outra distribuição ( $2^{\text {as }}$ a $9^{\text {as }}$ avaliações) é que, na curva com todos os tempos, há mais casos para uns participantes do que para outros. Por isso, optou-se por analisar também uma distribuição uniforme por participante. Como o número mínimo de vídeos assistidos é nove, considerou-se apenas os tempos das segundas às nonas avaliações. Nesta, em 96\% dos casos tomaram até dois minutos para responder; em $68 \%$ dos casos precisaram de menos do que 1 minuto; e em 31\%, não mais que 30 segundos. A mediana foi de 43 segundos. Desde o início da concepção do formato do experimento, não se pretendia dispor filmes com extensões variadas (e em loop) no formato final do método. A ideia de apresentar filmes 
solicitando que o respondente gaste o tempo necessário para efetuar sua análise foi apenas uma forma de estimar a duração mais adequada dos vídeos.

A definição do tempo adequado foi feita por meio da mediana. Dessa forma, optou-se por vídeos de 40 segundos de duração. Para atender as pessoas que levam mais tempo para decidir sua nota, será permitido visualizar o vídeo quantas vezes for desejado.

Não é desejado que os respondentes analisem os vídeos por pouco tempo, como ocorreu em cerca de $20 \%$ dos casos. Por isso, definiu-se como tempo mínimo de observação a visualização do filme por completo ao menos uma vez, por dois motivos. O primeiro é que a percepção no começo do vídeo pode ser diferente no final, uma vez que a distribuição de tráfego na simulação não é constante, ou seja, pode haver uma variação de densidade ao longo do trecho, pois o fluxo é aleatório. O segundo é que pode haver diferença nos critérios considerados na avaliação, caso o avaliador não assista a todos os eventos presentes no filme.

Na sessão final (Parte IV), duas sentenças avaliavam a opinião dos respondentes quanto ao tempo de questionário e o tempo de duração dos vídeos ( $O$ questionário está cansativo; Os filmes eram curtos).

Por conta do formato do piloto, não é possível considerar essas opiniões como parâmetro para modificar o questionário, já que os participantes assistiam aos vídeos até onde queriam e, por isso, dificilmente os considerariam curtos. Além disso, o questionário era finalizado quando se esgotava a tolerância do participante, sendo improvável que este não considerasse o questionário cansativo, como se pode ver na Figura 18.

O questionário está cansativo.

\begin{tabular}{lr}
\hline Não concordo totalmente & 9 \\
\hline Não concordo parcialmente & 6 \\
\hline Indiferente & 4 \\
\hline Concordo parcialmente & 15 \\
\hline Concordo totalmente & 1 \\
\hline
\end{tabular}

Os filmes eram curtos.

\begin{tabular}{l|r}
\hline Não concordo totalmente & 24 \\
\hline Não concordo parcialmente & 5 \\
\hline Indiferente & 3 \\
\hline Concordo parcialmente & 3 \\
\hline Concordo totalmente & 0 \\
\hline
\end{tabular}

Figura 18. Distribuições de respostas para avaliação da duração do questionário e dos filmes obtidas na sessão final

Durante a aplicação do questionário, notou-se compreensão dúbia em relação a proposição “Os filmes eram curtos". Alguns entenderam como uma sentença positiva e outros como negativa. 
Por isso, propôs-se a reescrita para "O tempo de vídeo foi suficiente para formar a minha avaliação".

\subsection{Impacto das características operacionais dos vídeos na avaliação da qualidade de serviço}

A finalidade desta análise foi verificar a capacidade de um vídeo simulado apresentar as informações necessárias para que o respondente julgasse adequadamente a qualidade do serviço oferecido na rodovia, além de averiguar a capacidade do respondente identificar diferenças entre cenários simulados.

Essa análise foi realizada por quatro modos: (a) através da sessão final do questionário, onde havia afirmações que sondavam a opinião do entrevistado por meio de itens Likert; (b) através da dispersão bivariada entre a percepção e densidade; (c) através da correlação entre a variável independente percepção $(p)$ e três variáveis independentes: velocidade média $(\mathrm{vm})$, percentual de veículos pesados (\%vp) e densidade do tráfego ( $k$; e e (d) por meio da análise de padrão de resposta de cada avaliador.

Nesta seção e nas seguintes, foram utilizadas 633 avaliações pelo motivo explicado no início do capítulo.

\subsubsection{Avaliação baseada na opinião do respondente}

Quanto à opinião do entrevistado, na parte final (Parte IV) do questionário online foram apresentadas nove afirmativas (Apêndice B), três das quais usadas para sondar a capacidade do respondente discernir entre os cenários. A Figura 19 mostra a distribuição de resposta dada pelos 35 respondentes a cada uma dessas afirmações.

Com relação à dificuldade em diferenciar os cenários, 69\% não tiveram dificuldade, enquanto que $29 \%$ indicaram ter parcialmente tido dificuldade. A existência de $60 \%$ de respostas que concordaram ou discordaram parcialmente pode ser justificada pela existência de filmes com condições operacionais de tráfego parecidas, uma vez que os filmes eram selecionados de maneira aleatória para cada avaliador.

Sobre o vídeo simulado fornecer informações suficientes para que a avaliação fosse feita, $89 \%$ concordaram que as informações fornecidas eram suficientes e sobre a qualidade e a resolução dos vídeos, $77 \%$ concordaram que os vídeos apresentavam qualidade satisfatória. 
Com base nessas afirmativas, percebe-se que há uma certa dificuldade em diferenciar os cenários e que essa dificuldade não está relacionada nem aos vídeos exibidos (gerados por microssimulação), nem a sua qualidade e resolução.

Como medida para eliminar essa dificuldade na diferenciação de cenários, propôs-se um ajuste no método: a adição da etapa de formatação do banco de dados para permitir um sorteio condicionado, de forma que sejam apresentados ao respondente vídeos em todas as condições operacionais.

\begin{tabular}{lr}
\hline \multicolumn{2}{c}{ Tive dificuldade em diferenciar os } \\
cenários apresentados nos vídeos, pois as \\
\begin{tabular}{lr} 
condições de tráfego eram pareci das. \\
\hline Não concordo totalmente & 13 \\
\hline Não concordo parcialmente & 11 \\
\hline Indiferente & 1 \\
\hline Concordo parcialmente & 10 \\
\hline Concordo totalmente & 0 \\
\hline
\end{tabular}
\end{tabular}

\begin{tabular}{|c|c|}
\hline \multicolumn{2}{|c|}{$\begin{array}{l}\text { Os filmes que assisti me forneceram } \\
\text { informações suficientes para avaliar as } \\
\text { condições de tráfego. }\end{array}$} \\
\hline Não concordo totalmente & 0 \\
\hline Não concordo parcialmente & 3 \\
\hline Indiferente & 1 \\
\hline Concordo parcialmente & 9 \\
\hline Concordo totalmente & 22 \\
\hline
\end{tabular}

Os vídeos eram de qualidade e apresentavam uma boa resolução.

\begin{tabular}{l|r}
\hline Não concordo totalmente & 2 \\
\hline Não concordo parcialmente & 5 \\
\hline Indiferente & 1 \\
\hline Concordo parcialmente & 14 \\
\hline Concordo totalmente & 13 \\
\hline
\end{tabular}

Figura 19. Distribuições de respostas às sentenças cujo propósito era (i) avaliar a capacidade do respondente discernir os cenários apresentados; (ii) avaliar a qualidade de serviço por meio de cenários microssimulados; e (iii) verificar a qualidade dos vídeos

\subsubsection{Relação entre a percepção e as características da corrente de tráfego}

Dando continuidade ao estudo do impacto das características operacionais da corrente de tráfego na avaliação dos cenários apresentados, é fundamental para validação do método que haja uma relação inversamente proporcional entre a densidade da corrente de tráfego e a percepção da qualidade de serviço; relação esta relatada na literatura (TRB, 2010).

Para isso, foram criados gráficos que apresentam a dispersão de valores entre a densidade média (entre carros e caminhões para o instante da gravação) medida no detector $(k m d)$ e a mediana (para cada vídeo) da percepção de qualidade $(p)$. Cada gráfico a seguir apresenta os valores para 
uma categoria de percentual de veículo pesado (\%vp) na corrente ( $0 \%$ - Figura $20 ; 20 \%$ - Figura $21 ; 40 \%$ - Figura 22 ).

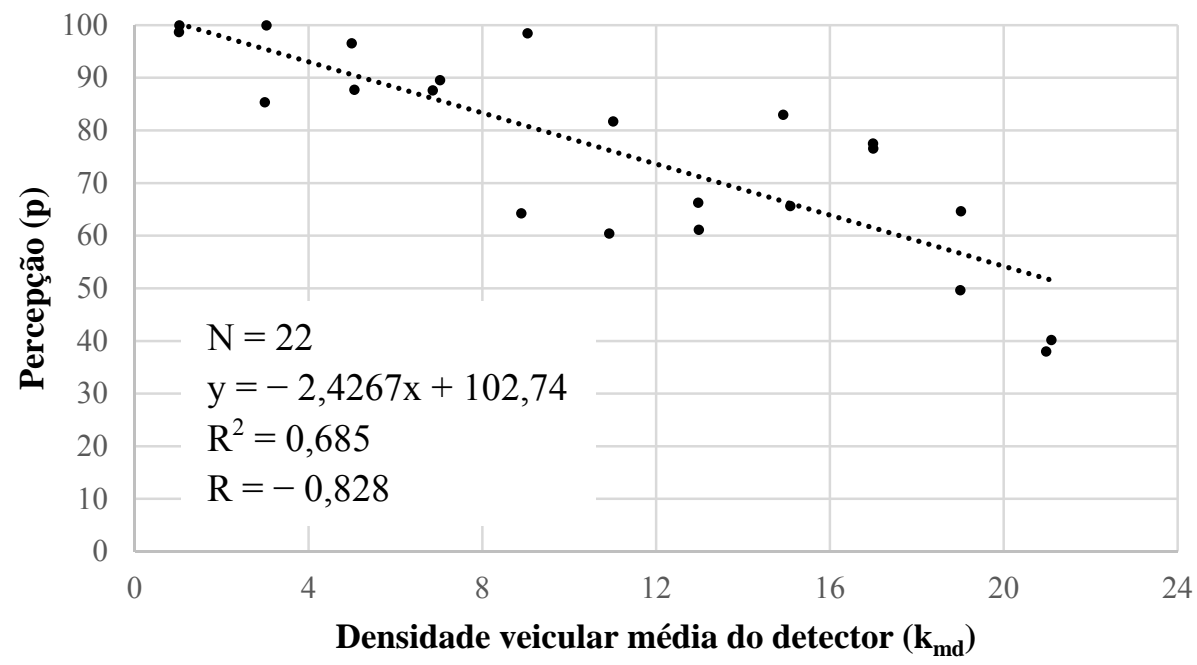

- $\quad$ Mediana (0\% veículo pesado) Linear (Mediana (0\% veículo pesado))

Figura 20. Relação entre a mediana da percepção de qualidade de serviço $(p)$ e a densidade média do detector $\left(k_{m d}\right)$, para $0 \%$ de veículos pesados na corrente de tráfego

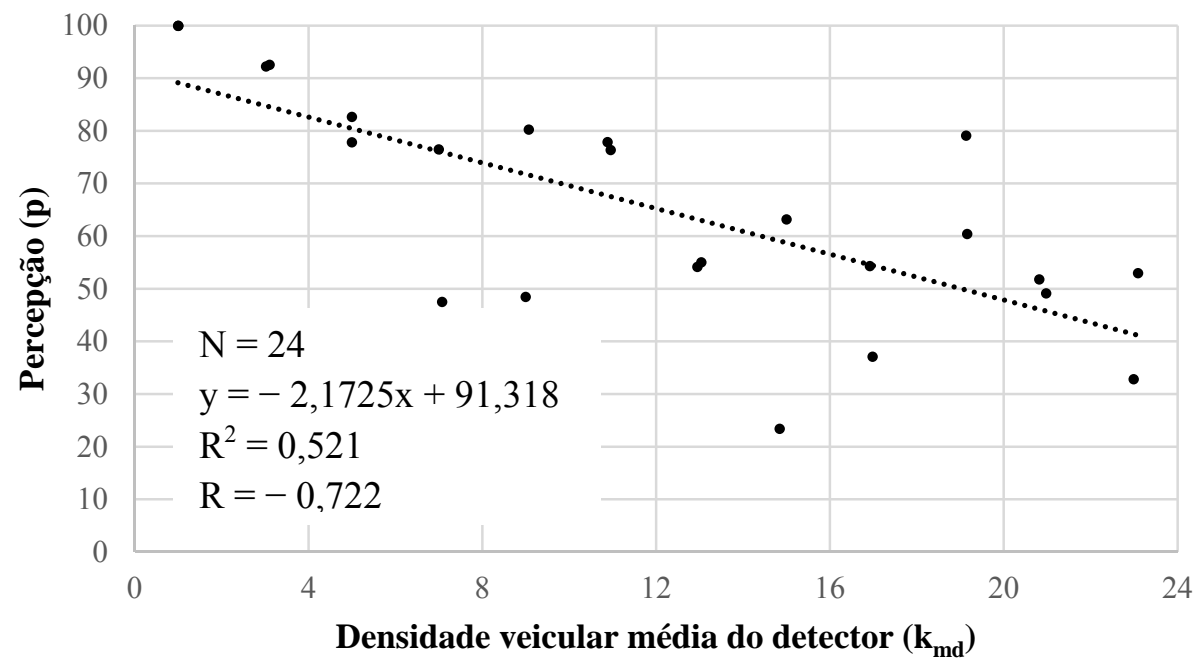

- Mediana (20\% veículo pesado) …..... Linear (Mediana (20\% veículo pesado))

Figura 21. Relação entre a mediana da percepção de qualidade de serviço $(p)$ e a densidade média do detector $\left(k_{m d}\right)$, para $20 \%$ de veículos pesados na corrente de tráfego

É perceptível, através da análise dos gráficos, que existe uma relação inversamente proporcional entre a percepção e a densidade. A linha linear de tendência e os coeficientes de correlação e de determinação comprovam a correlação negativa entre essas duas variáveis. 


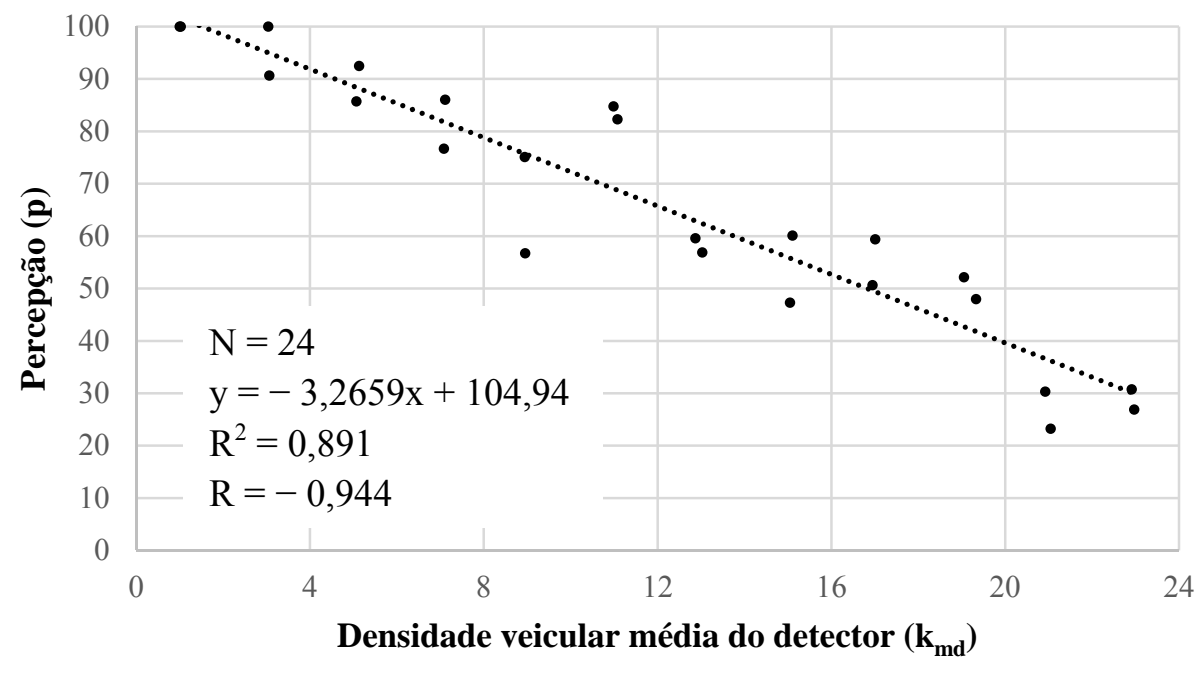

- Mediana (40\% veículo pesado) Linear (Mediana (40\% veículo pesado))

Figura 22. Relação entre a mediana da percepção de qualidade de serviço $(p)$ e a densidade média do detector $\left(k_{m d}\right)$, para $40 \%$ de veículos pesados na corrente de tráfego

Para quantificar essa relação, calculou-se a correlação entre a percepção e a densidade, considerando todas as avaliações (ou seja, sem segmentar os dados por \%vp e utilizando as percepções ao invés das medianas) e o valor encontrado foi - 0,522, com significância menor que 0,001 .

Quanto às demais variáveis independentes analisadas, o valor para a correlação entre a percepção $(p)$ e a velocidade média no tempo $(v m)$ foi de 0,443 , uma correlação diretamente proporcional; enquanto que a correlação entre a percepção e o percentual de veículos pesados foi a mais baixa, no valor de $-0,135$. Na Tabela 5, encontram-se esses resultados, assim como o resultado do teste de significância (sig), para duas extremidades, e as correlações segmentando os dados por respondente. A Tabela 5 também apresenta o tamanho da amostra utilizada para calcular as correlações.

A baixa correlação para \%vp pode ter relação com a escolha do tipo de terreno (plano) para o traçado da rodovia virtual. Em terrenos planos, e após ter vencido a inércia do repouso, os veículos pesados alcançam velocidades comparáveis aos veículos leves, deixando de ser um obstáculo na corrente de tráfego. Porém, um estudo aprofundado é necessário para afirmar isso com segurança já que a versão do simulador usada não é apropriada para concluir a respeito, uma vez que não considera o desempenho veicular. Dessa forma, entre veículos leves e pesados a única diferença entre as classes veiculares para a simulação era a faixa de valores para a velocidade desejada. 
Tabela 5. Coeficiente de correlação de Pearson $(R)$ e respectiva significância (sig), para duas extremidades, entre a variável dependente percepção $(p)$ e as variáveis independentes densidade média do detector $\left(k_{m d}\right)$, velocidade média no tempo $(v m)$ e percentual de veículo pesado (\%vp), por avaliador e de forma conjunta (geral)

\begin{tabular}{|c|c|c|c|c|c|c|c|}
\hline \multirow{2}{*}{ Avaliador } & \multirow{2}{*}{$\begin{array}{c}\text { Tamanho } \\
\text { da } \\
\text { amostra }\end{array}$} & \multicolumn{2}{|c|}{$\begin{array}{c}\mathbf{k}_{\mathrm{md}} \\
\text { [veic/(km.faixa)] }\end{array}$} & \multicolumn{2}{|c|}{ vm (km/h) } & \multicolumn{2}{|c|}{$\% v p$} \\
\hline & & $\mathbf{R}$ & Sig & $\mathbf{R}$ & Sig & $\mathbf{R}$ & Sig \\
\hline $\mathrm{P}$ (Avaliador 1) & 65 & $-0,486$ & 0,000 & 0,413 & 0,001 & $-0,100$ & 0,428 \\
\hline $\mathrm{P}$ (Avaliador 2) & 28 & $-0,280$ & 0,150 & $-0,083$ & 0,673 & 0,205 & 0,296 \\
\hline P (Avaliador 3) & 20 & $-0,779$ & 0,000 & 0,845 & 0,000 & 0,041 & 0,862 \\
\hline P (Avaliador 4) & 10 & $-0,611$ & 0,060 & 0,119 & 0,743 & $-0,372$ & 0,290 \\
\hline $\mathrm{P}$ (Avaliador 5) & 50 & $-0,844$ & 0,000 & 0,692 & 0,000 & $-0,182$ & 0,206 \\
\hline P (Avaliador 6) & 15 & $-0,893$ & 0,000 & 0,639 & 0,010 & $-0,105$ & 0,711 \\
\hline P (Avaliador 7) & 10 & $-0,905$ & 0,000 & 0,895 & 0,000 & $-0,17$ & 0,638 \\
\hline P (Avaliador 8) & 40 & $-0,804$ & 0,000 & 0,779 & 0,000 & $-0,136$ & 0,403 \\
\hline P (Avaliador 9) & 5 & $\mathbf{0 , 0 1}$ & 0,987 & 0,359 & 0,553 & 0,577 & 0,308 \\
\hline P (Avaliador 10) & 15 & $-0,696$ & 0,004 & 0,774 & 0,001 & $-0,215$ & 0,441 \\
\hline P (Avaliador 11) & 10 & $-0,859$ & 0,001 & 0,647 & 0,043 & $-0,347$ & 0,327 \\
\hline P (Avaliador 12) & 40 & $-0,767$ & 0,000 & 0,756 & 0,000 & $-0,354$ & 0,025 \\
\hline P (Avaliador 13) & 10 & $-0,648$ & 0,043 & 0,160 & 0,659 & $-0,198$ & 0,583 \\
\hline P (Avaliador 14) & 10 & 0,557 & 0,095 & $-0,717$ & 0,020 & 0,254 & 0,478 \\
\hline P (Avaliador 15) & 10 & 0,306 & 0,389 & $-0,280$ & 0,434 & $-0,310$ & 0,384 \\
\hline P (Avaliador 16) & 10 & $-0,587$ & 0,074 & $-0,094$ & 0,797 & 0,536 & 0,110 \\
\hline P (Avaliador 17) & 10 & 0,367 & 0,298 & $-0,247$ & 0,492 & 0,035 & 0,924 \\
\hline P (Avaliador 18) & 25 & $-0,78$ & 0,000 & 0,626 & 0,001 & 0,027 & 0,900 \\
\hline P (Avaliador 19) & 10 & $-0,946$ & 0,000 & 0,791 & 0,006 & $-0,51$ & 0,132 \\
\hline P (Avaliador 20) & 10 & $-0,606$ & 0,063 & 0,796 & 0,006 & 0,182 & 0,615 \\
\hline P (Avaliador 21) & 20 & $-0,672$ & 0,001 & 0,51 & 0,022 & $-0,435$ & 0,055 \\
\hline P (Avaliador 22) & 15 & $-0,839$ & 0,000 & 0,754 & 0,001 & $-0,217$ & 0,437 \\
\hline P (Avaliador 23) & 15 & $-0,396$ & 0,144 & 0,295 & 0,285 & $-0,513$ & 0,050 \\
\hline P (Avaliador 24) & 15 & $-0,785$ & 0,001 & 0,835 & 0,000 & $-0,072$ & 0,799 \\
\hline P (Avaliador 25) & 20 & $-0,707$ & 0,000 & 0,528 & 0,017 & $-0,217$ & 0,359 \\
\hline P (Avaliador 26) & 20 & $-0,976$ & 0,000 & 0,687 & 0,001 & $-0,399$ & 0,081 \\
\hline P (Avaliador 27) & 10 & $-0,602$ & 0,065 & 0,756 & 0,011 & $-0,279$ & 0,436 \\
\hline P (Avaliador 28) & 20 & $-0,741$ & 0,000 & 0,854 & 0,000 & $-0,093$ & 0,696 \\
\hline P (Avaliador 29) & 20 & $-0,84$ & 0,000 & 0,688 & 0,001 & 0,053 & 0,824 \\
\hline P (Avaliador 30) & 25 & $-0,632$ & 0,001 & 0,314 & 0,126 & $-0,19$ & 0,364 \\
\hline P (Avaliador 31) & 15 & $-0,006$ & 0,984 & $-0,252$ & 0,365 & 0,075 & 0,791 \\
\hline P (Avaliador 32) & 10 & $-0,829$ & 0,003 & 0,546 & 0,102 & $-0,118$ & 0,746 \\
\hline P (Avaliador 33) & 10 & $-0,89$ & 0,001 & 0,471 & 0,170 & 0,368 & 0,295 \\
\hline P (Avaliador 34) & 10 & $-0,808$ & 0,005 & 0,527 & 0,118 & $-0,688$ & 0,028 \\
\hline $\mathrm{P}($ Avaliador 35$)$ & 5 & $-0,989$ & 0,001 & 0,741 & 0,152 & 0,261 & 0,672 \\
\hline $\begin{array}{c}\text { Percepção } \\
\text { Conjunta }\end{array}$ & 633 & $-0,522$ & 0,000 & 0,443 & 0,000 & $-0,135$ & 0,001 \\
\hline
\end{tabular}


Outra hipótese que surgiu durante o experimento piloto a partir da opinião dos respondentes é a incapacidade de um cenário microssimulado representar alguns fatores que segundo os respondentes são prejudiciais à qualidade de serviço da rodovia. Esses fatores são o barulho gerado pelo motor de caminhão, que é desconfortável; e o comportamento agressivo dos motoristas de caminhão, que, como relataram, rotineiramente trancam veículos menores. Assim, trafegar ao lado de um veículo maior gera tensão pelo medo do que pode suceder (eventual 'trancamento').

Analisando as correlações por avaliadores, notou-se que algumas correlações apresentaram sinais contrários ao esperado (destacadas na Tabela $5 \mathrm{em}$ negrito), contrariando a fundamentação teórica, que aponta um impacto negativo na qualidade do serviço da rodovia com: (a) o aumento de densidade veicular na via; (b) o aumento do percentual de veículos pesados na composição do tráfego; ou (c) a redução indesejada de velocidade. Entretanto, vale destacar que além de analisar o sinal da correlação, deve-se analisar o valor da significância estatística do resultado, que indica a probabilidade do resultado encontrado ter sido obtido ao acaso. Isto é, os resultados com valores de significância altos possuem chance alta de serem diferentes em outra amostra.

No entanto, optou-se por manter esses indivíduos na amostra, pois, sua exclusão não implicou em alteração significativa nos valores das correlações gerais (considerando todos os indivíduos). Além disso, as correlações gerais, em todas as variáveis, apresentaram valores compatíveis com a literatura.

Continuando a análise das respostas de cada avaliador, há outros padrões de respostas incoerentes: (a) o que apresenta correlação extremamente baixa com a variável principal em questão; e (b) o formado por respostas que não variam com a mudança da condição operacional (densidade) de tráfego. Vale investigar a existência desses tipos de resposta, pois podem ter origem em pessoas que não responderam à pesquisa com seriedade (por exemplo, disseram que tudo está ótimo ou que tudo está péssimo) ou em avaliadores que não conseguem perceber a variação da condição operacional entre os cenários.

$\mathrm{Na}$ análise por meio de gráficos de dispersão bivariada, por avaliador, não foi identificado nenhum usuário que se enquadrasse no perfil de respostas parecidas para todos os cenários avaliados. Caso houvesse, a exclusão dessas respostas seria justificada (Hair Jr. et al., 2005). 


\subsection{Opinião do respondente}

Das nove sentenças que sondavam a opinião dos respondentes na sessão final do questionário, quatro abordam a escala métrica e a forma de condução do veículo pelo motorista da simulação: Avaliar os cenários por meio da escala métrica (posicionar o cursor entre extremos) foi simples, eu não tive dificuldade; Eu preferiria avaliar os cenários através de outro tipo de escala; Eu conduziria o carro da mesma forma (ou de forma semelhante) que o motorista da simulação dirigiu; A forma como o motorista da simulação dirigiu não prejudicou a minha análise sobre o cenário apresentado.

Sobre o uso da escala métrica para fornecer a resposta, $83 \%$ dos respondentes concordaram, mesmo que parcialmente, que não foi complicado utilizá-la. Entretanto, a predominância de respostas positivas não se repetiu quando se perguntava sobre a preferência em avaliar por meio de outro tipo de escala, como pode ser visto nas Figura 23 e Figura 24, 34\% concordaram; 43\% discordaram; e 23\% manifestaram-se como indiferente.

Com o intuito de investigar quais seriam essas preferências, foi perguntado durante o questionário aos que concordaram quais escalas prefeririam usar. Estes propuseram: (i) modificar para a escala categórica; (ii) colocar uma graduação na escala contínua segmentando a escala com valores numéricos ou simplesmente com uma marcação; (iii) modificar para a escala discreta; e (iv) dispor uma escala contínua para cada critério de avaliação. Embora as sugestões sejam pertinentes, até mesmo para um teste futuro, as sugestões apenas indicaram preferência e não invalidaram o uso da escala contínua como proposto pelo método.

\begin{tabular}{l}
$\begin{array}{c}\text { Avaliar os cenários por meio da escala métrica } \\
\text { (posicionar o cursor entre extremos) foi simples, } \\
\text { eu não tive dificuldade. }\end{array}$ \\
\hline Não concordo totalmente
\end{tabular}

\section{Eu preferiria avaliar os cenários através de outro tipo de escala.}

\begin{tabular}{ll}
\hline Não concordo totalmente & 9 \\
\hline Não concordo parcialmente & 6 \\
\hline Indiferente & 8 \\
\hline Concordo parcialmente & 9 \\
\hline Concordo totalmente & 3 \\
\hline
\end{tabular}

Figura 23. Distribuições de respostas para perguntas sobre a escala adotada para avaliar a qualidade de serviço

O outro assunto sondado teve o intuito de verificar a hipótese de que o comportamento do motorista da simulação influencia a percepção dos respondentes sobre a qualidade de serviço. 
Nesse assunto, foram usadas duas sentenças que têm suas distribuições de resposta apresentadas na Figura 24.

\begin{tabular}{l}
$\begin{array}{l}\text { Eu conduziria o carro da mesma forma (ou } \\
\text { de forma semelhante) que o motorista da } \\
\text { simulação dirigiu. }\end{array}$ \\
\hline Não concordo totalmente \\
\hline Não concordo parcialmente \\
\hline Indiferente
\end{tabular}

\begin{tabular}{lr}
\hline $\begin{array}{l}\text { A forma como o motorista da simulação } \\
\text { dirigiu não prejudicou a minha análise } \\
\text { sobre o cenário apresentado. }\end{array}$ \\
\hline Não concordo totalmente & 7 \\
\hline Não concordo parcialmente & 8 \\
\hline Indiferente & 3 \\
\hline Concordo parcialmente & 7 \\
\hline Concordo totalmente & 10 \\
\hline
\end{tabular}

Figura 24. Distribuições de respostas para perguntas sobre as características comportamentais dos motoristas das simulações

Sobre a identificação de semelhança em relação à forma do motorista da simulação dirigir, constatou-se que $49 \%$ concordaram e $43 \%$ discordaram. Nesse caso, houve predominância de respostas nas opções que apresentavam uma opinião parcial (71\%). Como relatado, a parcialidade ocorreu predominantemente porque a resposta a essa pergunta só podia ser dada uma única vez e, portanto, deveria basear-se em todos os vídeos assistidos: para alguns vídeos, os respondentes concordariam, enquanto que para outros não.

Por meio desses tipos de observações feitas pelos respondentes, percebeu-se que o comportamento do condutor da simulação era considerado na avaliação do cenário, o que corroborou a ideia de inserir a etapa de validação dos vídeos, que seria implementada antes da aplicação do questionário com o intuito de minimizar o impacto na avaliação de critérios nãooperacionais, como o comportamento do condutor; sem trazer prejuízo à análise, uma vez que o objetivo da pesquisa é a análise da percepção de variáveis operacionais.

Em complemento a isso, durante o acompanhamento da aplicação dos questionários, notou-se que outras variáveis não-operacionais como clima, manobras e segurança viária foram usadas como critério de avaliação por alguns respondentes.

Para exemplificar uma dessas situações, nos filmes, o clima variava simplesmente entre nuvens e nuvens com sol; porém, alguns respondentes julgaram que dirigir com tempo nublado seria pior que dirigir com sol entre nuvens, indicando que o clima havia influenciado na percepção da qualidade de serviço da rodovia virtual. A utilização desse critério na avaliação não havia sido prevista pelos pesquisadores, pois para estes, as duas situações seriam praticamente 
idênticas, até porque a diferença entre os cenários se dava unicamente em função do sentido da via em que o vídeo estava sendo gravado, ou seja, era o mesmo céu em perspectivas diferentes. Em função disso, seria importante a inserção de uma etapa no método que identificasse os critérios marcantes percebidos em cada filme e selecionasse para as etapas seguintes apenas aqueles filmes com situações não-operacionais neutras, evitando a existência de ruídos na análise causados por variáveis não-operacionais.

A análise da outra afirmação (A forma como o motorista da simulação dirigiu não prejudicou a minha análise sobre o cenário apresentado) também reforçou a ideia da etapa de validação dos vídeos, pois $43 \%$ dos respondentes não concordaram com a sentença, indicando que o comportamento do condutor influenciou a avaliação, mesmo que as instruções do questionário (e do tutorial) não mencionassem o comportamento do condutor como item a ser considerado na avaliação.

Nessa sentença, a palavra "não" gerou confusão aos avaliadores, principalmente, quando estes consideravam que a forma de condução havia prejudicado. Pois, para afirmar que havia sido prejudicado, precisavam discordar da sentença. Por isso, na edição final, retirou-se o "não" para evitar essa confusão de raciocínio.

A partir do exposto, caso pretenda-se utilizar essas sentenças, elas devem ser colocadas juntamente com a apresentação de cada cenário. Na versão editada do questionário, essas duas proposições foram retiradas da sessão final (Parte IV), já que uma resposta geral não se mostrou eficaz; e decidiu-se também não apresentar as sentenças juntamente com cada cenário, pois foi considerado que tornaria o questionário extenso e cansativo.

Sobre o tutorial, percebeu-se aceitação pelos respondentes para apresentação das regras do experimento, por ser mais simples e requerer menos esforço para a compreensão do que era necessário. Como modificação para o tutorial, recomenda-se destacar que outros tipos de variáveis (além das operacionais) não devem ser consideradas na avaliação.

\subsection{Edição dos enunciados e das alternativas do questionário}

No Apêndice B, estão apresentadas as questões exatamente como foram aplicadas no experimento piloto (representadas pelas questões QEP - Questão Experimento Piloto) e as questões editadas para a versão final do questionário com base na opinião do respondente e no interesse da questão para o pesquisador (representadas pelas questões QMP - Questão Método Proposto). 
No experimento piloto, para todas as questões que existiam dúvidas do pesquisador sobre seu entendimento, foram adicionadas questões, logo abaixo dessas, que avaliavam a compreensão textual, a compreensão das alternativas, a existência de alternativas ambíguas, a ausência de alternativa que contemplasse a resposta desejada, a escala utilizada, o tutorial etc. No Apêndice B encontram-se essas questões, assim como a quantidade de resposta dada pelos respondentes a cada alternativa.

A justificativa de inserir perguntas (QEP 1.7 até QEP 1.9) que investigue se o respondente trabalha em órgãos gestores de rodovias, em concessionárias ou como motorista profissional é permitir uma análise comparativa entre as categorias. Essa abordagem foi realizada nos trabalhos de Hostovsky, Wakefield e Hall (2004) e Obelheiro (2010); e mostrou-se adequada para o presente método.

Para reforçar a avaliação apenas em termos de densidade veicular e velocidade, o enunciado da questão (QEP 3.3) foi reformulado (QMP 3.2).

Alguns conceitos foram compreendidos com dificuldade e foram substituídos no questionário por palavras do cotidiano. Em outros casos, explicou-se com mais detalhes, por exemplo: o termo 'cenário' foi confundido com a ambientação, logo, foi substituído por 'vídeo'; esclareceu-se que 'ida' e 'volta' são viagens distintas; para o termo 'veículo conjugado' foi dado um exemplo; a expressão 'pista dupla' foi substituída por 'duplicada'; e retirou-se dos enunciados a palavra 'conforto'. O que mais gerou confusão foi rodovia rural; neste, muitos confundiram com estrada sem pavimento.

Durante a aplicação do experimento piloto notou-se que a questão QEP 1.18 (Autoavaliação do comportamento do condutor) gerou dúvida de resposta e não se mostrou eficaz. Foi reclamado que é um tipo de avaliação complicada. Esperava-se essa dificuldade por ser um critério subjetivo e, por esses motivos, propôs-se a exclusão da questão e sua substituição pela pergunta QMP 1.14 (Velocidade desejada). Caso o pesquisador que for aplicar o questionário proposto desejar identificar o perfil de comportamento do condutor, pode buscar na literatura uma escala de atitude como a DBQ (Driver Behaviour Questionnaire), a qual possui versão traduzida para o português (QCM - Questionário do Comportamento do Motorista) e aplicações em estudos brasileiros (Pinatti, 2007). 



\section{ANÁLISE DE DADOS PROPOSTA}

Em continuidade aos assuntos discutidos no capítulo anterior, discute-se, neste capítulo, a análise dos dados proposta pelo método sugerido por este estudo. Inicialmente, serão mostrados aspectos relativos aos métodos de seleção de observações atípicas, para em seguida, apresentar o método de análise proposto para identificação dos limites de densidade veicular para cada nível de serviço em fluxo não-congestionado.

\subsection{Eliminação de observações atípicas}

Observações atípicas podem ocorrer por causas tais como: (a) o respondente teve dificuldade em usar a escala de resposta do questionário, fornecendo uma resposta diferente da pretendida; (b) o avaliador penalizou um evento do vídeo assistido de forma mais severa que os demais respondentes; (c) o julgamento do vídeo baseou-se em um critério não utilizado pelos demais avaliadores; (d) o respondente é incapaz de diferenciar os cenários simulados; ou (e) o respondente contraria o senso comum.

Como as causas de observações atípicas são várias, é provável que existam informações atípicas nos dados coletados na aplicação do questionário. Por isso, deve-se aplicar métodos de identificação de respostas inconsistentes (outliers).

A aplicação de tais métodos cria uma nova variável no banco de dados que marca as observações atípicas, permitindo que o seu efeito seja estudado posteriormente (Hair Jr. et al., 2005).

Field (2005) sugere que os outliers devem ser analisados com maior rigor a fim de encontrar a explicação que o torna um dado incomum, para, com base em sua causa, decidir sobre a manutenção ou exclusão do banco de dados. Por exemplo, quando o outlier é proveniente de erro de observação, de procedimento ou erro na entrada de dados, Hair Jr. et al. (2005) indicam sua exclusão ou, caso possível, sua correção por um método adequado.

Neste estudo, as informações discrepantes não serão excluídas da análise, uma vez que a técnica multivariada escolhida para processar os dados utiliza a probabilidade de ocorrência de um evento e, considerando que as observações atípicas têm baixa probabilidade de ocorrência, os resultados provavelmente não serão afetados por respostas inconsistentes e discrepantes.

Para identificar os pontos candidatos ao rótulo de outlier sugere-se utilizar os métodos do escores padrão, diagrama em caixa (box-plot) e análise dos resíduos da modelagem. 
O primeiro teste realizado com os dados do experimento piloto foi o dos escores padrão. Nesse caso, a comparação foi entre a dispersão de notas dadas a um mesmo vídeo, ou seja, para cada um dos 70 cenários, as notas foram padronizadas (média zero e desvio-padrão 1), para que a partir de seus escores padronizados resultantes fossem identificadas as observações discrepantes. Foi adotado um escore de corte \pm 2 (Hair Jr. et al., 2005). Por esse método, foram identificadas 21 observações atípicas (Apêndice C).

O segundo método utilizado foi o diagrama de caixa (box-plot), que permitiu analisar os dados de forma bivariada (uma variável estratificada e uma contínua). A variável contínua nos três casos avaliados foi a percepção $(p)$ dos cenários, enquanto que a variável estratificada no primeiro caso foi o percentual de veículos pesados $(0 \% ; 20 ; 40 \%)$, mostrado na Figura 25; no segundo caso foi a velocidade média instantânea no tempo do veículo (V1 - menor que 90 m/h; V2 - de 90 a 100 km/h; V3 - de 100 a 110 km/h; V4 - de 110 a 120 km/h; e V5 - maior que $120 \mathrm{~km} / \mathrm{h}$ ), como se pode ver na Figura 26; e no terceiro caso, foi a densidade pretendida para cada vídeo, como se vê na Figura 27.

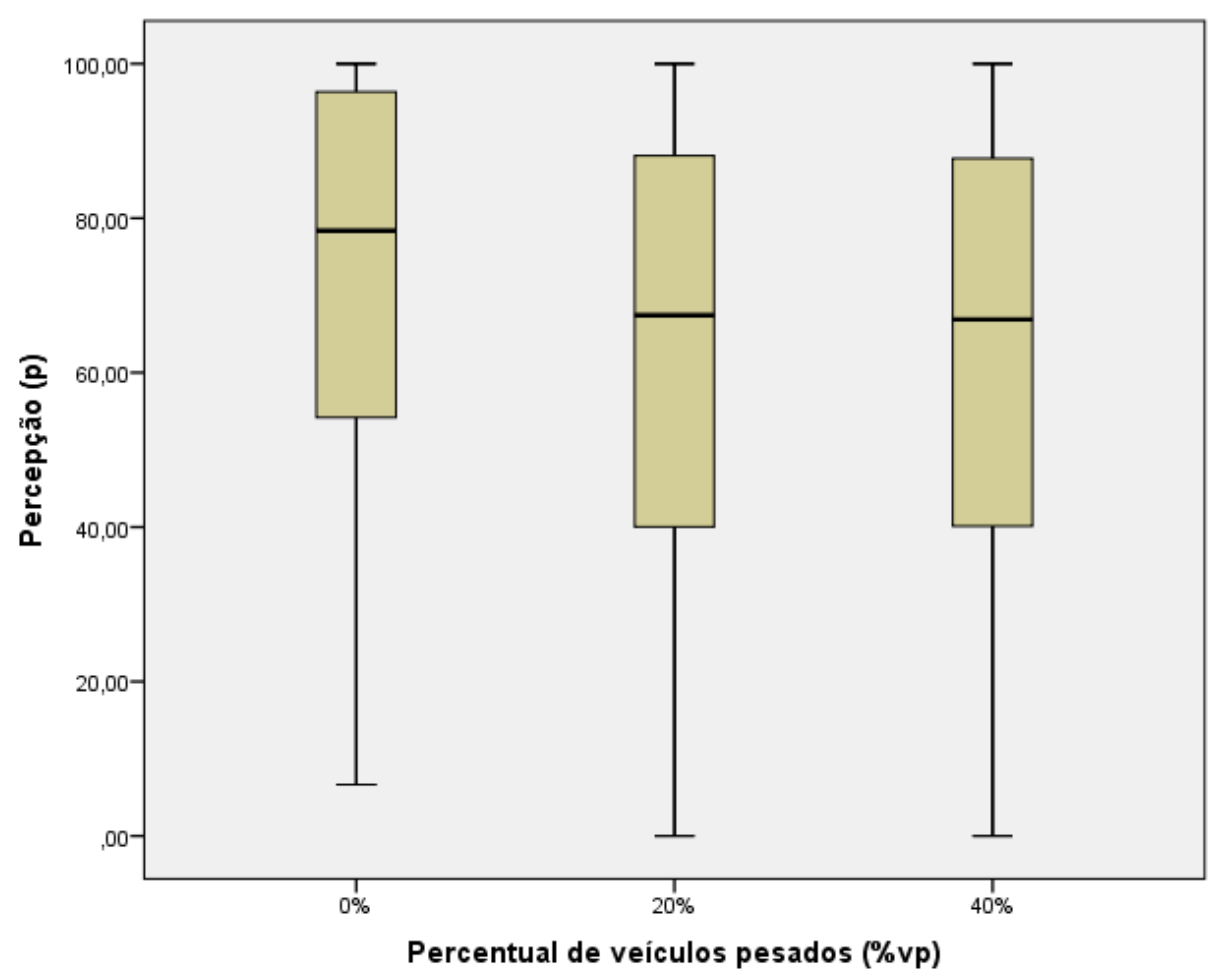

Figura 25. Diagrama em caixa apresentando a variação das notas para cada categoria de percentual de veículos pesados 


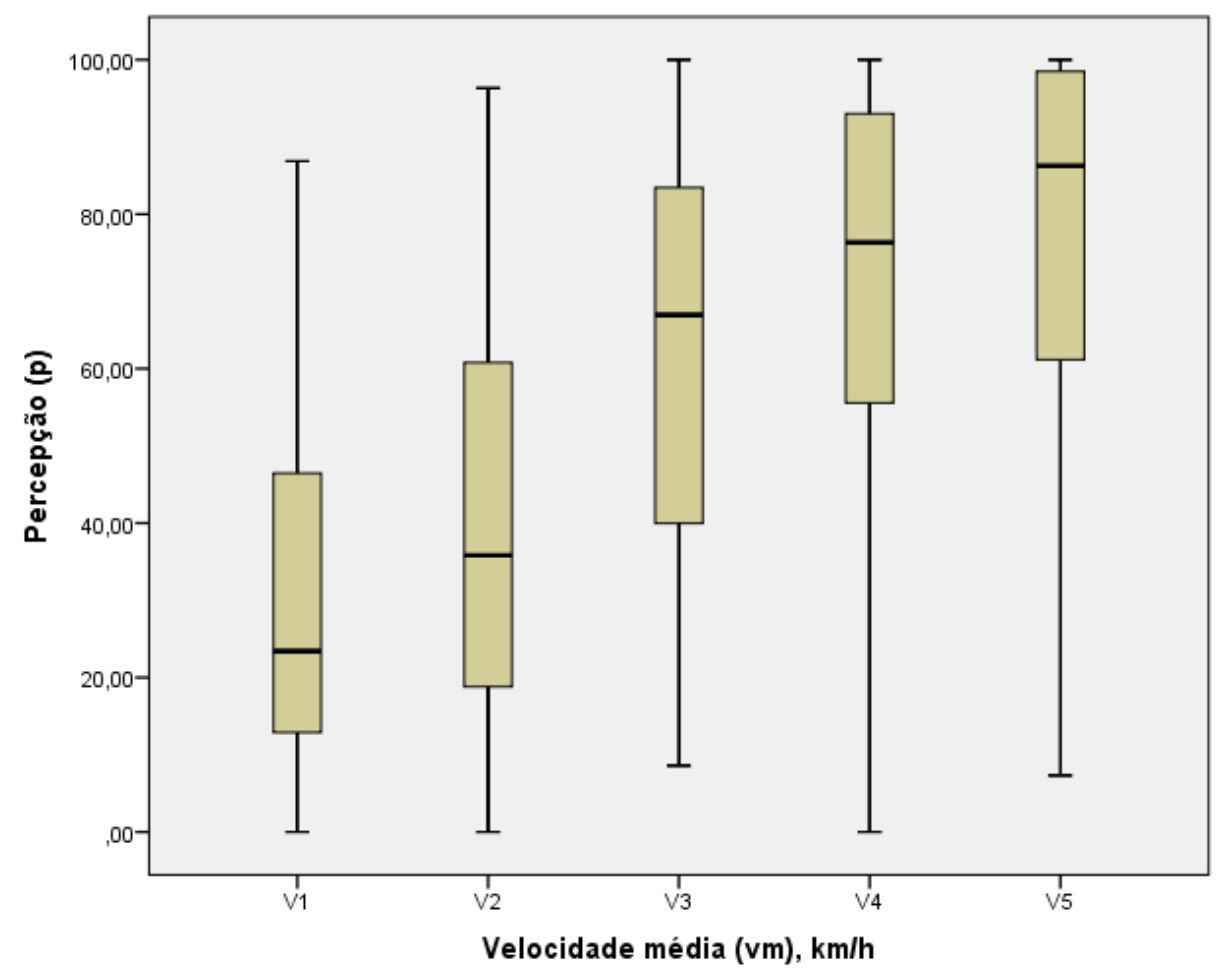

Figura 26. Diagrama em caixa apresentando a variação das notas para cada classe de velocidade média no tempo

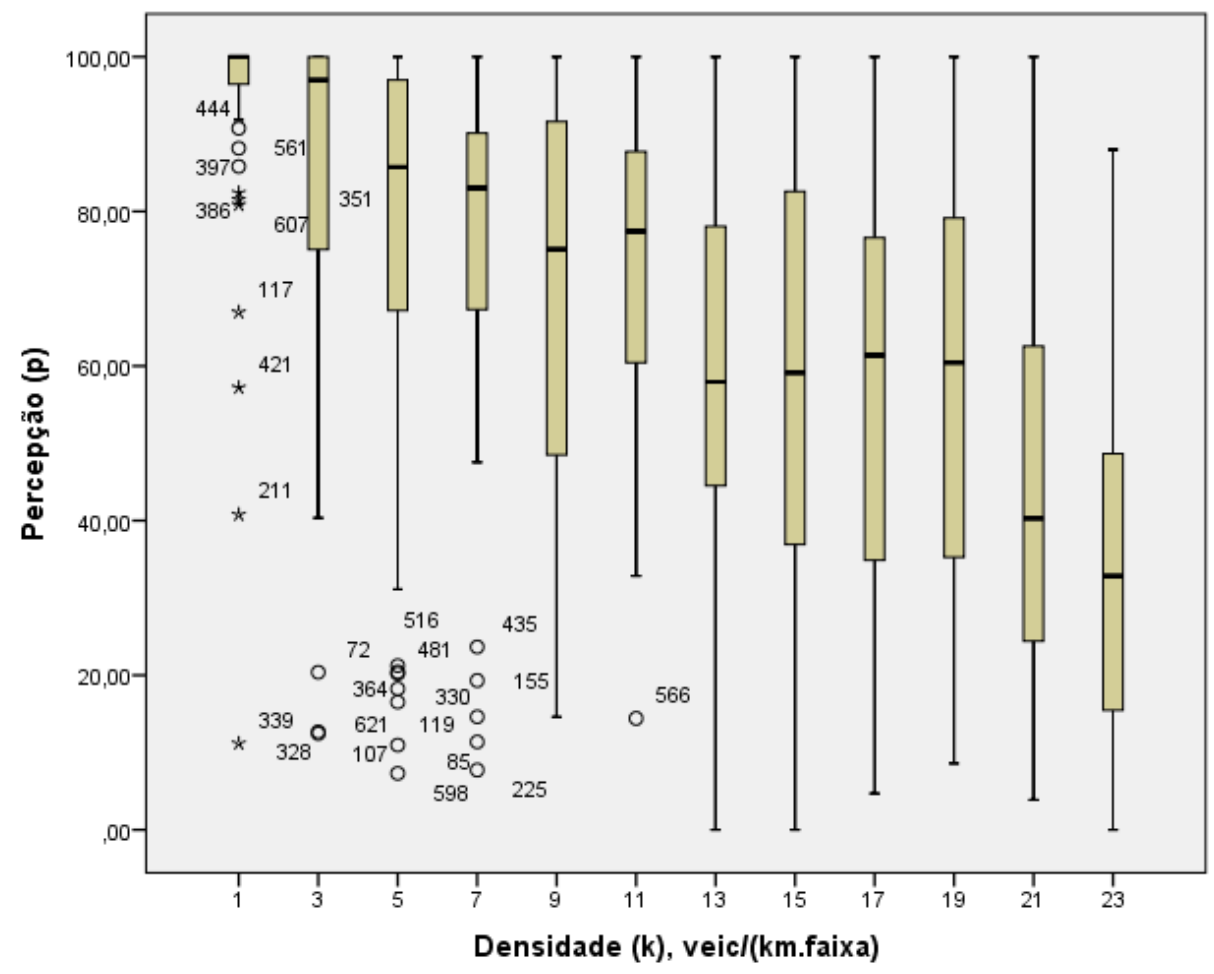

Figura 27. Diagrama em caixa apresentando a variação das notas para cada densidade [veic/(km.faixa)]; estrelas são observações atípicas extremas e círculos são observações atípicas moderadas 
Percebe-se que nos dois primeiros casos (\%vp e vm), não foi identificada nenhuma observação atípica. Já no terceiro $(k)$ foram identificadas 26 observações, sendo 19 observações atípicas moderadas (mild) - representado por círculo - e 7 outliers extremos (extreme) - representado por estrela.

Para calcular os outliers moderados, utiliza-se o valor de corte da equação (1); e para calcular os extremos, usa-se o valor de corte resultante da equação (2) (IBM, 2013).

$$
\begin{array}{lll}
Q_{1}-1,5 . d q & \text { ou } & Q_{3}+1,5 . d q \\
Q_{1}-3 . d q & \text { ou } & Q_{3}+3 . d q
\end{array}
$$

em que:

$d q:$ diferença entre o terceiro e o primeiro quartil

Q1: primeiro quartil

Q3: terceiro quartil

A hipótese levantada para a inexistência de observações discrepantes para \%vp e vm é que as notas têm baixa correlação com essas variáveis, de forma que a distribuição de valores está bem distribuída, o que resultou em um valor alto para a distância entre o $1^{\circ}$ e o $3^{\circ}$ quartil, gerando, consequentemente, uma caixa (box-plot) comprida.

Por último, foram identificados os dados discrepantes por meio da análise de resíduos 'estudentizados' da regressão. Definiu-se que o ponto de corte seria de 2 desvios-padrão (Field, 2005). Por esse método, foram identificados 20 casos.

A Tabela 7, no Apêndice $\mathrm{C}$, apresenta os casos que foram selecionados por ao menos um método. Interessante destacar que a análise de resíduos da regressão não apontou como observação discrepante nenhum ponto selecionado pelos outros dois métodos, o que leva a pensar que o modelo representou bem a probabilidade dos outliers ocorrerem.

\subsection{Identificação dos limites dos níveis de serviço}

A etapa seguinte consiste em analisar as respostas coletadas com os questionários na aplicação do experimento piloto para determinar os limiares dos níveis de serviço. O processo proposto para alcançar esse objetivo, baseia-se em regressão logística, como é apresentado no item a seguir. 
A regressão logística binomial, ou modelo Logit, é uma técnica multivariada que utiliza uma transformação não-linear para prever e explicar uma variável dependente dicotômica (categórica de 2 níveis), que assume valores 0 ou 1, utilizando como base variáveis independentes de natureza contínua, discreta ou categórica (Field, 2005; Hair Jr. et al., 2005). A relação entre as variáveis na análise logística é uma curva em formato de S (Figura 28) e tem caráter não-linear (Hair Jr. et al., 2005). Essa relação baseia-se na probabilidade de um evento (variável dependente) ocorrer dado um cenário (combinação de variáveis independentes), artifício usado para modelar a relação entre as variáveis e que possibilitou representar uma distribuição categórica (variável dependente com imagem 0 ou 1) através de uma distribuição contínua (probabilidade de ocorrência do evento, imagem entre 0 e 1).

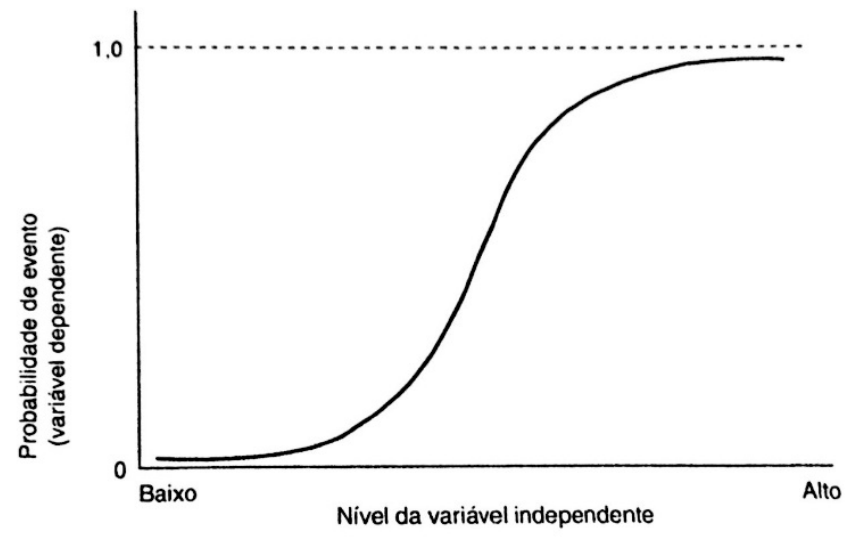

Figura 28. Exemplo de curva Logit (Hair Jr. et al., 2005)

A formulação da regressão logística para a regressão binomial simples (uma variável independente) é dada pela Equação (3):

$$
\mathrm{P}(\mathrm{Y})=\frac{1}{1+e^{-\left(b_{0}+b_{1} x_{1}+\varepsilon_{i}\right)}}
$$

e: base do logaritmo neperiano (natural);

bo: intercepto no eixo-y;

$\mathrm{b}_{1}$ : coeficiente da correspondente variável independente $\mathrm{x}_{1}$;

X1: variável independente;

$\varepsilon_{i}$ : termo residual. 


\subsubsection{Discretização da variável}

Como a técnica de regressão logística binomial usa como variável dependente dados binários e como variável independente dados contínuos, discretos ou categóricos, foi necessário discretizar a variável dependente 'percepção' $(p)$, uma vez que ela foi obtida por meio de uma escala métrica contínua.

Como solução para a discretização da variável foi escolhido um método de agrupamento de dados (análise de cluster), técnica que possibilita a criação de categorias dentro de um conjunto de dados, baseando-se em uma medida de similaridade. O método escolhido foi o k-means.

A análise de cluster calculou as medidas de similaridade entre os casos coletados baseando-se na variável percepção $(p)$, gerando 5 grupos (quantidade definida a priori). Na Figura 29, podese observar a dispersão dos casos observados e seu respectivo agrupamento definido pela análise de cluster, por meio de um gráfico percepção versus densidade que o vídeo simulado apresenta $(p \times k)$.

Para caracterizar cada grupo criado, foram calculadas algumas medidas descritivas, como a média aritmética, o desvio-padrão, o valor máximo, o valor mínimo e a quantidade de casos em cada grupo (Tabela 6). Na Figura 30, apresenta-se a distribuição de frequência em função da densidade para cada grupo.

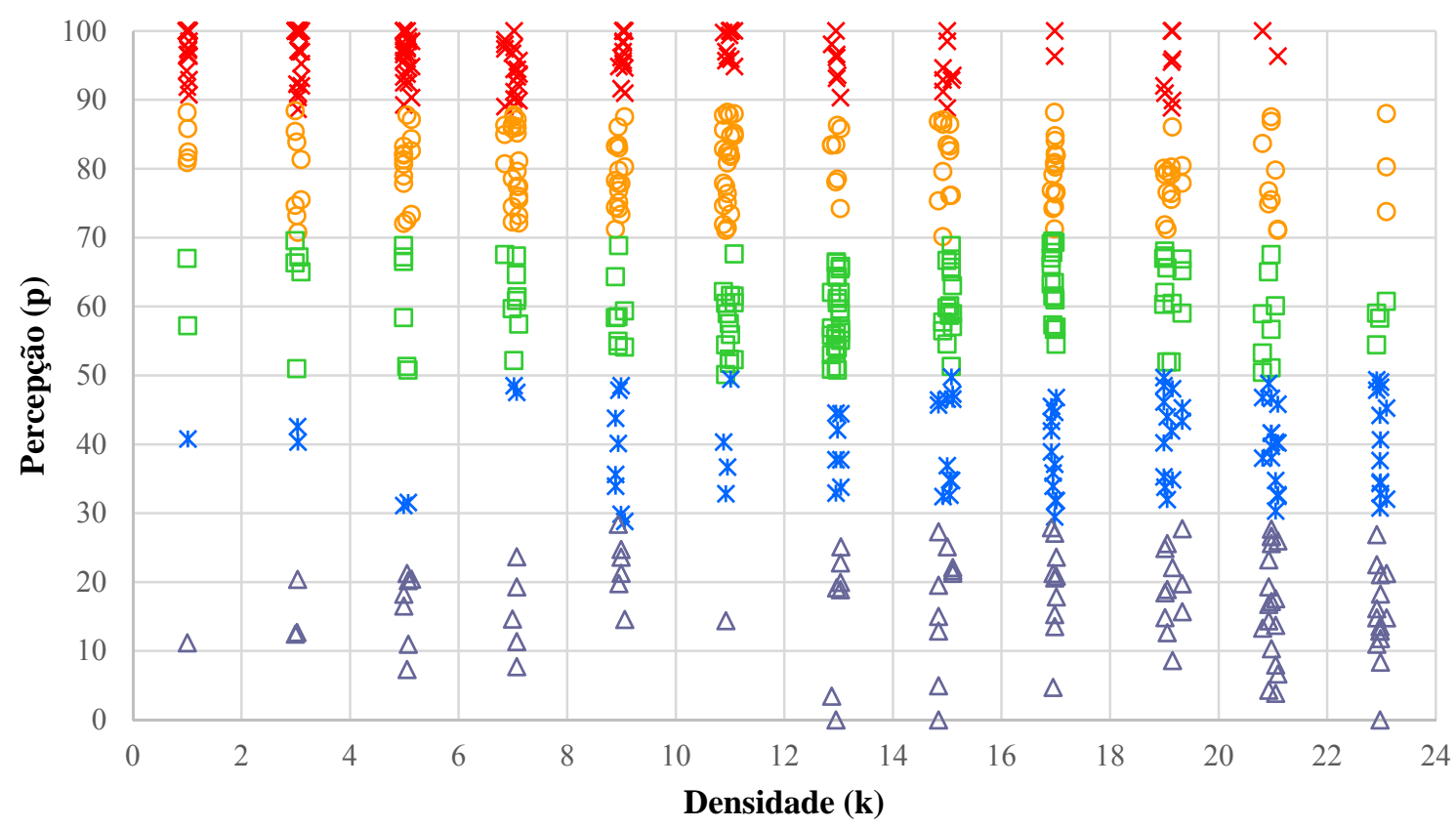

$\times$ Grupo 1 OGrupo $2 \quad \square$ Grupo $3 \quad *$ Grupo $4 \quad \Delta$ Grupo 5

Figura 29. Resultado encontrado para o agrupamento $k$-means em 5 níveis, baseado na medida percepção da qualidade de serviço 
Tabela 6. Estatística descritiva dos grupos formados pela análise de cluster k-means

\begin{tabular}{crrrrr}
\hline \multirow{2}{*}{ Grupo } & Número de casos & \multicolumn{5}{c}{ Percepção (p) } \\
\cline { 3 - 6 } & em cada grupo & \multicolumn{1}{c}{ Média } & Desvio-padrão & Máximo & Mínimo \\
\hline 1 & 176 & 97,1 & 3,4 & 100,0 & 88,6 \\
2 & 150 & 80,1 & 5,2 & 88,4 & 70,1 \\
3 & 123 & 60,1 & 5,6 & 69,5 & 50,1 \\
4 & 90 & 40,1 & 6,2 & 49,8 & 28,8 \\
5 & 94 & 17,1 & 7,0 & 28,4 & 0,0 \\
\hline
\end{tabular}

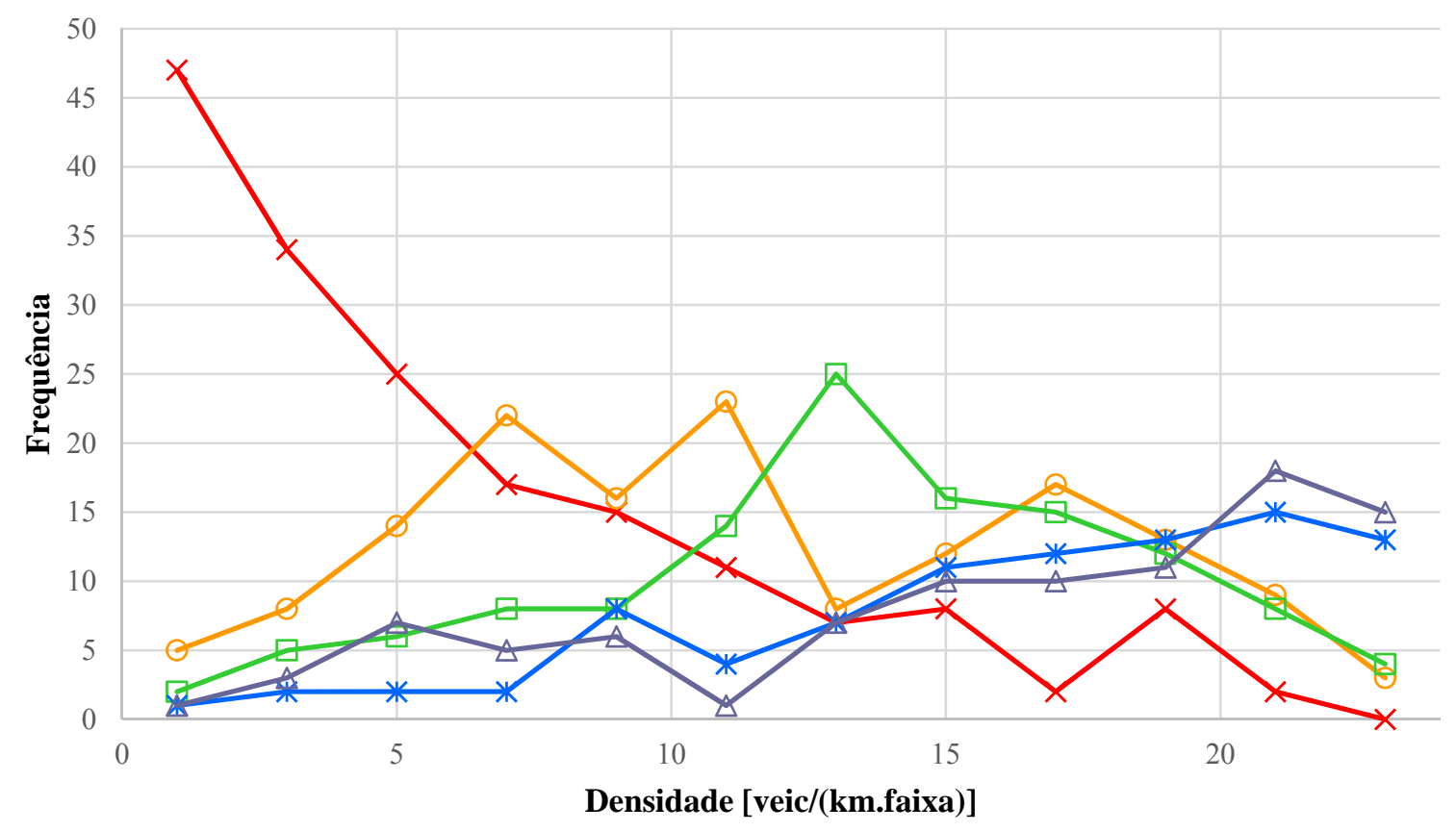

* Grupo $1 \rightarrow$ Grupo $2 \quad \square$ Grupo $3 \rightarrow$ Grupo $4 \rightarrow$ Grupo 5

Figura 30. Histograma da densidade para cada cluster baseado na variável percepção da qualidade de serviço

A partir desses dados, foi possível desenvolver um esquema para criar funções logísticas de uma maneira que fosse possível obter os limiares dos níveis de serviço em fluxo nãocongestionado. $\mathrm{O}$ esquema proposto possui os seguintes passos:

1. Criar uma variável binária em que os casos do primeiro grupo (Grupo 1) tem valor 1 e os demais casos (Grupo 2 a $n$ ) tem valor 0 ;

2. Calcula-se a probabilidade estimada $(P)$ de um indivíduo pertencer ao grupo em questão (Grupo i), considerando como variável independente a densidade $k$ e como variável dependente a variável binária;

3. Calcula-se a probabilidade estimada de um indivíduo não pertencer ao Grupo $i$, ou seja, a probabilidade complementar (1-P);

4. Eliminam-se todos os casos do Grupo $i$; 
5. A variável binária passa a ter como valores 1 os indivíduos do Grupo $i+1$ e os indivíduos dos demais grupos continuam com o valor 0 ;

6. Repete-se o passo 2 e o passo 3, de obtenção das probabilidades; e o passo 4, sendo nesse passo eliminados os casos do grupo em questão, o Grupo $i+1$;

7. Continua-se o processo até que a variável binária seja formada pelos casos do penúltimo grupo (com valor de 1) e do último grupo (com valor de 0 ). No caso de utilizar um cluster de 5 grupos, tem-se, respectivamente, o Grupo 4 e o Grupo 5.

Com base nas informações obtidas pelo esquema montado, é possível traçar as curvas probabilidade estimada $x$ densidade e probabilidade complementar $x$ densidade, como apresentadas na Figura 31. Cabe destacar que os valores do eixo das abscissas foram omitidos na Figura 31 e na Figura 32, pois as conclusões do modelo Logit com os dados do experimento piloto não podem ser expandidas para a população, uma vez que a amostra apresentou perfis homogêneos.

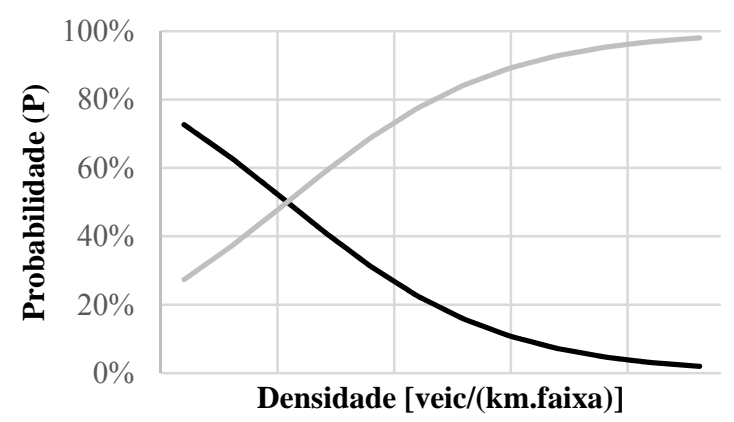

—_Probabilidade de pertencer ao Grupo 1

——Probabilidade de não pertencer ao Grupo 1

Limiar entre NS A e NS B

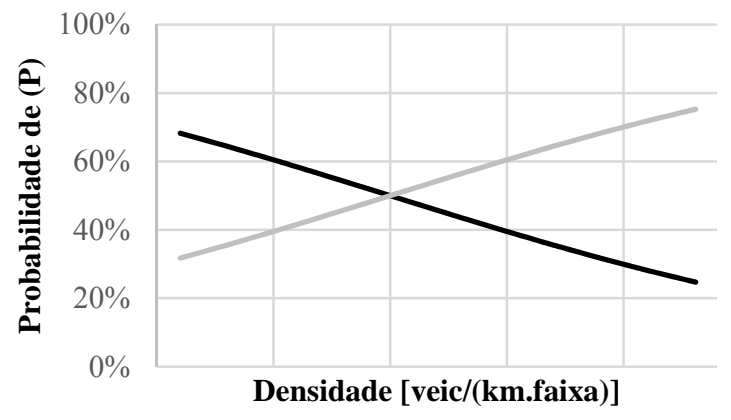

— Probabilidade de pertencer ao Grupo 3

__ Probabilidade de não pertencer ao Grupo 3

Limiar entre NS C e NS D

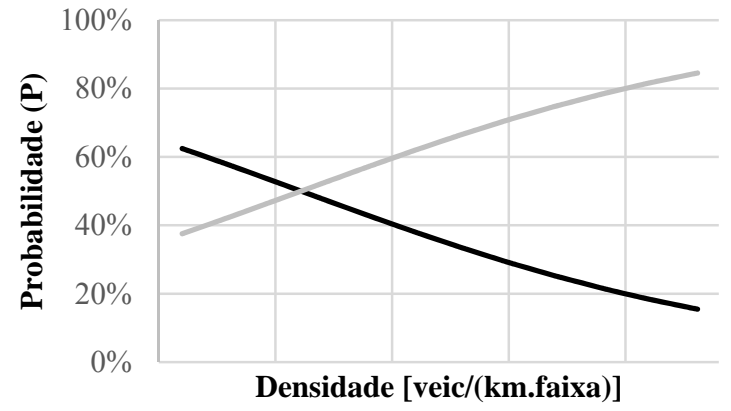

——Probabilidade de pertencer ao Grupo 2

——Probabilidade de não pertencer ao Grupo 2

Limiar entre NS B e NS C

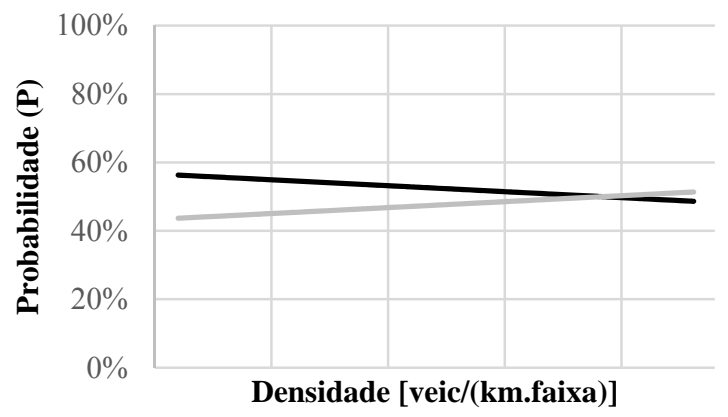

— Probabilidade de pertencer ao Grupo 4

—_Probabilidade de não pertencer ao Grupo 4

Limiar entre NS D e NS E

Figura 31. Funções logísticas e suas complementares que estimam a probabilidade de elementos com uma densidade veicular específica pertencer ou não a um dado nível de serviço 
Uma informação que pode ser extraída da Figura 31 é uma estimativa do limite entre os níveis de serviço, que, por definição da presente pesquisa, representa o ponto de intersecção entre as duas curvas (probabilidade estimada e sua complementar), ou seja, o ponto que apresenta a mesma chance de pertencer ou não aquele grupo. Isto é, a densidade correspondente a esse ponto pode ser considerada como o limite do nível de serviço percebido pelos respondentes.

A título de averiguar quantos níveis de serviço são percebidos, sugere-se verificar a existência de curvas logísticas praticamente sobrepostas. Nesse caso, pode-se pensar que os elementos daqueles grupos podiam ser considerados como elementos de um grupo só. Assim, seria interessante refazer os passos juntando os dados dos grupos em questão.

Para realizar a subdivisão em 5 níveis, o número de níveis de serviço usado pelo HCM, devese utilizar o mesmo método, porém, com uma adaptação no passo 4: quando forem eliminados os casos do grupo anterior, deve-se eliminar também os casos que tenham densidade menores do que o ponto de corte (limite do nível de serviço). As etapas, já adaptadas, estão apresentadas a seguir e o resultado nessa outra situação está apresentado na Figura 32:

1. Criar uma variável binária em que os casos do primeiro grupo (Grupo 1) tem valor 1 e os demais casos (Grupo 2 a 5) tem valor 0 ;

2. Calcula-se a probabilidade estimada $(P)$ de um indivíduo pertencer ao grupo em questão (Grupo i), considerando como variável independente a densidade $k$ e como variável dependente a variável binária;

3. Calcula-se a probabilidade estimada de um indivíduo não pertencer ao Grupo $i$, ou seja, a probabilidade complementar (1-P);

4. Eliminam-se todos os casos do Grupo $i$ e os casos que possuem valor da variável independente $k$ menores que o valor do ponto de corte (intersecção entre a curva de probabilidade estimada e a sua complementar);

5. A variável binária passa a ter como valores 1 os indivíduos do Grupo $i+1$ e os indivíduos dos demais grupos continuam com o valor 0 ;

6. Repete-se o passo 2 e o passo 3, de obtenção das probabilidades; e o passo 4, sendo nesse passo eliminados os casos do grupo em questão, o Grupo $i+1$, e os casos com densidade menor que o novo ponto de corte;

7. Continua-se o processo até que a variável binária seja formada pelos casos do penúltimo grupo (com valor de 1) e do último grupo (com valor de 0), respectivamente, o Grupo 4 e o Grupo 5.

Por meio do experimento piloto, notou-se que a regressão logística foi adequada para alcançar o objetivo da pesquisa. Além disso, foi útil para uma análise de dados provenientes de avaliação subjetiva com presença de outliers e de ruídos na distribuição. 


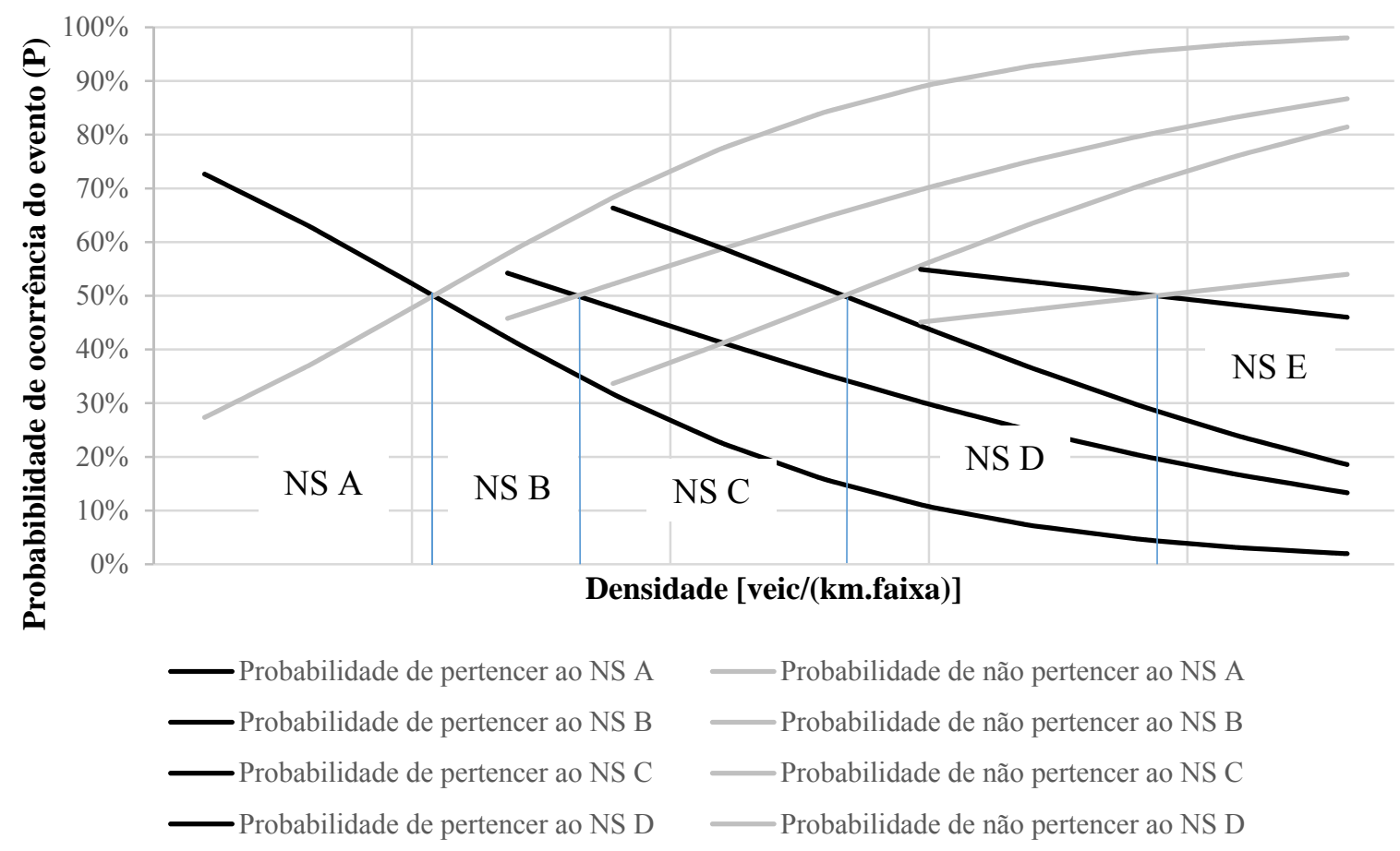

Figura 32. Funções logísticas e suas complementares que estimam a probabilidade de elementos com uma densidade específica pertencer ou não a um dado nível de serviço

Mesmo assim, uma vez que o objetivo é delimitar os níveis em função de $k$, propôs-se adaptações no método para diminuir a incidência dos ruídos causados por vm e \%vp na percepção da qualidade dos cenários. Para isso, sugere-se: (i) que a cada avaliador seja sorteada uma categoria de \%vp para que os vídeos apresentados sejam homogêneos quanto ao \%vp e variem exclusivamente em $k$; e (ii) que a seleção dos vídeos exclua os filmes de carros que estejam trafegando em velocidade acima da máxima permitida pela legislação, inferior a menos $10 \mathrm{~km} / \mathrm{h}$ da velocidade máxima ou inferior a máxima delimitada pelo fluxo. 


\section{CONSIDERAÇÕES FINAIS}

Esta pesquisa limitou suas conclusões a questões relacionadas ao método proposto, pois, para concluir sobre outros tópicos, seria preciso que o simulador de tráfego usado para criar os vídeos estivesse calibrado a uma condição de tráfego do Brasil. É indispensável, portanto, calibrar o modelo antes da aplicação final do questionário, a fim de estimar os limites entre os níveis de serviço como percebidos pelos usuários brasileiros.

O formato final do questionário, modificado a partir das informações coletadas no experimento piloto, está apresentado no Apêndice B. O questionário pode ser aplicado para estimar os limites de nível de serviço, asseguradas a prévia calibração do simulador a uma condição brasileira e à execução de todas as etapas sugeridas no formato final do método. A seguir, apresentam-se as conclusões provenientes do estudo, que levaram a constatar que o método proposto alcançou o objetivo desejado.

O método propõe a apresentação de cenários de 40 segundos, sendo permitido assistir aos vídeos quantas vezes for desejado. Além disso, para todos os avaliadores serão mostrados 14 filmes, sendo dez para a análise da percepção do usuário sobre a qualidade de serviço. Os outros quatro vídeos serão usados para estudar a variação de resposta fornecida a duas condições de tráfego similares por um mesmo respondente. Na continuidade do estudo, recomenda-se a comparação da escala contínua com a escala discreta e com a escala categórica.

A etapa de validação dos vídeos é importante para evitar que critérios não contemplados pelo pesquisador na análise dos dados sejam considerados na avaliação do cenário e para evitar o surgimento de ruídos provenientes da percepção da qualidade em função desses critérios desconsiderados na análise. Sobre a etapa de formatação do banco de dados, após executá-la e reaplicar o questionário, sugere-se que seja verificada a melhoria na opinião do respondente sobre sua dificuldade em discernir entre cenários simulados.

No experimento piloto, constatou-se que os cenários simulados apresentaram as informações necessárias para o respondente julgar a qualidade de serviço da rodovia virtual e não foi identificado nada que desqualificasse o método proposto.

Sobre o impacto das variáveis operacionais dos vídeos na percepção de qualidade de serviço, as três variáveis apresentaram correlação em conformidade ao indicado pela literatura, sendo a densidade a que apresentou a maior correlação. Entretanto, esperava-se que a correlação do percentual de veículos pesados fosse mais alta. A redução do impacto na percepção da qualidade de serviço causado pela presença de caminhões pode ter ocorrido tanto pela 
incapacidade do simulador usado representar o desempenho veicular dos veículos pesados, como pelo fato da rodovia virtual ter sido criada em terreno plano.

Outra hipótese é que um cenário simulado não fornece o necessário para representar a sensação causada pela presença de caminhões na corrente de tráfego. Mais precisamente, quanto ao barulho gerado pelo motor de caminhão, que amedronta certos viajantes, e o desconforto causado pela insegurança em trafegar ao lado de um caminhão, devido à proximidade a um veículo maior e ao medo de um eventual 'trancamento'.

Assim, para uma melhor análise do impacto de veículos pesados na qualidade de serviço, recomenda-se para estudo futuro a aplicação do método proposto com cenários elaborados por um simulador que considere o desempenho veicular, variando a inclinação e o comprimento de rampas e analisando o impacto do número de faixas de rolamento.

A questão sobre a manutenção dos respondentes que tiveram um sinal contrário ou uma correlação entre sua percepção e a condição operacional muito menor que a correlação da percepção conjunta (geral) mostrou-se irrelevante no experimento piloto, pois sua exclusão não gerou significativa mudança na correlação da percepção conjunta. A manutenção tem como vantagem tornar o método mais simples porque exclui o passo de identificação dos avaliadores que não responderam em conformidade com a média.

Os casos identificados pela análise de resíduos da regressão não foram casos identificados como observações atípicas pelos métodos utilizados, o que sugere a validação da regressão logística ao propósito. Entretanto, recomenda-se a realização da análise logística excluindo os outliers, a fim de estudar o efeito destes no método em proposição.

No experimento piloto, a regressão logística binomial simples mostrou-se útil para alcançar o objetivo de delimitar os níveis de serviço em função da variável concentração veicular.

Vale mencionar que a regressão logística binomial múltipla (variáveis independentes: $k$ e \%vp) foi testada aos fins do estudo. Nesse teste, os indicadores de qualidade do ajuste (-2LL) melhoraram, mas a análise múltipla impossibilitou a definição dos limites de nível de serviço na dimensão da densidade. Apesar da necessidade de aprofundar o estudo para concluir a respeito, aparentemente a regressão logística binomial múltipla é adequada apenas se os limites forem definidos em função das variáveis usadas na análise, ou seja, por uma análise de múltiplos indicadores. Isto é, se a análise múltipla utilizar $k$ e o \%vp, os limites de níveis de serviço devem ser definidos na dimensão formada por essas duas variáveis $(k, \% v p)$. 
Por ora, indica-se que o método proposto pode ser aplicado em qualquer país, desde que um simulador microscópico devidamente calibrado para refletir as condições operacionais locais esteja disponível; e que o método proposto pode ser utilizado na estimativa dos limites de nível de serviço para outros componentes do sistema viário após adaptação do método ao elemento (ou sistema) viário em consideração.

Por fim, durante a elaboração desta pesquisa, surgiram ideias que não foram postas em prática por conta da limitação de tempo e que serão apresentadas para permitir a continuidade do estudo iniciado, visando o seu aprimoramento e uma contribuição ainda maior ao tema.

Assim, além das recomendações sugeridas anteriormente, sugere-se determinar a unidade de percepção da qualidade de serviço em termos de densidade veicular, com a finalidade de diminuir o número de níveis para a variável densidade e, consequentemente, o número de cenários. Outra sugestão seria utilizar o modelo Probit como alternativa ao modelo Logit ou ainda usar uma análise baseada em lógica fuzzy para avaliar se esta seria uma abordagem mais adequada em análises baseadas em avaliação subjetiva. 



\section{REFERÊNCIAS}

Andrade, G. R. de (2012). Capacidade e relação fluxo-velocidade em autoestradas e rodovias de pista dupla paulistas. Dissertação de Mestrado, Escola de Engenharia de São Carlos, Universidade de São Paulo, São Carlos, SP.

Andrade, G. R. de, Rodrigues Silva, K. C. \& Puty Filho, S. de A. (2011). Panorama tecnológico e normativo da avaliação operacional das concessões rodoviárias. In: Anais do VII Congresso Brasileiro de Rodovias e Concessões - CBR\&C. Foz do Iguaçú, PR: ABCR.

Choocharukul, K., Sinha, K. C. \& Mannering, F. L. (2004). User perceptions and engineering definitions of highway level of service: an exploratory statistical comparison. Transportation Research Part A, 38, pp. 677-689.

Cunha, A. L. B. N. da \& Setti, J. R. (2009). Fatores de equivalência para caminhões em rodovias de pista dupla. In: Anais do VI Congresso Brasileiro de Rodovias e Concessões $C B R \& C$. Florianópolis: ABCR.

Cunha, A. L. B. N. da (2007). Avaliação do impacto da medida de desempenho no equivalente veicular de caminhões. Dissertação de Mestrado, Escola de Engenharia de São Carlos, Universidade de São Paulo, São Carlos, SP.

DNIT (2006a). Manual de pavimentação: publicação IPR-719 (3 $3^{\mathrm{a}}$ ed.). Rio de Janeiro: Brasil, Ministério dos Transportes, Departamento Nacional de Infraestrutura de Transportes, Instituto de Pesquisas Rodoviárias.

DNIT (2006b). Manual de estudos de tráfego: publicação IPR-723. Rio de Janeiro: Brasil, Ministério dos Transportes, Departamento Nacional de Infraestrutura de Transportes, Instituto de Pesquisas Rodoviárias.

Faria, C. A. (1991). Avaliação do nível de serviço do transporte coletivo urbano sob o ponto de vista do usuário: o enfoque multivariado. Tese de Doutorado, Escola Politécnica, Universidade de São Paulo, São Paulo.

Field, A. (2005). Discovering statistics using SPSS (and sex, drugs and rock ' $n$ ' roll) (2a ed.). Londres, Thousand Oaks, Nova Deli: Sage Publications. ISBN 0-7619-451-6.

Hair Jr., J. F., Anderson, R. E., Tatham, R. L. \& Black, W. C. (2005). Análise multivariada de dados ( $5^{\mathrm{a}}$ ed., A. S. Sant'Anna \& A. Chaves Neto, trads.) Porto Alegre: Bookman. ISBN 0-13-017706-7.

Hall, F., Wakefield, S. \& Al-Kaisy, A. (2001). Freeway quality of service: what really matters to drivers and passengers?. Transportation Research Record: Journal of the Transportation Research Board, 1776, pp. 17-23.

Hostovsky, C. \& Hall, F. L. (2003). Freeway quality of service: perceptions from tractor-trailer drivers. Transportation Research Record: Journal of the Transportation Research Board, 1852, pp. 19-25. 
Hostovsky, C., Wakefield, S. \& Hall, F. L. (2004). Freeway users'perceptions of quality of service: comparison of three groups. Transportation Research Record: Journal of the Transportation Research Board, 1883, pp. 150-157.

IBM Software Group (2013). SPSS Statistics - Manual Reference, Versão 22.

Nakamura, H., Suzuki, K. \& Ryu, S. (2000). Analysis of the interrelationship among traffic flow conditions, driving behavior, and degree of driver's satisfaction on rural motorways. In: Transportation Research Circular, E-C018: Proceedings of the $4^{\text {th }}$ International Symposium on Highway Capacity (pp. 42-52). Maui, Hawaii, USA: TRB.

Obelheiro, M. R. (2010). Método de análise de níveis de serviço em praças de pedágio brasileiras. Dissertação de Mestrado, Escola de Engenharia, Universidade Federal do Rio Grande do Sul, Porto Alegre.

Oliveira, M. L. de (2009). Método para determinação de nível de serviço em praças de pedágio. Tese de Doutorado, Escola de Engenharia, Universidade Federal do Rio Grande do Sul, Porto Alegre.

Papadimitriou, E., Mylona, V. \& Golias, J. (2010). Perceived level of service, driver, and traffic characteristics: piecewise linear model. Journal of Transportation Engineering, 136(10), pp. 887-894.

Pasquali, L. (2009). Psicometria. Revista da Escola de Enfermagem da USP, 43, pp. 992-999.

Pereira, J. C. R. (2004). Análise de dados qualitativos: Estratégias metodológicas para as ciências da saúde, humanas e sociais ( $3^{\mathrm{a}}$ ed.). São Paulo: Editora da Universidade de São Paulo (EDUSP). ISBN 85-314-0523-8.

Pinatti, A. (2007). Avaliação do questionário sobre o comportamento de motoristas: uma distinção entre erros e violações. Dissertação de Mestrado, Faculdade de Filosofia, Ciências e Letras de Ribeirão Preto, Universidade de São Paulo, Ribeirão Preto, SP.

Setti, J. R. (2009). Highway capacity manual ou um manual de capacidade rodoviária brasileiro?. In: Anais do VI Congresso Brasileiro de Rodovias e Concessões - CBR\&C. Florianópolis: ABCR.

Soares, L. R. (1965). A capacidade das vias e o congestionamento do tráfego (IPR: 108 - GTT - 65 - 09). In: Anais do I Simpósio sôbre Pesquisas Rodoviárias. Rio de Janeiro: IPR.

Stevens, S. S. (1975). Psychophysics: introduction to its perceptual, neural, and social prospects ( $1^{\text {a }}$ ed., G. Stevens, Ed.). New York, London, Sydney, Toronto: John Wiley \& Sons. ISBN 0-471-82437-2.

TCU (2008). Processo TC-016.189/2008-9, Acórdão n 2104/2008 - TCU - Plenário. Brasília, DF, Sessão 24 de setembro de 2008 (Ata 38/2008): Brasil, Tribunal de Contas da União, Relator Ministro Ubiratan Aguiar. 
TRB (1985). Special Report 209: Highway Capacity Manual. Washington D.C.: Transportation Research Board. ISBN 0-309-03821-9.

TRB (2010). Highway Capacity Manual (5 ed.). Washington D.C.: Transportation Research Board. ISBN 978-0-309-16077-3.

Utimura, F. S., Setti, J. R., Egami, C. Y. \& Mon-Ma, M. L. (2007). Verificação da acurácia de estimativas do nível de serviço em rodovias de pista simples no Estado de São Paulo. In: Anais do XXI Congresso de Pesquisa e Ensino em Transportes - ANPET. Rio de Janeiro: ANPET.

Washburn, S. S. \& Kirschner, D. S. (2006). Rural freeway level of service based on traveler perception. Transportation Research Record: Journal of the Transportation Research Board, 1988, pp. 31-37.

Washburn, S. S., Ramlackhan, K. \& McLeod, D. S. (2004). Quality-of-service perceptions by rural freeway travelers: exploratory analysis. Transportation Research Record: Journal of the Transportation Research Board, 1883, pp. 132-139. 

APÊNDICE A 



\section{ETAPA DE VALIDAÇÃO DOS FILMES}

a. Marque os critérios considerados em sua avaliação sobre a qualidade da viagem apresentada pelo vídeo abaixo e defina se é um critério positivo ou negativo.

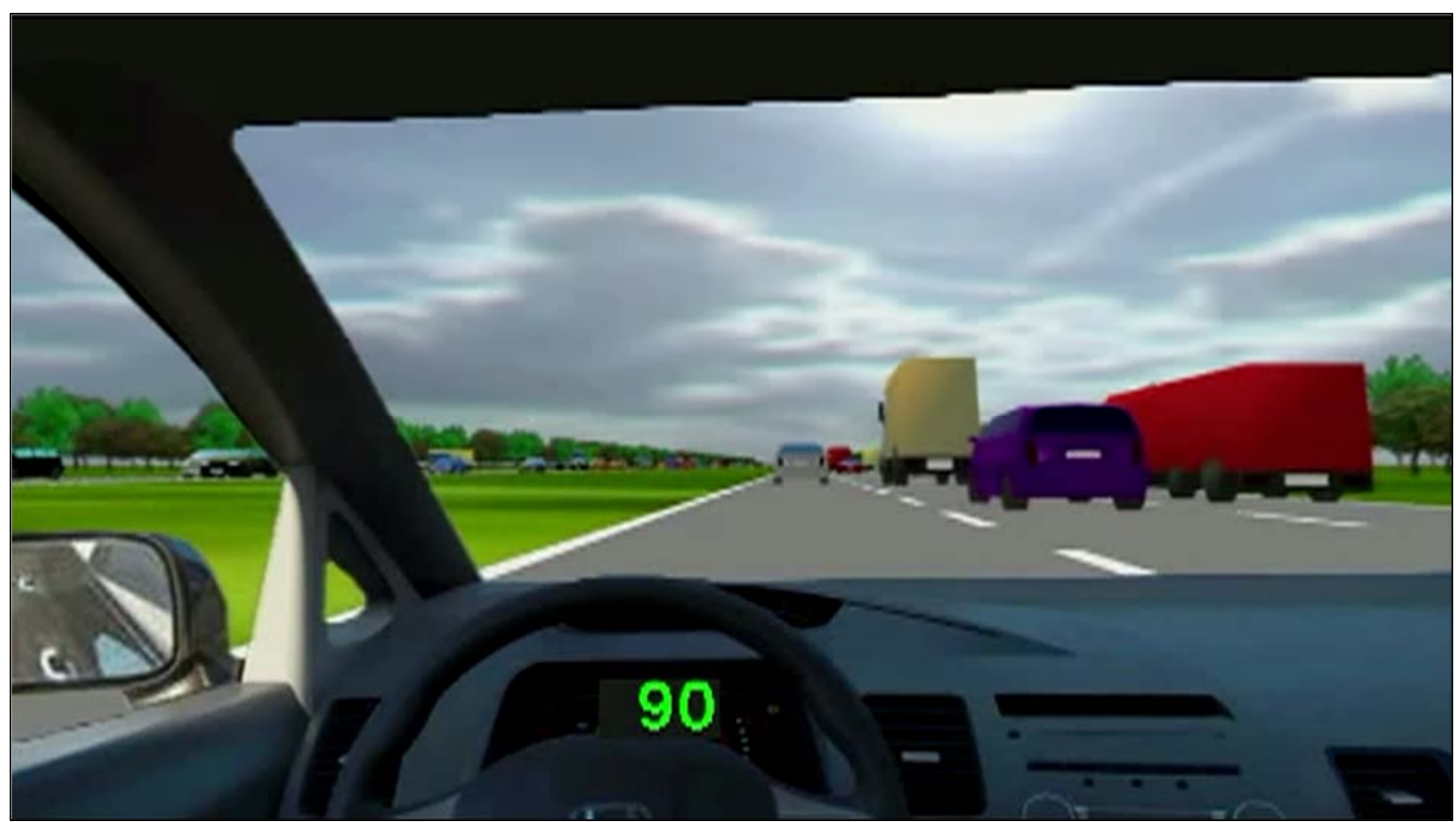

Marque esta caixa caso observe variações nas condições de tráfego ao longo do vídeo (por exemplo, variação na quantidade de veículos; variação na velocidade; etc.). ${ }^{1}$.

\begin{tabular}{|l|c|c|}
\cline { 2 - 3 } \multicolumn{1}{c|}{} & Positivo & Negativo \\
\hline$\square$ Condições climáticas desfavoráveis (chuva, etc.) & $\square$ & $\square$ \\
\hline$\square$ Presença de veículos longos e/ou pesados (ex: caminhão) & $\square$ & $\square$ \\
\hline $\begin{array}{l}\square \text { Comportamento inadequado do motorista (manobras } \\
\text { bruscas; faixa inadequada, mudança de faixa sem justificativa; } \\
\text { formas de ultrapassagem; etc.) }\end{array}$ & $\square$ & $\square$ \\
\hline $\begin{array}{l}\square \text { Comportamento inadequado de terceiros (manobras bruscas; } \\
\text { faixa inadequada, mudança de faixa sem justificativa; formas de } \\
\text { ultrapassagem; etc.) }\end{array}$ & $\square$ & $\square$ \\
\hline $\begin{array}{l}\square \text { Questões relativas à segurança viária (traçado da rodovia; } \\
\text { sinalização; etc.) }\end{array}$ & $\square$ & $\square$ \\
\hline
\end{tabular}

\footnotetext{
${ }^{1} \mathrm{Na}$ configuração do website, caso selecione esta caixa, programar para que o respondente siga para o próximo vídeo.
} 


\begin{tabular}{|l|c|c|}
\cline { 2 - 3 } \multicolumn{1}{l|}{} & Positivo & Negativo \\
\hline$\square$ Questão de segurança durante a viagem (situações de riscos) & $\square$ & $\square$ \\
\hline$\square$ Condição de tráfego do sentido oposto (viagem de volta) & $\square$ & $\square$ \\
\hline$\square$ Muito movimento na rodovia & $\square$ & $\square$ \\
\hline$\square$ Rodovia com pouco (ou nenhum) movimento & $\square$ & $\square$ \\
\hline$\square$ O veículo poderia estar mais rápido & $\square$ & $\square$ \\
\hline$\square$ Veículo em baixa velocidade & $\square$ & $\square$ \\
\hline$\square$ Velocidade acima da máxima permitida & $\square$ & $\square$ \\
\hline$\square$ Veículo em alta velocidade & $\square$ & $\square$ \\
\hline$\square$ Veículo lento na rodovia impedindo a passagem & $\square$ & $\square$ \\
\hline$\square$ Veículos lentos trafegando nas faixas vizinhas (diferencial \\
de velocidade entre faixas)
\end{tabular}


APÊNDICE B 



\section{INTRODUÇÃO}

QEP 0.1 .

Olá,

Convidamos você a participar voluntariamente de uma pesquisa da Universidade de São Paulo (USP), cujo tema é "Avaliação da qualidade da viagem em rodovias rurais". Sua participação consistirá em responder a um questionário, com tempo estimado para sua conclusão de 30 minutos.

Destacamos que as informações fornecidas através do questionário serão mantidas unicamente com nossa equipe, apenas para fins de pesquisa; como também, que não há interesse na identificação dos respondentes.

Caso concorde em colaborar com este instrumento de pesquisa, solicitamos que marque a caixa de seleção a seguir e siga as instruções.

Agradecemos sua colaboração.

- Concordo em responder ao questionário

$\mathrm{QMP}^{2}$ 0.1.

Olá,

Convidamos você a participar voluntariamente de uma pesquisa da Universidade de São Paulo (USP), cujo tema é "Qualidade da viagem em rodovias". Sua participação consistirá em responder a um questionário, com tempo estimado para sua conclusão de $\mathbf{3 0}$ minutos.

Destacamos que as informações fornecidas através do questionário serão mantidas unicamente com nossa equipe, apenas para fins de pesquisa; como também, que não há interesse na identificação dos respondentes.

Caso concorde em colaborar com este instrumento de pesquisa, solicitamos que marque a caixa de seleção a seguir e siga as instruções.

Agradecemos sua colaboração.

○ Concordo em responder ao questionário 


\section{CARACTERIZAÇÃO DO PERFIL DO RESPONDENTE}

QEP 1.1.

QMP 1.1. Ano de nascimento:

\section{QEP 1.2.}

QMP 1.2. Gênero:

○ Feminino

○ Masculino

\section{QEP 1.3.}

QMP 1.3. Grau de escolaridade:

$\circ$ a. Ensino fundamental incompleto $\left(1^{\circ}\right.$ ao $9^{\circ}$ ano $)$

$\circ$ b. Ensino fundamental completo $\left(1^{\circ}\right.$ ao $9^{\circ}$ ano $)$

O c. Ensino médio incompleto ( $1^{\circ}$ ao $3^{\circ}$ ano $)$

$\circ$ d. Ensino médio completo $\left(1^{\circ}\right.$ ao $3^{\circ}$ ano $)$

○ e. Ensino superior incompleto (graduação)

O f. Ensino superior completo (graduação)

\section{QEP 1.4.}

QMP 1.4. Ano que obteve sua carteira de motorista (esta informação está presente em sua habilitação):

○ Não possuo carteira de motorista ${ }^{3}$

o Ano:

QEP 1.5. Categoria de sua carteira de motorista:

[Ajuda: Você pode selecionar mais de uma categoria. Por exemplo, para o caso da categoria $\mathrm{AB}$, marque a caixa de seleção da categoria $\mathrm{A}$ e da $\mathrm{B}$ ]

$\square$ i. $\quad$ A [veículo de 2 ou 3 rodas]

$\square$ ii. B [Categoria Padrão: veículo leve, de 4 rodas e cuja lotação não exceda a 8 lugares, excluído o do motorista]
iii. C [veículo pesado]
iv. D [veículo cuja lotação exceda a 8 lugares, excluído o do motorista]
v. E [veículo conjugado]

${ }^{3}$ A seleção desta opção finaliza o questionário. 
QMP 1.5. Categoria de sua carteira de motorista:

[Ajuda: Você pode selecionar mais de uma categoria. Por exemplo, para o caso da categoria $\mathrm{AB}$, marque a caixa de seleção da categoria $\mathrm{A}$ e da $\mathrm{B}]$

i. A [veículo de 2 ou 3 rodas] Ex: Moto

$\square$ ii. B [Categoria Padrão: veículo leve, de 4 rodas e cuja lotação não exceda a 8 lugares, excluído o do motorista] Ex: Carro

iii. C [veículo pesado] Ex: Caminhão

iv. D [veículo cuja lotação exceda a 8 lugares, excluído o do motorista] Ex: Ônibus

v. E [veículo conjugado] Ex: Caminhão com reboque

QEP 1.6.

QMP (EXCLUIR) Analisando a questão e as alternativas anteriores, por favor, avalie as afirmações a seguir:

Concordo Discordo

O texto da questão anterior está claro, compreendi o que foi pedido sem dificuldades.

$33 / 35^{4} \quad 0 / 35$

As alternativas estão claras, entendi a que cada uma se referia.

$32 / 35$

$1 / 35$

Encontrei alternativas que diziam a mesma coisa (ambíguas).

Em caso de afirmativo, aponte quais logo a seguir.

$2 / 35$

$31 / 35$

Nenhuma alternativa contemplou a minha resposta desejada.

$3 / 35$

$30 / 35$

QEP 1.7. Você trabalha como motorista profissional?

○ Sim

○ Não

QMP 1.6 Você trabalha como motorista profissional?

O Sim

○ Não, mas já trabalhei

○ Não

QEP 1.8. Você trabalha em órgão gestor de rodovias?

○ Sim

○ Não

\footnotetext{
${ }^{4}$ Número de respostas/Quantidade de participantes no experimento piloto
} 
QMP 1.7. Você trabalha em órgão gestor de rodovias?

O Sim

○ Não, mas já trabalhei

○ Não

QEP 1.9. Você trabalha em concessionária de rodovias?

○ Sim

○ Não

QMP 1.8. Você trabalha em concessionária de rodovias?

O Sim

○ Não, mas já trabalhei

○ Não

QEP 1.10.

QMP (EXCLUIR) Analisando as três perguntas anteriores, por favor, avalie a afirmação a seguir:

\section{Concordo Discordo}

A primeira pergunta está clara, compreendi a questão.

$35 / 35 \quad 0 / 35$

A segunda pergunta está clara, compreendi a questão.

$35 / 35$

$0 / 35$

A terceira pergunta está clara, compreendi a questão.

$35 / 35$

$0 / 35$

QEP 1.11. Com que frequência você viaja em rodovias?

O a. Nunca

o b. Raramente

○ c. Uma vez por mês

$\circ$ d. Mais de uma vez por mês

$\circ$ e. Uma vez por semana

$\circ \mathrm{f}$. Mais de uma vez por semana

o g. Uma vez por dia

$\bigcirc$ h. Mais de uma vez por dia 
QMP 1.9. Responda com base nos dois últimos anos:

Com que frequência você viaja em rodovias como motorista ou como passageiro?

(Neste questionário, considere a ida como uma viagem e a volta como outra).

O a. Não viajei

$\circ$ b. De vez em quando (até 4 viagens ao ano)

○ c. As minhas viagem não são frequentes (até 12 viagem ao ano)

○ d. Duas vezes por mês

$\circ$ f. Mais de duas vezes por mês

$\bigcirc$ g. Duas vezes por semana

$\circ$ h. Mais de duas vezes por semana

○ i. Duas vezes por dia

○ j. Mais de duas vezes por dia

QEP 1.12.

QMP (EXCLUIR) Analisando a questão e as alternativas anteriores, por favor, avalie as afirmações a seguir:

Concordo Discordo

As alternativas estão claras, entendi a que cada uma se referia. $\quad 30 / 35 \quad 5 / 35$

Encontrei alternativas que diziam a mesma coisa (ambíguas).

$\begin{array}{lrr}\text { Em caso de afirmativo, aponte quais logo a seguir. } & 1 / 35 & 34 / 35\end{array}$

$\begin{array}{lll}\text { Nenhuma alternativa contemplou a minha resposta desejada. } & \text { 4/35 }\end{array}$

QEP 1.13. Tipo de veículo mais usado por você nas viagens em rodovias rurais:

○ a. Automóvel

$\circ$ b. Caminhonete

○ c. Van

$\circ$ d. Motocicleta

○ e. Caminhão

$\circ$ f. Ônibus

g. Outros 
QMP 1.10. Tipo de veículo mais usado por você nas viagens em rodovias (como motorista ou como passageiro):
○ a. Automóvel
○ b. Caminhonete
O c. Van
○ d. Motocicleta
○ e. Caminhão
o f. Ônibus
$\circ$ g. Outros

\section{QEP (Inexistente)}

QMP 1.11. Você costuma enfrentar congestionamento em rodovias?

○ Sim

O Não

\section{QEP 1.14.}

QMP 1.12. Nas suas viagens em rodovias, com que frequência você é o motorista?

$\bigcirc$ a. Nunca ou quase nunca

$\circ$ b. Aproximadamente metade das vezes

○ c. Quase sempre ou sempre

QEP 1.15.

QMP (EXCLUIR) Analisando a questão e as alternativas anteriores, por favor, avalie as afirmações a seguir:

\section{Concordo Discordo}

As alternativas estão claras, entendi a que cada uma se referia.

$32 / 35$

Encontrei alternativas que diziam a mesma coisa (ambíguas).

Em caso de afirmativo, aponte quais logo a seguir.

Nenhuma alternativa contemplou a minha resposta desejada.

$$
3 / 35
$$

QEP 1.16. Você está acostumado a dirigir em rodovias de pista dupla no estado de São Paulo?

o Sim

○ Não 
QMP 1.13. Você está acostumado a dirigir em rodovias duplicadas no estado de São Paulo? O Sim

O Não

\section{QEP 1.17.}

QMP (EXCLUIR) Analisando a questão anterior, por favor, avalie a afirmação a seguir:

$$
\text { Concordo Discordo }
$$

O texto da questão anterior está claro, compreendi o que foi pedido sem dificuldades.

QEP 1.18.

Quando você é o motorista da viagem, qual consideração você faz sobre o seu comportamento conduzindo o veículo? Para responder, clique no cursor e posicione-o, entre os dois extremos, no ponto que, na sua opinião, representa o seu comportamento.

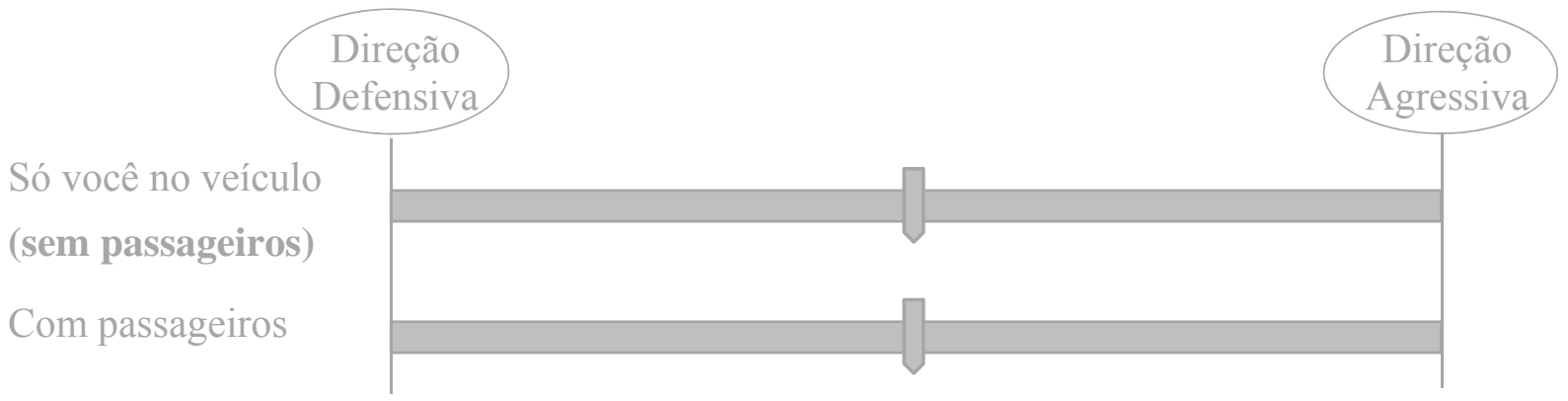

\section{QMP 1.14.}

Se você estivesse dirigindo em uma rodovia, qual velocidade você gostaria de manter (velocidade desejada $\mathrm{em} \mathrm{km} / \mathrm{h}$ )?

Só você no veículo

(sem passageiros) $(\mathrm{km} / \mathrm{h})$

Com passageiros $(\mathrm{km} / \mathrm{h})$ 
QEP 1.19.

QMP (EXCLUIR) Analisando a questão e a escala de resposta do quesito anterior, por favor, avalie as afirmações a seguir:

\begin{tabular}{|c|c|c|c|}
\hline $\begin{array}{l}\text { Não } \\
\text { concordo } \\
\text { totalmente }\end{array}$ & $\begin{array}{l}\text { Não concordo } \\
\text { parcialmente }\end{array}$ & Indiferente & $\begin{array}{c}\text { Concordo } \\
\text { parcialmente }\end{array}$ \\
\hline
\end{tabular}

O texto da questão anterior está claro, compreendi o que foi pedido sem

$0 / 35$

$0 / 35$

$3 / 35$

$30 / 35$

dificuldades.

Entendi como responder a questão por conta da explicação contida em seu

$1 / 35$

$2 / 35$

$7 / 35$

$20 / 35$ texto.

Não tive dificuldade em utilizar este tipo de escala para fornecer a $1 / 35$ $2 / 35$ $0 / 35$ $12 / 35$ $18 / 35$ minha resposta desejada.

Entendi os extremos da escala: direção defensiva e $0 / 35$ $2 / 35$ $0 / 35$ $4 / 35$ $27 / 35$ direção agressiva. 


\section{VÍDEO TREINO - QUALIDADE DA VIAGEM}

QEP 2.1.

A partir de agora, você vai assistir a filmes e apontar a sua avaliação sobre os cenários presentes neles.

Para entender como deve ser feito, assista ao vídeo a seguir, nele há um tutorial que explica como realizar as avaliações e quais fatores do cenário dos filmes devem ser analisados durante a sua visualização.

Destaca-se que o cenário apresentado nos vídeos deve ser avaliado pensando na qualidade da viagem em termos das condições de tráfego, conforto e velocidade:

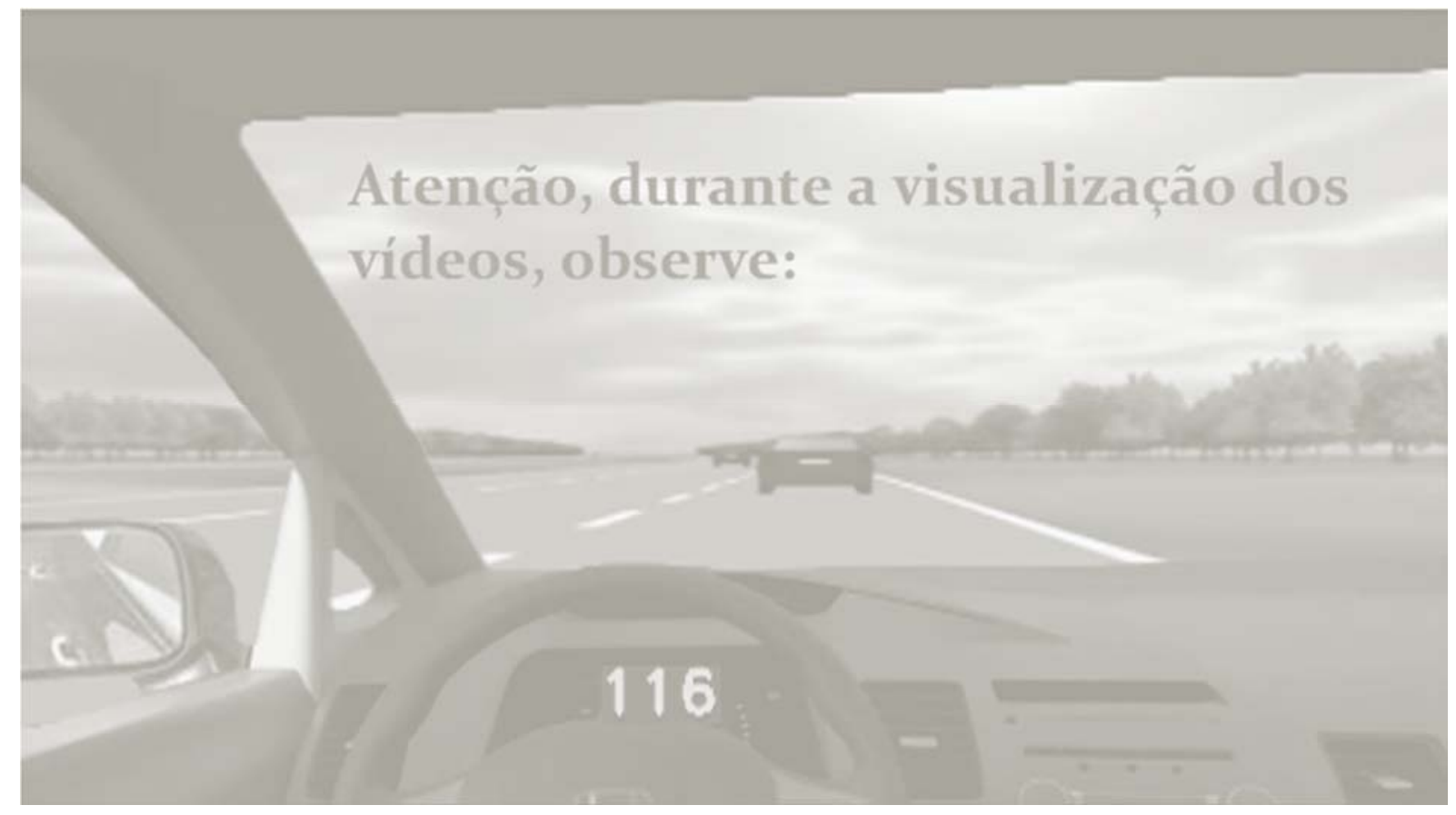

Clique no cursor e posicione-o, entre os dois extremos, no ponto que você acha que representa a qualidade da viagem mostrada no vídeo:

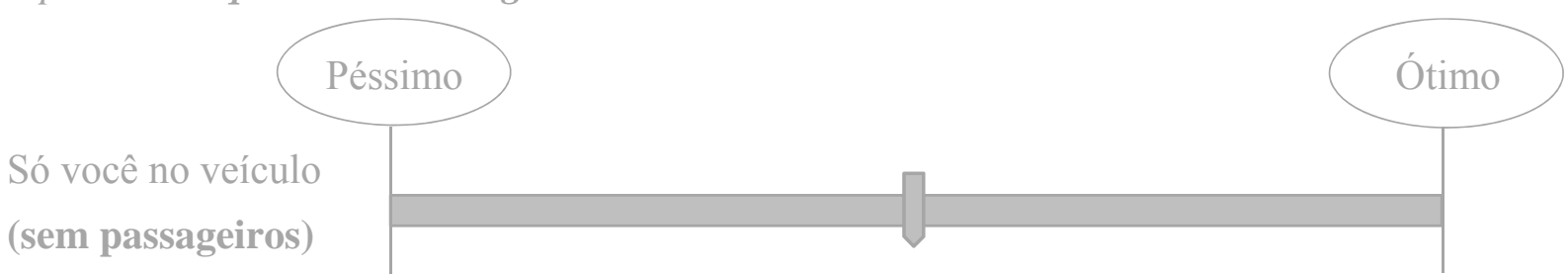




\section{QMP 2.1.}

A partir de agora, você vai assistir a filmes e apontar a sua avaliação sobre os cenários presentes neles.

Para entender como deve ser feito, assista ao vídeo a seguir, nele há um tutorial que explica como realizar as avaliações e quais fatores dos filmes devem ser analisados durante a sua visualização.

Destaca-se que os vídeos devem ser avaliados pensando na qualidade da viagem em termos da velocidade e da quantidade de veículos na pista. Considere que o veículo estaria sendo conduzido por você.

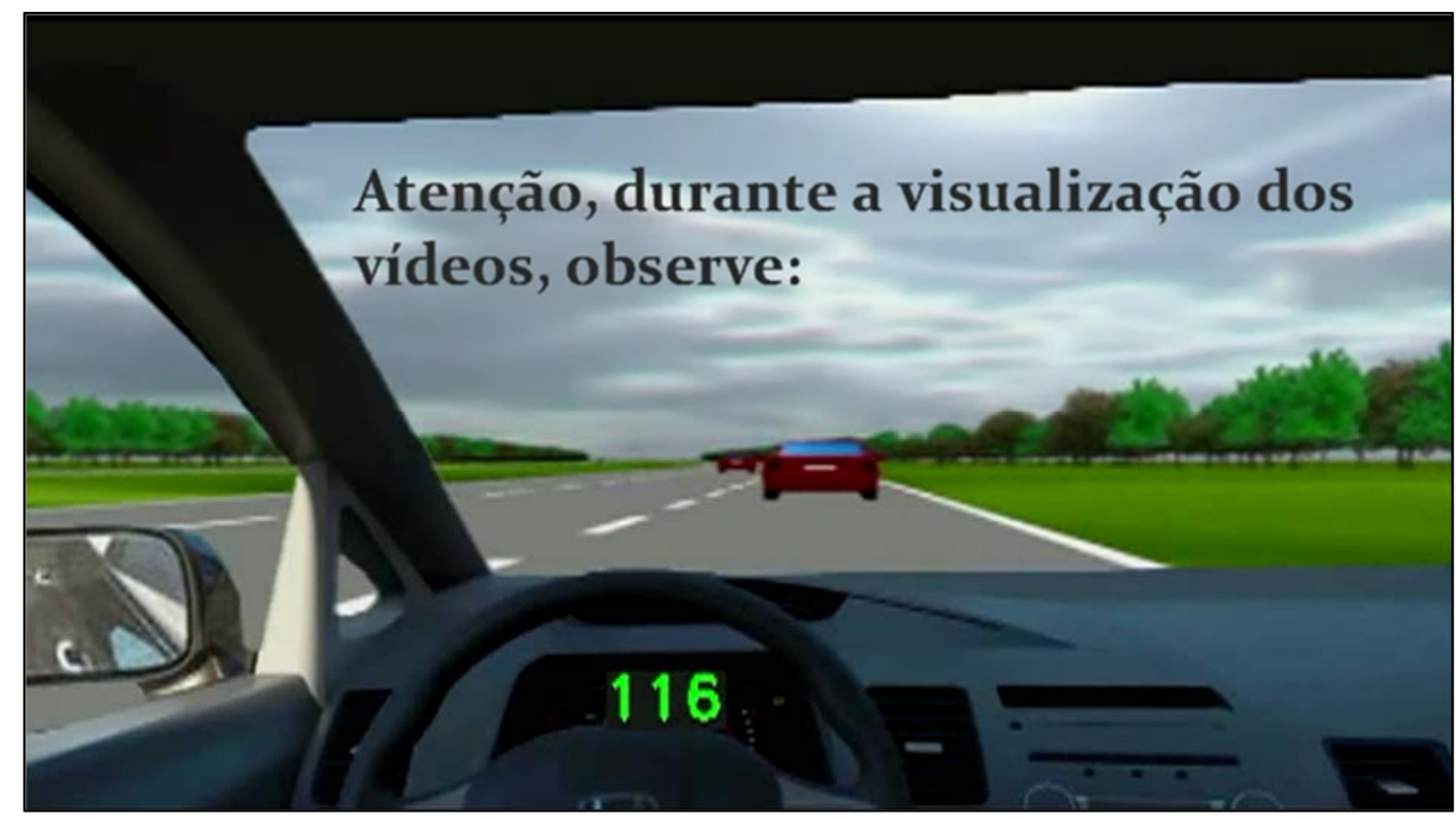

Clique no cursor e posicione-o, entre os dois extremos, no ponto que você acha que representa a qualidade da viagem mostrada no vídeo treino; apenas para mostrar que você entendeu como usar a escala.

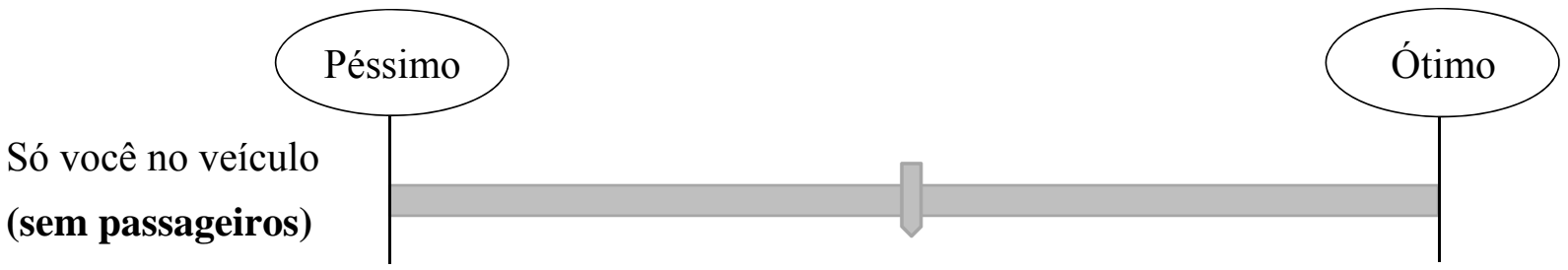

Não entendi a escala de resposta, prefiro não continuar. 
QEP 2.2.

QMP (EXCLUIR) Analisando o enunciado, a escala de resposta e o vídeo tutorial apresentados anteriormente, por favor, avalie as afirmações a seguir:

\begin{tabular}{|c|c|c|c|}
\hline $\begin{array}{l}\text { Não } \\
\text { concordo } \\
\text { totalmente }\end{array}$ & $\begin{array}{l}\text { Não concordo } \\
\text { parcialmente }\end{array}$ & Indiferente & $\begin{array}{c}\text { Concordo } \\
\text { parcialmente }\end{array}$ \\
\hline
\end{tabular}

O texto da enunciado acima está claro, compreendi o que foi
$0 / 35$
$2 / 35$
$0 / 35$
$4 / 35$
$29 / 35$

pedido sem dificuldades.

Entendi como responder o enunciado por conta da explicação contida em seu

$3 / 35$

$8 / 35$

$23 / 35$ texto.

Entendi os extremos da escala: péssimo e ótimo.

$1 / 35$

$0 / 35$

$5 / 35$

$29 / 35$

Antes de assistir

ao tutorial, eu já tinha entendido o que era para

$1 / 35$

$2 / 35$

$6 / 35$

$18 / 35$

$8 / 35$

fazer.

O tutorial foi útil para explicar quais fatores eu deveria observar na minha $2 / 35$ $0 / 35$ $0 / 35$ $2 / 35$ avaliação sobre a qualidade da viagem. 


\section{AVALIAÇÃO DE CENÁRIOS RODOVIÁRIOS}

QEP 3.1. Nesta etapa serão exibidos 9 vídeos similares ao 'vídeo treino', onde cada um apresentará uma condição de tráfego distinta ou igual aos demais.

Após a visualização dos vídeos, avalie a qualidade da viagem pensando em termos das condições de tráfego, conforto e velocidade.

\section{Atenção:}

1. Registre a sua avaliação assim que decidir a sua nota, não é preciso esperar o fim do vídeo. Os vídeos serão apresentados em loop, reiniciando toda vez que chegar ao final, de uma maneira que você determinará o tempo necessário para avaliar o vídeo;

\section{Durante o vídeo não há ocorrência de incidentes;}

3. O fluxo horário se mantém constante durante todo o filme, as variações de tráfego que ocorrem são pontuais;

4. A unidade da velocidade do painel do veículo é $\mathrm{km} / \mathrm{h}$;

5. A velocidade máxima permitida na rodovia é de $120 \mathrm{~km} / \mathrm{h}$.

QMP 3.1. Nesta etapa, serão exibidos 9 vídeos similares ao 'vídeo treino'; cada um apresentará uma condição de tráfego distinta ou igual aos demais.

Após a visualização dos vídeos, avalie a qualidade da viagem em termos da velocidade e da quantidade de veículos na pista.

\section{Atenção:}

1. Durante o vídeo não há ocorrência de incidentes;

2. A condição de tráfego se mantém constante durante todo o filme, as variações de tráfego que ocorrem são pontuais;

3. A unidade da velocidade do painel do veículo é $\mathrm{km} / \mathrm{h}$;

4. A velocidade máxima permitida na rodovia é de $120 \mathrm{~km} / \mathrm{h}$. 
QEP 3.2.

QMP (EXCLUIR) Analisando o enunciado anterior, por favor, avalie as afirmações a seguir:

$\begin{array}{ccccc}\text { Não } & \text { Não concordo } & \text { Indiferente } & \begin{array}{c}\text { Concordo } \\ \text { parcialmente }\end{array} & \begin{array}{c}\text { Concordo } \\ \text { totalmente }\end{array} \\ \text { totalmente } & \text { parcialmente }\end{array}$

O texto do enunciado

anterior está claro,

compreendi sem

$0 / 35$

$0 / 35$

$0 / 35$

$7 / 35$

$28 / 35$

dificuldades.

As informações contidas no enunciado anterior já foram ditas antes, achei o texto repetitivo.

\section{QEP 3.3 até 3.11}

\section{Questão Tipo (Bloco com 9 cenários)}

Avalie o cenário do vídeo a seguir pensando na qualidade da viagem em termos das condições de tráfego, conforto e velocidade:

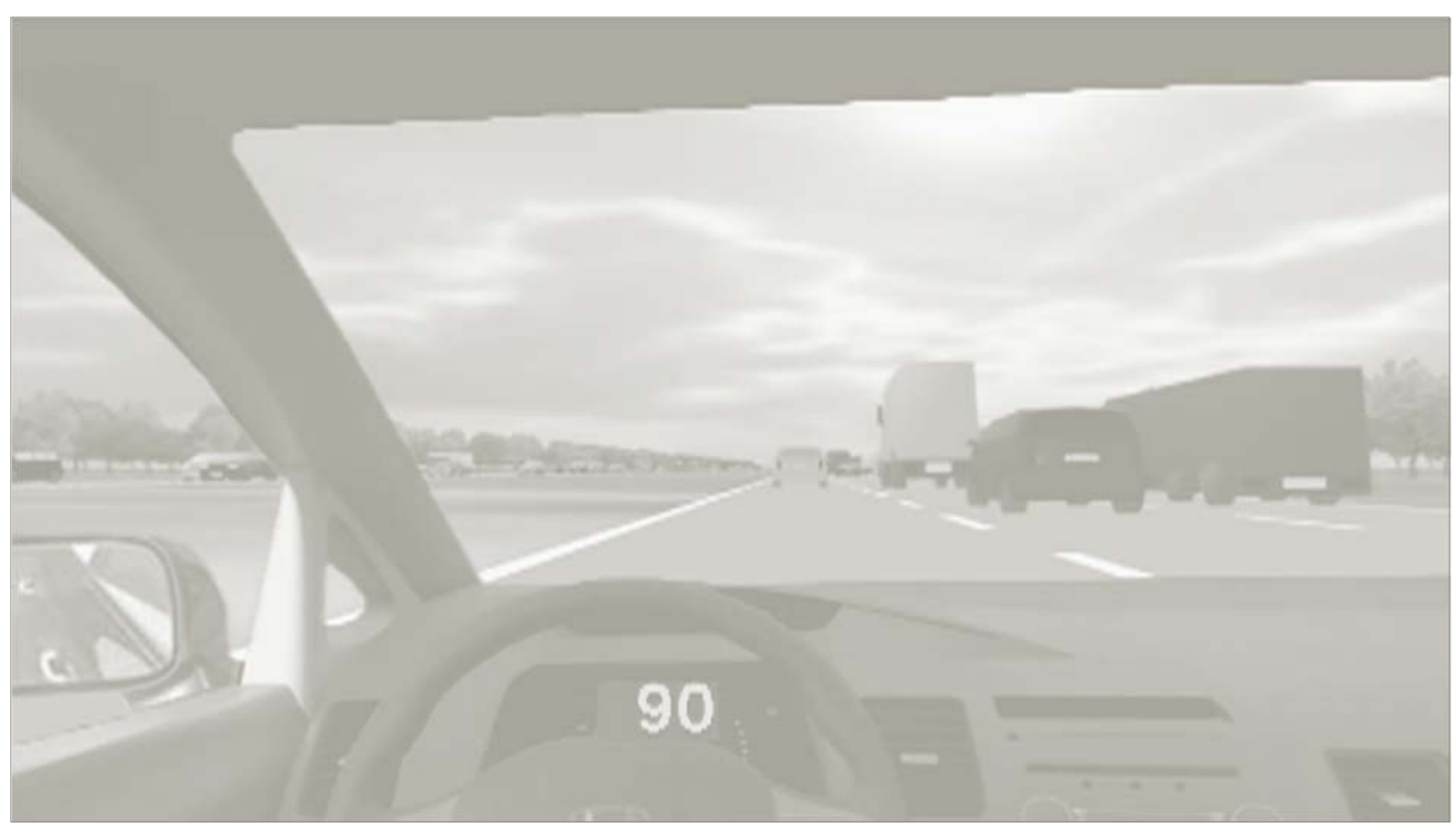

Clique no cursor e posicione-o para fornecer a sua avaliação.

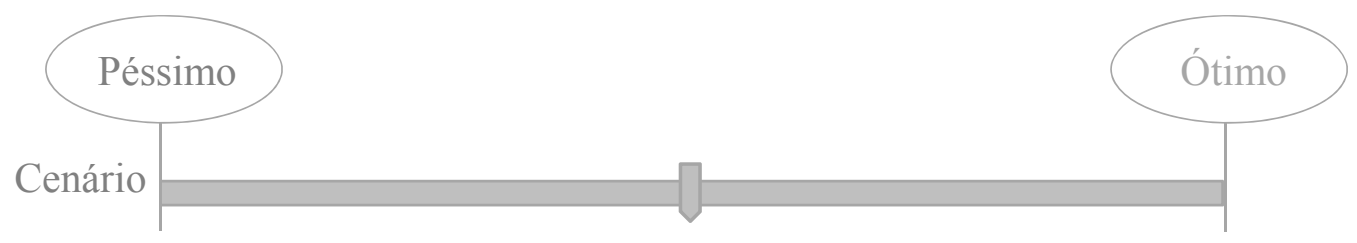


QMP 3.2 até 3.10.

\section{Questão Tipo (Bloco com 9 cenários)}

Avalie a qualidade da viagem apresentada pelo vídeo a seguir em termos da velocidade e da quantidade de veículos na pista. Considere que o veículo estaria sendo conduzido por você.

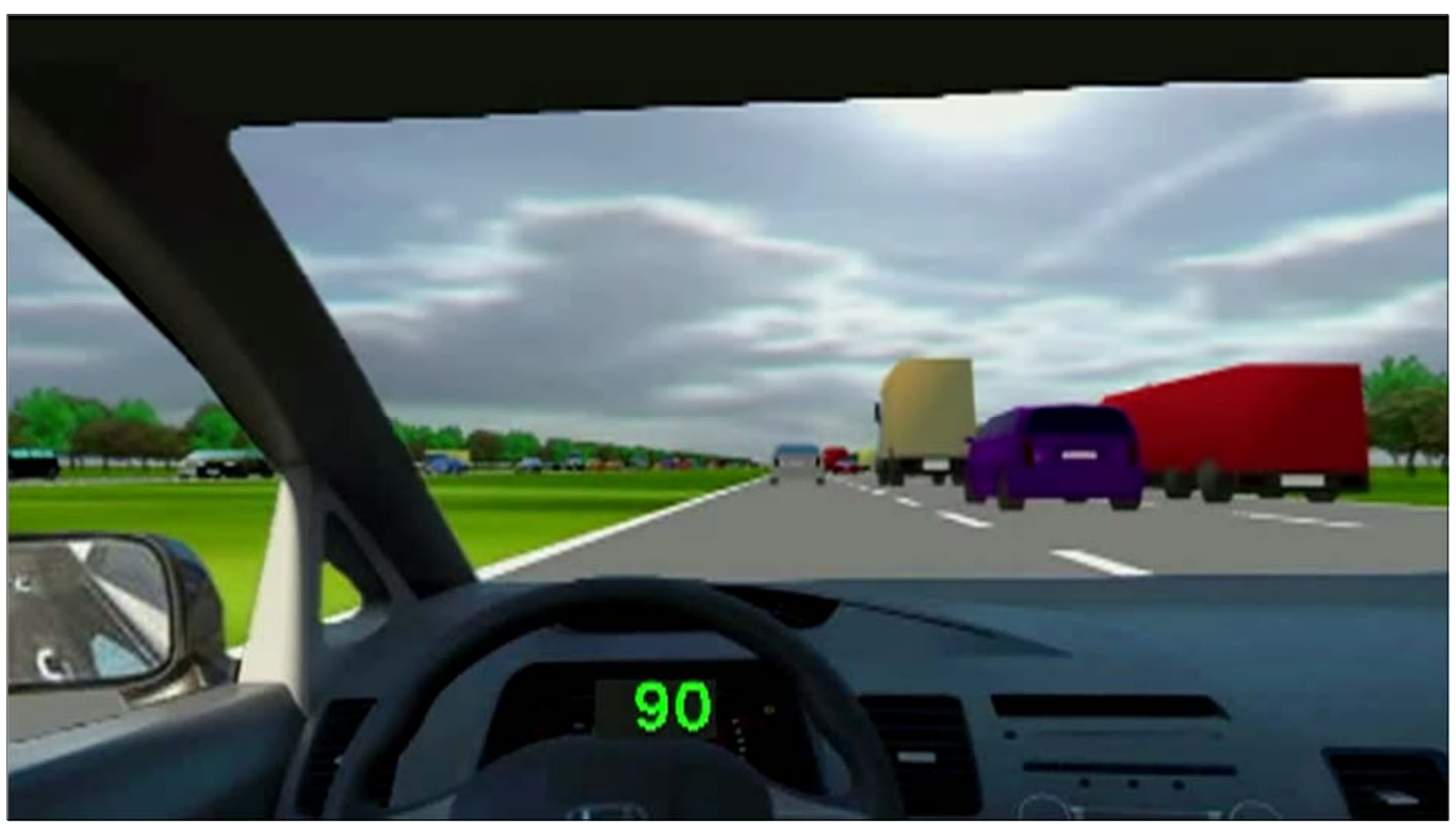

Clique no cursor e posicione-o para fornecer a sua avaliação.

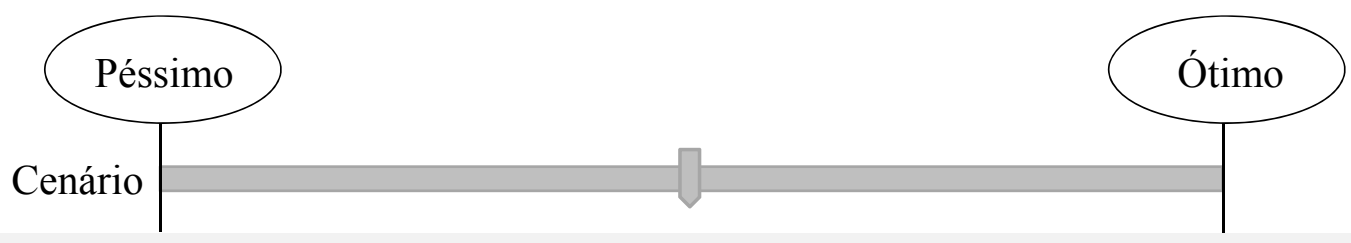

\section{QEP 3.12}

QMP (EXLUIR) Para continuar colaborando com nossa pesquisa, você aceita assistir e avaliar mais 5 vídeos?

○ Aceito continuar colaborando

○ Não aceito. 
QEP 3.13. até QEP 3.17

Questão Tipo (Bloco com 5 cenários)

Avalie o cenário do vídeo a seguir pensando na qualidade da viagem em termos das condições de tráfego, conforto e velocidade:

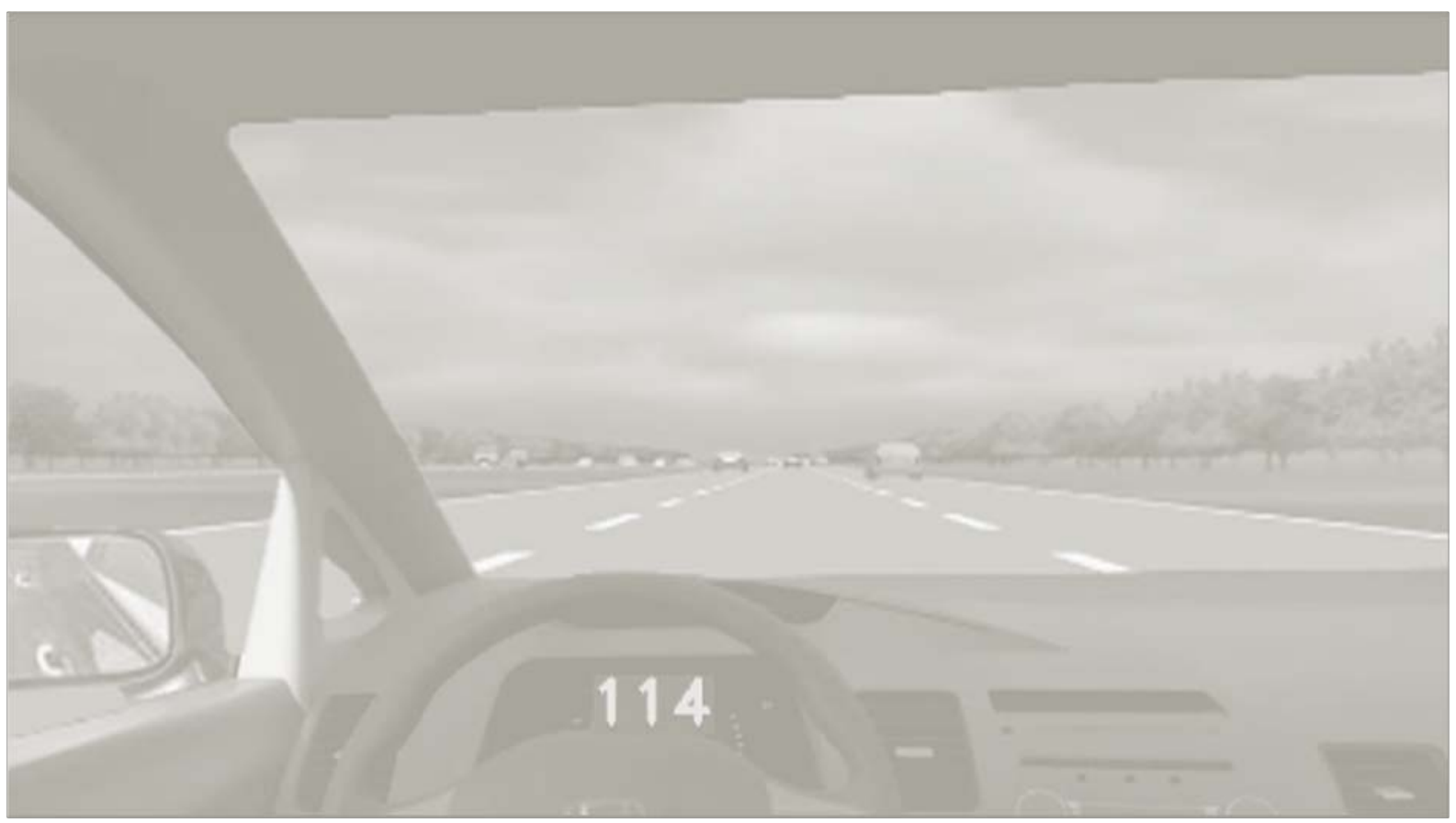

Clique no cursor e posicione-o para fornecer a sua avaliação.

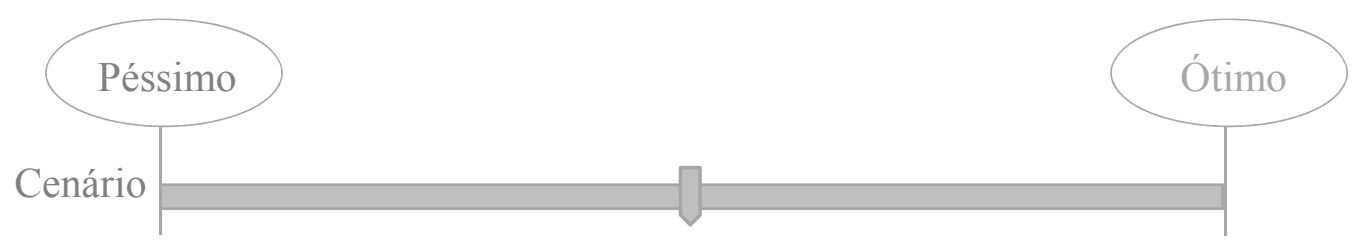


QMP 3.11 até QMP 3.15

\section{Questão Tipo (Bloco com 5 cenários)}

Avalie a qualidade da viagem apresentada pelo vídeo a seguir em termos da velocidade $\mathbf{e}$ da quantidade de veículos na pista. Considere que o veículo estaria sendo conduzido por você.

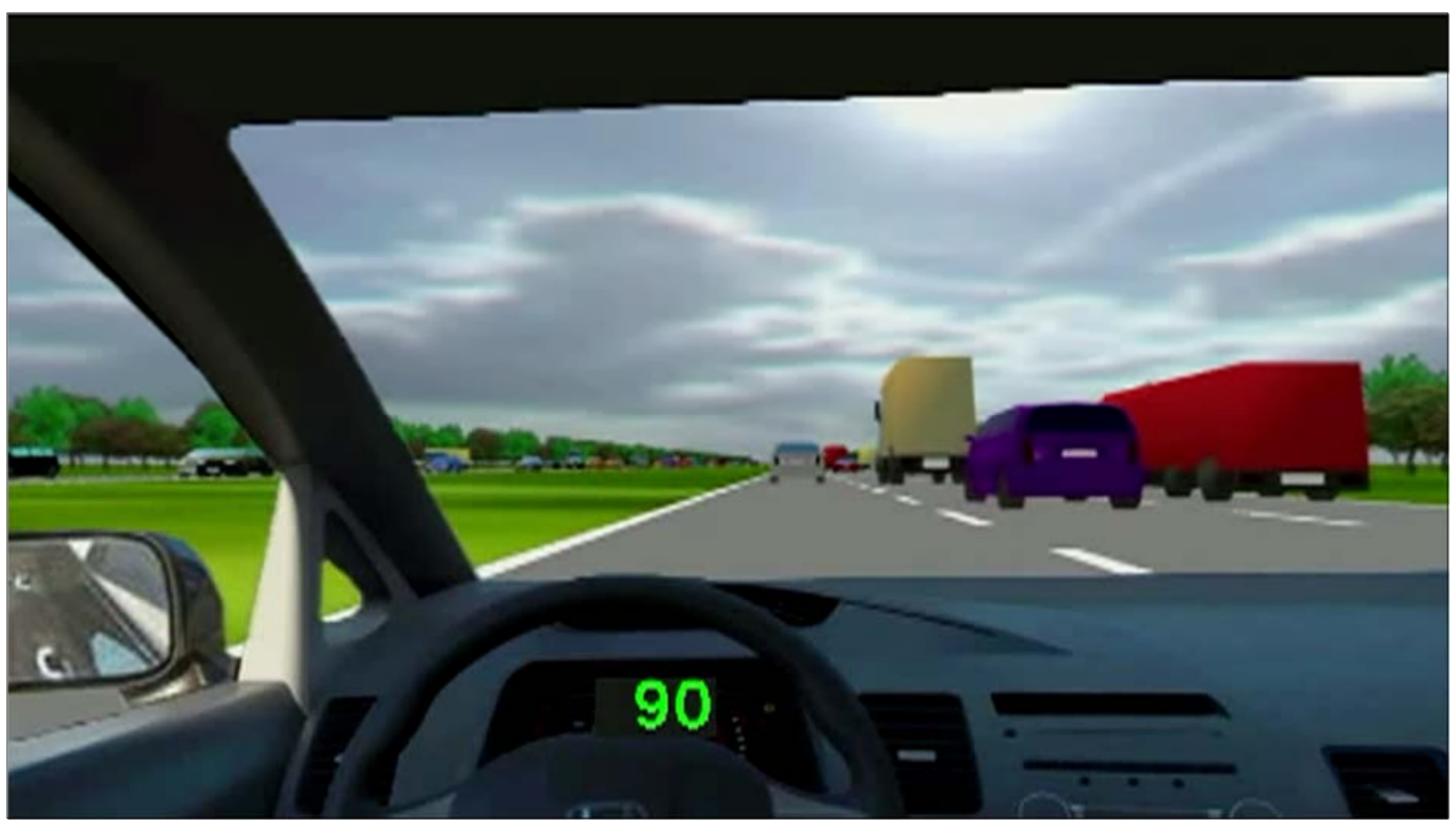

Clique no cursor e posicione-o para fornecer a sua avaliação.

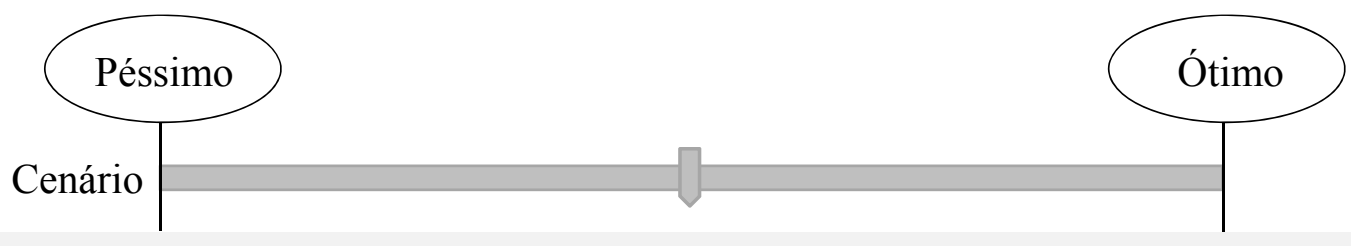

\section{QEP 3.18.}

QMP (EXCLUIR) Para continuar colaborando com nossa pesquisa, você aceita assistir e avaliar mais 5 vídeos?

$\circ$ Aceito continuar colaborando

○ Não aceito. 


\section{COMENTÁRIOS E SUGESTÕES}

QEP 4.1.

Analisando o questionário que você acabou de responder, leia as proposições a seguir e marque a alternativa mais adequada:

\begin{tabular}{|c|c|c|c|}
\hline $\begin{array}{l}\text { Não } \\
\text { concordo } \\
\text { totalmente }\end{array}$ & $\begin{array}{l}\text { Não concordo } \\
\text { parcialmente }\end{array}$ & Indiferente & $\begin{array}{c}\text { Concordo } \\
\text { parcialmente }\end{array}$ \\
\hline
\end{tabular}

O questionário está cansativo.
$9 / 35$
$6 / 35$
$4 / 35$
$15 / 35$
$1 / 35$

Tive dificuldade em diferenciar os cenários apresentados nos vídeos, $13 / 35$ $11 / 35$ $1 / 35$

$10 / 35$

$0 / 35$ pois as condições de tráfego eram parecidas.

Os filmes que assisti me forneceram informações suficientes para avaliar as condições de tráfego.

Os filmes eram curtos.

$5 / 35$

$3 / 35$

$3 / 35$

$0 / 35$

Os vídeos eram de qualidade e apresentavam

Eu conduziria o carro da mesma forma (ou de forma semelhante) que o motorista

da simulação dirigiu.

A forma como o motorista da simulação dirigiu não prejudicou a minha análise sobre o cenário

apresentado.

Avaliar os cenários por meio da escala métrica (posicionar o cursor entre extremos) foi simples, eu

não tive dificuldade.

Eu preferiria avaliar os cenários através de outro tipo de escala. 
QMP 4.1.

Analisando o questionário que você acabou de responder, leia as proposições a seguir e marque a alternativa mais adequada:

$\begin{array}{ccccc}\begin{array}{c}\text { Discordo } \\ \text { totalmente }\end{array} & \begin{array}{l}\text { Discordo } \\ \text { em parte }\end{array} & \text { Em dúvida } & \begin{array}{c}\text { Concordo } \\ \text { em parte }\end{array} & \begin{array}{c}\text { Concordo } \\ \text { totalmente }\end{array}\end{array}$ Não sei

O questionário está cansativo.

Tive dificuldade em diferenciar os filmes, pois as condições de tráfego eram parecidas.

Os vídeos que assisti me forneceram informações suficientes para avaliar as condições de tráfego.

O tempo do vídeo foi suficiente para formar a minha avaliação.

Os vídeos eram de qualidade e apresentavam uma boa resolução.

Avaliar os filmes por meio da escala métrica (posicionar o cursor entre extremos) foi simples, eu não tive dificuldade.

Eu preferiria avaliar os filmes através de outro tipo de escala.

\section{QEP}

QMP 4.2.

Caso tenha algum comentário e/ou sugestão que queira fornecer para nossa equipe, favor deixá-lo no campo a seguir: 
APÊNDICE C 

Tabela 7. Apresentação dos casos rotulados como outliers pelo método dos escores padrão, de box-plot e resíduo estudentizado

\begin{tabular}{|c|c|c|c|c|c|}
\hline ID & $\begin{array}{l}\text { Número } \\
\text { do vídeo }\end{array}$ & Avaliação & $\begin{array}{l}\text { Escores Padrão } \\
\text { (Por vídeos) }\end{array}$ & $\begin{array}{l}\text { Diagrama em } \\
\text { Caixa (Por } \\
\text { densidade) }\end{array}$ & $\begin{array}{c}\text { Resíduo } \\
\text { estudentizado: } \\
\text { regressão logística }\end{array}$ \\
\hline 10 & 10 & 92,0 & 1,8 & & 4,5 \\
\hline 31 & 31 & 93,6 & 1,9 & & 2,9 \\
\hline 43 & 43 & 92,9 & 0,9 & & 2,9 \\
\hline 45 & 45 & 91,0 & 1,4 & & 4,5 \\
\hline 54 & 54 & 98,5 & 1,2 & & 2,9 \\
\hline 56 & 56 & 95,9 & 1,0 & & 4,6 \\
\hline 72 & 2 & 20,4 & $-2,1$ & Moderado & \\
\hline 85 & 15 & 11,4 & $-1,1$ & Moderado & \\
\hline 87 & 17 & 40,3 & $-2,1$ & & \\
\hline 95 & 25 & 67,2 & $-2,7$ & & \\
\hline 107 & 37 & 12,5 & $-2,3$ & Moderado & \\
\hline 108 & 38 & 21,2 & $-1,4$ & Moderado & \\
\hline 113 & 43 & 32,4 & $-2,1$ & & \\
\hline 117 & 47 & 67,0 & $-2,2$ & Extremo & \\
\hline 119 & 49 & 16,5 & $-2,3$ & Moderado & \\
\hline 130 & 60 & 40,3 & $-2,2$ & & \\
\hline 155 & 15 & 19,3 & $-0,8$ & Moderado & \\
\hline 161 & 21 & 88,8 & 0,6 & & 4,5 \\
\hline 192 & 52 & 36,7 & $-2,1$ & & \\
\hline 211 & 1 & 40,8 & $-2,2$ & Extremo & \\
\hline 225 & 15 & 7,7 & $-1,2$ & Moderado & \\
\hline 237 & 27 & 61,4 & $-2,2$ & & \\
\hline 253 & 43 & 91,2 & 0,8 & & 2,9 \\
\hline 254 & 44 & 96,4 & 0,9 & & 3,6 \\
\hline 291 & 11 & 96,3 & 1,8 & & 5,6 \\
\hline 301 & 21 & 95,5 & 1,0 & & 4,5 \\
\hline 323 & 43 & 94,6 & 1,0 & & 2,9 \\
\hline 328 & 48 & 12,7 & $-2,2$ & Moderado & \\
\hline 330 & 50 & 14,6 & $-2,2$ & Moderado & \\
\hline 334 & 54 & 100,0 & 1,3 & & 2,9 \\
\hline 336 & 56 & 89,9 & 0,9 & & 4,6 \\
\hline 339 & 59 & 11,2 & $-2,7$ & Extremo & \\
\hline 351 & 1 & 81,5 & $-0,2$ & Extremo & \\
\hline 364 & 14 & 18,2 & $-1,9$ & Moderado & \\
\hline 386 & 36 & 82,4 & $-2,6$ & Extremo & \\
\hline 394 & 44 & 100,0 & 1,0 & & 3,6 \\
\hline 397 & 47 & 88,2 & $-0,4$ & Moderado & \\
\hline 421 & 1 & 57,2 & $-1,4$ & Extremo & \\
\hline 428 & 8 & 92,9 & 1,8 & & 2,9 \\
\hline 432 & 12 & 94,2 & $-2,8$ & & \\
\hline
\end{tabular}


Tabela 7. (Continuação) Apresentação dos casos rotulados como outliers pelo método dos escores padrão, de box-plot e resíduo estudentizado

\begin{tabular}{lrrrrr}
\hline ID & $\begin{array}{c}\text { Número } \\
\text { do vídeo }\end{array}$ & Avaliação & $\begin{array}{c}\text { Escores Padrão } \\
\text { (Por vídeos) }\end{array}$ & $\begin{array}{c}\text { Diagrama em } \\
\text { Caixa (Por } \\
\text { densidade) }\end{array}$ & $\begin{array}{c}\text { Resíduo } \\
\text { estudentizado: } \\
\text { regressão logística }\end{array}$ \\
\hline 435 & 15 & 23,7 & $-0,7$ & Moderado & \\
444 & 24 & 90,8 & $-1,9$ & Moderado & \\
464 & 44 & 15,3 & $-\mathbf{2 , 1}$ & & \\
481 & 61 & 20,2 & $-1,2$ & Moderado & \\
516 & 26 & 20,4 & $-2,4$ & Moderado & \\
520 & 30 & 3,4 & $-2,1$ & & 5,5 \\
544 & 54 & 88,8 & 0,9 & & \\
547 & 57 & 100,0 & 1,7 & & \\
561 & 1 & 85,8 & 0,0 & Moderado & \\
566 & 6 & 14,4 & $-1,7$ & Moderado & \\
569 & 9 & 31,8 & $-2,4$ & & \\
580 & 20 & 67,0 & 0,8 & & \\
598 & 38 & 7,3 & $-1,8$ & Moderado & \\
607 & 47 & 80,9 & $-1,0$ & Extremo & \\
609 & 49 & 97,2 & 0,9 & & \\
621 & 61 & 11,0 & $-1,5$ & Moderado & \\
623 & 63 & 19,8 & $-2,2$ & & \\
\hline
\end{tabular}

